University of Louisville

ThinkIR: The University of Louisville's Institutional Repository

Electronic Theses and Dissertations

$12-2008$

\title{
The role of Hsp90 in PC-12 cell survival.
}

Christina Blume Clark

University of Louisville

Follow this and additional works at: https://ir.library.louisville.edu/etd

\section{Recommended Citation}

Clark, Christina Blume, "The role of Hsp90 in PC-12 cell survival." (2008). Electronic Theses and Dissertations. Paper 257.

https://doi.org/10.18297/etd/257

This Doctoral Dissertation is brought to you for free and open access by ThinkIR: The University of Louisville's Institutional Repository. It has been accepted for inclusion in Electronic Theses and Dissertations by an authorized administrator of ThinkIR: The University of Louisville's Institutional Repository. This title appears here courtesy of the author, who has retained all other copyrights. For more information, please contact thinkir@louisville.edu. 


\title{
THE ROLE OF HSP90 IN PC-12 CELL SURVIVAL
}

\author{
By
}

\author{
Christina Blume Clark \\ B.A., Washington University in St. Louis, 2002
}

Dissertation

Submitted to the

Faculty of the Graduate School

of the University of Louisville in

Partial Fulfillment of the Requirements

for the Degree of Doctor of Philosophy

Pharmacology and Toxicology

Department of Pharmacology and Toxicology

University of Louisville

Louisville, Kentucky

December 2008 
Copyright 2008 by Christina Blume Clark

All rights reserved 


\title{
THE ROLE OF HSP90 IN PC-12 CELL SURVIVAL
}

\author{
By
}

Christina Blume Clark

B.A., Washington University in St. Louis, 2002

A Dissertation Approved on

December 5, 2008

By the following Dissertation Committee:

Dissertation Director 


\section{DEDICATION}

This dissertation is dedicated to my devoted husband Jeremy Clark and to those family, friends, and colleagues, who have been supportive of my dreams and those of my husband. I am especially grateful to my husband, Gerda and Herb Wiegand, Anna and Dieter Blume, Linda and Larry Clark, and Ruby Shull for their encouragement and advice over the years. I am thankful that my mother and my grandparents inspired me to become a scientist by introducing me to ornithology. 


\section{ACKNOWLEDGEMENTS}

I wish to thank my research mentor Dr. Evelyne Gozal for her guidance and patience, and her senior laboratory technician Roy Sachleben for his technical assistance. I also thank Darlene Burke for statistical analysis of data. I also acknowledge the Proteomics Core of the Kidney Disease Program for performing the proteomic analysis of my samples. In addition, I appreciate the constructive criticism and advice received from other members of my laboratory and from my dissertation committee, Dr. Gavin Arteel, Dr. Michal Hetman, Dr William Pierce, and Dr Madhavi Rane. I especially appreciate encouragement I received from my colleagues Qianwen (Sharon) and Jianxun (Greg) Wang and Drs. Karin Wetzelberger, Cyndi Miller, Delphine El Medhi, and Madhavi Rane. In addition, I wish to acknowledge financial support received from my NIH/NINDS F30 MD/PhD Student NRSA and the Brown Foundation and Dr. Evelyne Gozal's NIH HL-074296 and P20 RR-15576 grants. Finally, I am thankful for the constant support that the Pharmacology and Toxicology Department Graduate Program and the University of Louisville MD/PhD Program have provided to its students over the years. 


\title{
ABSTRACT \\ THE ROLE OF HSP90 IN PC-12 CELL SURVIVAL
}

\author{
Christina Blume Clark
}

December 5, 2008

The chaperone heat shock protein 90 (Hsp90) regulates physiologically and pathological cellular processes, by binding and stabilizing kinases involved in basal cellular functions and in cellular responses to stress, respectively. I hypothesize that Hsp90 binding to kinases Akt and Raf-1 and to co-chaperone Cdc37 and Akt-dependent phosphorylation of Hsp90 regulate PC-12 cell survival.

Hsp90 binding was inhibited using the classical Hsp90 inhibitor, Geldanamycin (GA). Disruption of Hsp90 binding by GA correlated with similar cell death at normoxia (RA) and at $0.1 \% \mathrm{O}_{2}$ sustained hypoxia $(\mathrm{SH})$, suggesting that $\mathrm{Hsp} 90$ binding plays a role in cell survival.

Indeed, GA cytotoxicity is attributed to disruption of Hsp90 binding, although the role of this drug's benzoquinone in its cytotoxicity was never studied. This study used GA, the antioxidant precursor $\mathrm{N}$-acetyl cysteine (NAC), and the classical quinone menadione (MEN), to shows that oxidative stress and disruption of Hsp90 binding contribute to GA cytotoxicity. In addition, Hsp90 binding promotes survival by regulating protein degradation. Proteasomal inhibition prevented MEN-induced protein degradation, but failed to inhibit GA-induced protein degradation. Thus, GA induces 
cytotoxicity by early disruption of Hsp90 binding, followed by oxidative stress-induced non-proteasomal protein degradation.

Additional factors, such as Akt-dependent phosphorylation of Hsp90, may promote survival by regulating $\mathrm{Hsp90}$ binding. Akt phosphorylates $\mathrm{Hsp90}$ in vitro and in PC-12 cells expressing active Akt or exposed to 6h SH, concomitant with increased Akt phosphorylation. Proteomic analysis of Hsp90 immunoprecipitates identified additional Hsp90-binding proteins that may be recruited to and released from the Hsp90 complex in response to $6 \mathrm{~h} \mathrm{SH}$. Most identified Hsp90 binding proteins dissociate in response to Akt inhibition by the Akt inhibitor, Akti1/2, suggesting that Akt phosphorylation regulates the protein associations of the Hsp90 complexes. Survival studies with Akti1/2 demonstrate that basal Akt phosphorylation, but not the 6h SH-induced increase in Akt phosphorylation is critical to survival. However, constitutive Akt phosphorylation is not sufficient to prevent death at $24 \mathrm{~h} \mathrm{SH}$, suggesting additional factors are required for survival to $\mathrm{SH}$.

In summary, Akt-dependent phosphorylation of $\mathrm{Hsp} 90$ regulates protein binding and PC-12 cell survival. 
TABLE OF CONTENTS

$\begin{array}{lc} & \text { PAGE } \\ \text { DEDICATION } & \text { iii } \\ \text { ACKNOWLEDGEMENTS } & \text { iv } \\ \text { ABSTRACT } & \mathrm{v} \\ \text { LIST OF FIGURES } & \text { viii } \\ \text { CHAPTERS } & \\ \text { I. INTRODUCTION } & 1 \\ \text { II. } \quad \text { METHODS AND MATERIALS } & 22 \\ \text { III. SPECIFIC AIM 1 RESULTS } & 34 \\ \text { IV. } \quad \text { SPECIFIC AIM 2 RESULTS } & 62 \\ \text { V. } \quad \text { DISCUSSION } & 80 \\ \text { VI. } \quad \text { FUTURE STUDIES } & 105 \\ \text { REFERENCES } & 109 \\ \text { APPENDICES } & 127 \\ \text { CURRICULUM VITAE } & 132\end{array}$




\section{LIST OF FIGURES}

\section{FIGURE}

PAGE

Figure 1. The function of heat shock proteins.

3

Figure 2. Heat shock protein 90 regulates a variety of cellular pathways and processes by binding to clients proteins and co-chaperones.

Figure 3. The structure of Hsp90.

Figure 4. GA inhibits the ATP-dependent chaperone cycle of Hsp90.

Figure 5. The classical quinone MEN is similar to GA.

Figure 6. Akt is regulated by binding to Hsp90 and Cdc37 and by dephosphorylation and phosphorylation.

Figure 7 . The stability and activity of Akt is positively regulated by binding of the Akt kinase domain to Hsp90.

Figure 8. Overview of methods for Specific Aim 1.

Figure 9. Overview of methods for Specific Aim 2.

Figure 10. Time course of GA-induced cell death, measured by MTT assay.

Figure 11. Effect of GA on cell survival to $6 \mathrm{~h}$ and $24 \mathrm{~h}$ RA and SH.

Figure 12. Effect of NAC ( $1 \mathrm{mM})$ on GA and MEN induced ROS production.

Figure 13. Effect of NAC (1 mM) on GA and MEN induced cell death, determined by Trypan Blue exclusion assay. 
Figure 14. Effect of NAC (1 mM) on GA- and MEN-induced decreases

in the expression of Hsp90-binding proteins and other proteins.

Figure 15. Effect of NAC (1 mM) on GA- and MEN-induced ubiquitination of proteins.

Figure 16. Effect of $20 \mu \mathrm{M} \mathrm{GA}$ on phosphorylation of Akt and expression of ubiquitinated proteins, Hsp90 complex proteins, ERK1, and $\beta$-actin in PC-12 cells exposed to $6 \mathrm{~h}$ and $24 \mathrm{~h}$ RA or SH.

Figure 17. Effect of MG-132 on protein ubiquitination and expression of Hsp90 complex proteins, ERK1, and $\beta$-actin in PC- 12 cells treated with MEN or GA, and exposed to SH.

Figure 18. Effect of MG-132 on expression of ubiquitinated proteins, superoxide dismutase 1 and $\beta$-actin in cells treated with GA or control.

Figure 19. Cell survival to 6h RA and $\mathrm{SH}$ in the presence or absence of DMSO, MEN, and GA.

Figure 20. Cell survival to 24h RA and SH in the presence or absence of DMSO, MEN, and GA.

Figure 21. Reactive oxygen species production at $6 \mathrm{~h} \mathrm{RA}$ and $\mathrm{SH}$ in the presence or absence of DMSO, MEN, and GA.

Figure 22. Reactive oxygen species production at $24 \mathrm{~h} \mathrm{RA}$ and $\mathrm{SH}$ in the presence or absence of DMSO, MEN, and GA.

Figure 23. Immunoblots of Cdc37 and Raf-1 in Hsp90 immunoprecipitates from PC-12 cells treated with GA or MEN, with and without NAC. 
Figure 24. Immunoblots of Cdc37 and Raf-1 in Hsp90 immunoprecipitates from cells treated with GA or MEN for $6 \mathrm{~h}$ and $24 \mathrm{~h}$, with or without NAC.

Figure 25. Immunoblots of Akt, Raf-1, and Cdc37 in Hsp90

immunoprecipitates from $\mathrm{PC}-12$ cells treated with RA or SH.

Figure 26. Hsp90 binding regulates PC-12 cell survival by regulating the degradation of Hsp90-binding proteins.

Figure 27. Hsp90 binding regulates PC- 12 cell survival by regulating the non-proteasomal degradation of Hsp90-binding proteins.

Figure 28. Effect of Akti1/2 on cell survival and 6h SH-induced phosphorylation of Akt.

Figure 29. Effect of inhibition of basal phosphorylation of Akt by a high dose of Akti $1 / 2$ on cell survival.

Figure 30. Effect of transfection of PC-12 cells with c-Myc tagged wild type Akt or constitutively active Akt-encoding DNA plasmids on cell survival to $24 \mathrm{~h} \mathrm{SH}$.

Figure 31. Confocal microscopy images of PC-12 cells co-immunostained for immunocytochemical staining of Akt and Hsp90 exposed to 6h RA or SH.

Figure 32. Akt phosphorylation assay of $\mathrm{Hsp} 90$, in vitro and in $\mathrm{PC}-12$ cells transfected with constitutively active Akt-encoding plasmids.

Figure 33. Hsp90, Akt, and phospho-Ser473 Akt immunoblots of control or PP2A-treated lysates from PC-12 cells exposed to $6 \mathrm{~h} \mathrm{SH}$ in presence or absence of Akti1/2 and separated by 2-D SDS PAGE. 
Figure 34. Immunoblots of Hsp90 and Akt immunoprecipitates from PC-12 cells exposed to $6 \mathrm{~h} \mathrm{SH}$ with and without Akti1/2.

Figure 35. Binding of proteins to Hsp90 complexes at RA and at SH may be globally regulated by Akt phosphorylation.

Figure 36. Immunoblot of the putative Hsp90-binding protein GRIP1 in PC-12 cells.

Figure 37. Akt phosphorylation of Hsp90 regulates PC-12 cell survival to hypoxia by altering Hsp90 binding to Akt, Raf-1, and Cdc37.

Figure 38. Cytoplasmic dynein heavy chain, identified as a putative Hsp90-binding protein only in lysates from $6 \mathrm{~h} \mathrm{SH}+$ DMSO cells, may assist Hsp90 in hypoxia-induced Akt-dependent translocation of its binding proteins to the nucleus.

Figure 39. GRIP1 binding proteins and their other binding proteins were identified by LC-MS-MS in Hsp90 immunoprecipitates.

Figure 40. For future studies, methods from Specific Aims 1 and 2 in combination with immunocytochemistry, confocal microscopy, and subcellular fractionation will be used. 


\section{CHAPTER I: INTRODUCTION}

\section{Hypoxia: Definition, diseases, and overview of hypoxia-induced signaling pathways}

Hypoxia is defined as limited oxygen supply to cells that interferes with cellular processes. Hypoxia is associated with a variety of pathological conditions, such as ischemic diseases, sleep apnea, cardiovascular and pulmonary diseases, or stroke, and also occurs in the center of cancerous tumors [1-3]. Acute hypoxia induces a stress response, that upregulates heat shock proteins and activates survival kinases, Akt and Raf-1 [4-8]. The growth factor-mediated PI3K/Akt pathway is implicated in the survival of neuronal cells to hypoxia and to a variety of injuries $[9,10]$. The Raf-1/MEK/ERK pathway is another survival pathway induced by hypoxia and other stressful conditions $[6,7,11]$.

\section{The PC-12 cell line is an established model for studying hypoxia-induced signaling}

The oxygen sensing neuroendocrine rat pheochromocytoma PC- 12 cell line is a model widely used to investigate these molecular responses to hypoxia [6]. PC-12 cells are similar to neuronal-like carotid body type I cells that sense hypoxia and hypercapnia and play a role in the cardiovascular responses to oxygen deprivation, by transmitting this sensory information to the petrosal nerve [6]. In response to hypoxia, PC-12 cells and carotid body type I cells activate kinase signaling pathways, release catecholeminergic neurotransmitters [12-15], and depolarize by inhibiting $\mathrm{O}_{2}$-sensitive outward $\mathrm{K}^{+}$currents [6, 16-19]. Compared to primary neurons, PC-12 cells are easier to culture, 
transform, and transfect. Therefore, this study used PC- 12 cells to study cellular responses to $0.1 \% \mathrm{O}_{2}$ sustained hypoxia $(\mathrm{SH})$.

\section{The heat shock protein family}

Primary responses to cellular stress involve the induction of heat shock proteins (Hsps). Hsps were first described as a family of proteins induced by and that protect cells from hyperthermia. Hsps are conserved chaperones that fold and stabilize proteins, refold misfolded proteins, and direct the elimination of irreversibly damaged proteins (Figure 1) [20-25]. In addition, Hsp function is critical to the subcellular targeting of newly synthesized proteins [20]. Hsps regulate proliferation, cell cycle, and pro- and antiapoptotic pathways, and are implicated in multiple pathologies (Figure 1) [21-25]. Recently, some Hsps have been shown to also protect cells against hypoxia and other adverse conditions. Induction of inducible Hsp70 in response to anoxia [5], hypoxia [26], and ischemia [27] has been widely studied. Hsp70 has been implicated in hypoxic [28] and ischemic pre-conditioning[29, 30], and protects the brain from ischemia [31-33]. Additional Hsps, such as Hsp27 and Hsp90 have been implicated in the cellular response to hypoxia [34-37].

\section{Introduction to the chaperone Hsp90}

Hsp90 regulates a broad spectrum of biological processes, by interacting with and stabilizing a wide variety of "client proteins," including several kinases, co-chaperones, transcription factors, receptors, Hsps, and other binding proteins (Figure 2) [38, 39]. The chaperone Hsp90 is one of the most abundant cytosolic Hsps [40, 41], and is primarily localized to the cytosol in unstressed cells. However, low levels of Hsp90 are known to be located in other subcellular compartments, including the plasma membrane, nucleus 


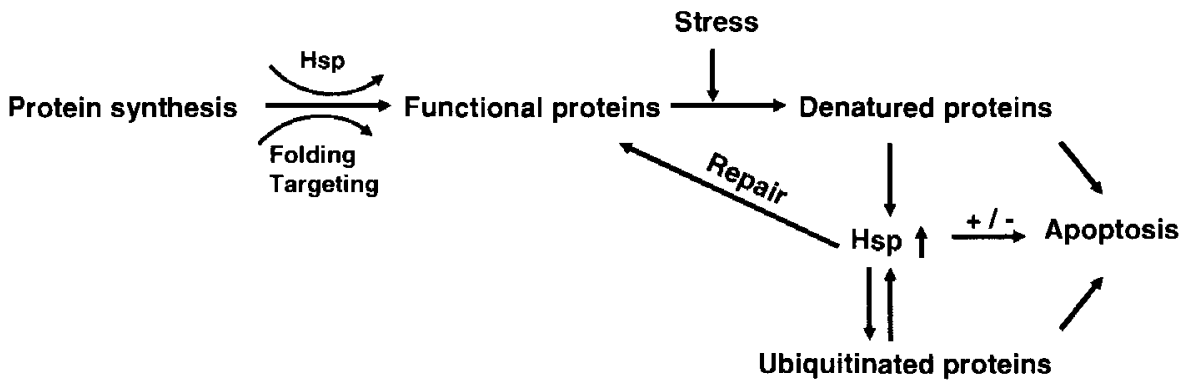

\section{Increased binding of damaged proteins compete with pro- and anti-apoptotic proteins binding to HSP and induce apoptosis.}

Figure 1. The functions of heat shock proteins. In unstressed cells, heat shock proteins fold proteins during protein synthesis. In stressed cells, expression of heat shock proteins is increased by denatured proteins, and heat shock proteins help repair and eliminate damaged proteins. By interacting with damaged proteins, heat shock proteins can direct stressed cells towards or away from cell death. 

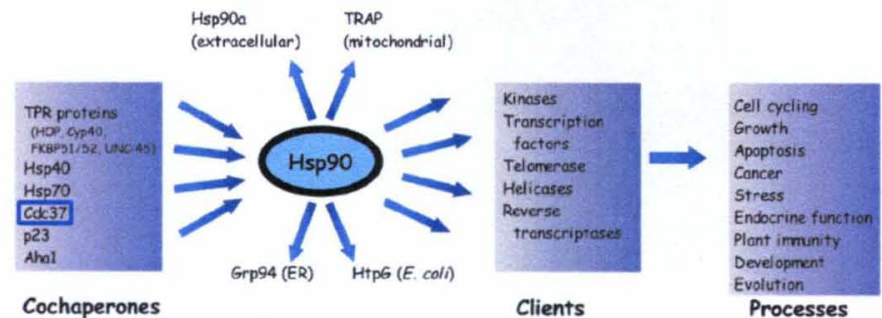

Cochaperones

Adapted from Toft et. al., 2004

Hsp90-binding proteins:

Receptors: SHR, GR, EGFR, PDGFR

Kinases: Raf-1, Akt, PDK1, ILK, Src

TF: HIF- $1 \alpha, \mathrm{HSF}, \mathrm{NF}-\mathrm{\kappa B}$

Other Chaperones: Hsp70, Cdc37

More proteins: $\mathrm{G} \alpha$ subunit of G-protein, p53, NOS

Figure 2. Heat shock protein 90 regulates a variety of cellular pathways and processes by binding to clients proteins and co-chaperones. 
and mitochondria in rat oligodendrocyte precursors derived from embryonic cerebral hemispheres [42]. Hsp90 may also be located in the perinuclear endoplasmic reticulum [43]. In addition, Hsp90 is located at the cytoskeleton, where it may maintain cytoskeletal architecture $[44,45]$. Upon stress, Hsp90 translocates from the cytosol to the nucleus [46, 47], and may also translocate from the cytoplasm to the cytoskeletal membrane in human platelets during platelet adhesion to collagen [48]. Thus, Hsp90 may shuttle its binding proteins to numerous subcellular locations in response to stress.

Two constitutive isoforms of Hsp90 exist, the more inducible Hsp90 $\alpha$ and the less inducible Hsp90 $\beta$. In cells, Hsp90 $\alpha$ and Hsp90 $\beta$ monomers, homodimers, and heterodimers occur in an equilibrium that may be shifted in response to stressful conditions, including hypoxia and cancer [49].

Each Hsp90 molecule has ATPase activity and carries two ATP-binding sites and multiple client protein and co-chaperone binding sites (Figure 3) [38]. The $\mathrm{N}$-terminal ATPase domain of Hsp90 harbors an ATP/ADP-binding site, that can bind to one molecule of ATP, ADP, GTP, or CTP [50, 51], or to the competitive Hsp90 inhibitors, Geldanamycin (GA) and Deguelin [52, 53]. The C-terminal ATP binding site of Hsp90 [50] (amino acids 657-677) binds to the Hsp90 inhibitor Novobiocin, which also allosterically inhibits the N-terminal ATP-binding site $[52,54,55]$. In addition, the Cterminal ATP binding site of Hsp90 is close to the binding site of Cisplatin, another Hsp90 inhibitor $[52,56,57]$.

The ATP-dependent chaperone cycle of Hsp90

The ATP-dependent chaperone cycle of Hsp90 regulates the binding of Hsp90 to proteins, and is critical to their maturation and stabilization (Figure 4) [40, 58]. Binding 


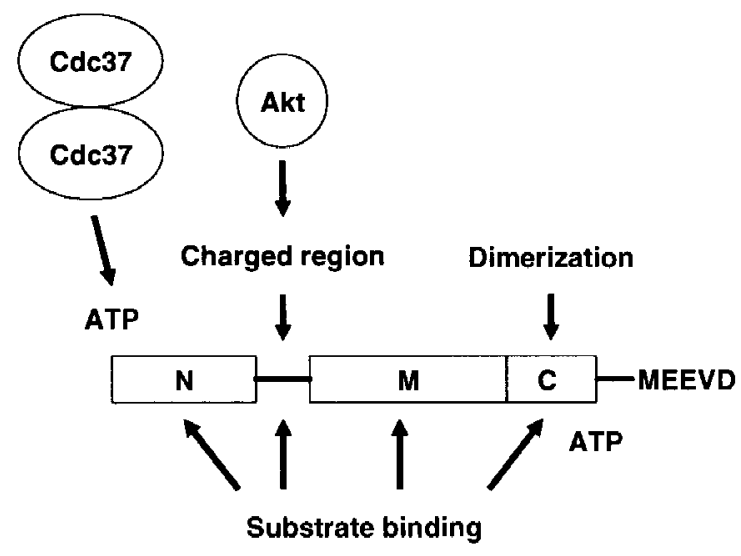

Figure 3. The structure of $\mathrm{Hsp90.}$ 


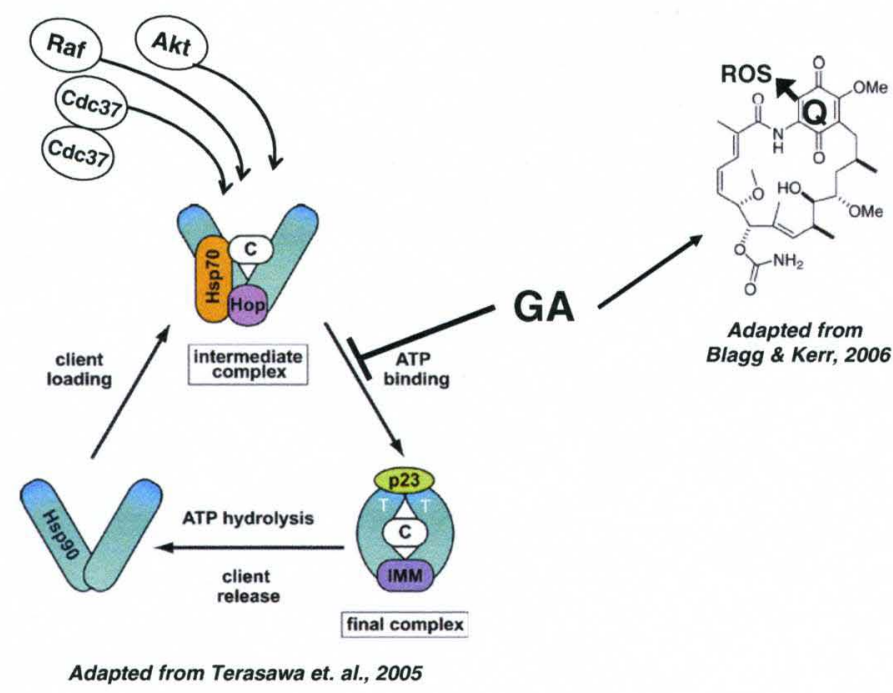

Figure 4. GA inhibits the ATP-dependent chaperone cycle of Hsp90. Dimeric open conformation Hsp90 binds to co-chaperones and client binding proteins. The Hsp90 complex then binds to ATP, causing Hsp90 to switch to a closed conformation that tightly holds on to co-chaperones and clients, allowing clients to mature and or become more stable. Clients and co-chaperones then dissociate from Hsp90 during ATP hydrolysis. GA inhibits the Hsp90 chaperone cycle by competing with ATP for binding to Hsp90, stalling co-chaperone- and client-bound Hsp90 in an open conformation, in which co-chaperones and incompletely processed clients are prone to dissociate. Immature and unstable clients released by $\mathrm{Hsp} 90$ are targeted for ubiquitination and degradation more so than mature stabilized clients. However, the quinone group of GA may induce oxidative stress, that may or may not modify the Hsp90 complex by oxidizing proteins. 
of ATP to the N-terminal ATP-binding domain alters the conformation of the Hsp90 dimers, allowing proteins to bind to or dissociate from the Hsp90 complex (Figure 4). Upon ATP hydrolysis, opening of the Hsp90 dimer allows the release of fully processed proteins, that are relatively resistant to ubiquitination and proteasomal degradation (Figure 4). GA, Deguelin, and Novobiocin, which inhibit the N-terminal ATP-binding site, decrease the expression of kinases and other Hsp90-binding proteins [51, 53, 54, 56, 59]. In contrast, the C-terminal ATP binding site of Hsp90 plays a role in the interactions of Hsp90 with steroid receptors. Cisplatin, which targets this later region of Hsp90, affects the expression of steroid receptors, without altering the expression of kinases in neuroblastoma cells $[51,54,56,59]$. In summary, ATP binding and hydrolysis regulate the binding of kinases, steroid receptors, and other proteins to Hsp90.

\section{The Hsp90 inhibitor Geldanamycin}

SiRNA silencing of Hsp90 is rarely used to study Hsp90 because the high expression of Hsp90 in cancer cells makes siRNA silencing of this chaperone challenging. Thus, GA has been extensively used to study the chaperone function of Hsp90. GA inhibits the chaperone function of Hsp90, by competing with ATP for binding to the N-terminal ATP-binding pocket of Hsp90 (Figure 4). GA binding disrupts the ATP cycle by locking the Hsp90 dimer in an "open" clamp conformation (Figure 4) $[41,60]$, that causes premature dissociation of incompletely processed client proteins.

These incompletely processed proteins are prone to ubiquitination and degradation, and their expression is consequently decreased. Decreased expression of pro-survival proteins may decrease cell survival, suggesting an important role for Hsp90 binding in regulating cell survival by regulating protein stabilities. Indeed, GA 
cytotoxicity is widely attributed to disruption of Hsp90 binding. Indeed, GA and its derivatives have been shown to disrupt cell cycle and induce apoptosis with significant decreases in Akt and ERK expression, in many cancer cells [61, 62].

GA decreases the expression of many Hsp90-binding proteins be increasing their proteasomal degradation, suggesting $\mathrm{Hsp} 90$ protects its binding proteins from proteasomal degradation. GA-induced disruption of Akt binding to Hsp90 was shown to decrease Akt expression by targeting Akt to proteasomal degradation [63]. In addition, GA induces proteasomal degradation of Raf-1 [64] and other kinases, including the mitogen-activated protein (MAP) kinase superfamily member, MOK [65]. GA also induces internalization of the Hsp90-binding kinase ErbB2, by a proteasome dependent pathway, that proceeds ErbB2 degradation by the lysosomes [66].

In addition, Finn et. al. propose a role for Hsp90 in negatively regulating chaperone mediated autophagy (CMA), a selective process that targets specific cytosolic proteins for lysosomal degradation [67]. Hsp90 inhibition by GA was shown to globally increase CMA [67], and Hsp90 may regulate the CMA of Hsp90-binding NFkB pathway kinases, NIK and IKK $[68,69]$. However, oxidative stress may induce CMA of oxidized proteins [70], and the role of GA-induced oxidative stress in CMA was not examined in these studies. In the absence of GA, Hsp90 binding may facilitate refolding of oxidized cytosolic proteins, preventing their translocation to lysosomes, that only accept unfolded proteins [67]. Regulation of CMA by Hsp90 may play a role in cellular survival. Indeed, alterations in CMA have been shown in models of normal aging and the age-related neurodegenerative diseases, Alzheimer's Disease and Parkinson's Disease [71]. 
GA and other ansamycin class inhibitors appear to preferentially target the Hsp90 complexes of cancer cells [72]. Therefore, several GA derivatives were moved to clinical trials to be combined with conventional chemotherapy [73-76]. However, GA and its less toxic derivatives are also toxic to normal cells, limiting the doses and durations of treatment that can be used [77]. While higher doses of GA display significant cytotoxicity, low doses of GA and of its derivatives are neuroprotective in P-19 neuronal cultures against antineoplastic drugs toxicity [78] and against dopamine toxicity in a mouse model of Parkinson disease [79]. This neuroprotective effect is believed to result from GA induction of Hsps, that is mediated by heat shock factor (HSF) release from Hsp90 binding and increased transcription of Hsp70 [79]. Therefore, the pro-survival effects of GA appear related to the release and induction of pro-survival proteins at lower doses, while this effect is unable to compensate for disruption of critical survival pathways at higher doses.

Disruption of Hsp90 binding may not be the only contribution of GA to cytotoxicity. GA carries a reactive benzoquinone moiety that generates reactive oxygen species (ROS) [80, 81]. ROS are produced by molecular oxygen-dependent redox-cycling of the drug's reactive quinone, during which the quinone is converted to a semiquinone via one-electron reduction by NADPH-dependent reductase enzymes [81]. Semiquinones undergo a one electron oxidation reaction with molecular oxygen that produces a cytotoxic superoxide radical and converts the semiquinone back into a quinone [82]. Thus, quinones may repeatedly redox-cycle, and superoxide products may produce additional ROS by interacting with proteins, lipids, and nucleic acids. This oxidative stress generated by GA may lead to cellular stress and demise via oxidation and 
degradation of proteins. However, the potential role of the GA benzoquinone group in GA cytotoxicity and disruption of Hsp90 binding has not been examined.

Therefore, to examine the relative contributions of oxidative stress and of disruption of Hsp90 binding to GA cytotoxicity, the classical quinone menadione (MEN) was used as a positive control for non-specific quinone-induced oxidative and arylation stress in cells. MEN is similar to GA in that both compounds have anticancer effects and each harbors one reactive quinone group, that produces ROS in cells, decreases NADPH, and non-enzymatically forms covalent conjugates with glutathione cysteine residues (Figure 5) [83-85]. In addition to using MEN, this study also assessed the effect of an antioxidant precursor on the outcomes of GA treatment. GA oxidative properties are related to its semiquinone cycling, which may deplete cells of NADPH required as a cofactor for gluthathione redox cycling. Therefore, the antioxidant precursor $\mathrm{N}$-acteyl cysteine (NAC) was selected because it reduces ROS by providing cellular reduced glutathione in an NADPH-independent manner. In addition, Fukuyo et. al. recently examined the role of oxidative stress in decreased expression and activity of the kinase BRaf induced by the GA analog, 17-demethoxygeldanamycin (17-DMAG) [86].

\section{Hsp90 binding regulates cell survival}

Hsp90 regulates cell survival by stabilizing its binding proteins. Indeed, disruption of Hsp90 binding increases client protein degradation [39, 87-89]. Hsp90 binds to Hsp70, and thereby regulates the stress responses and inductions of Hsp70 and of other heat shock proteins, by regulating the activity of heat shock factor (HSF) [90, 91]. In addition, Hsp90 also binds pro-apototic mitochondrial proteins released into the cytosol during stress and prevents apoptosome formation [13]. Hsp90 also binds to and 


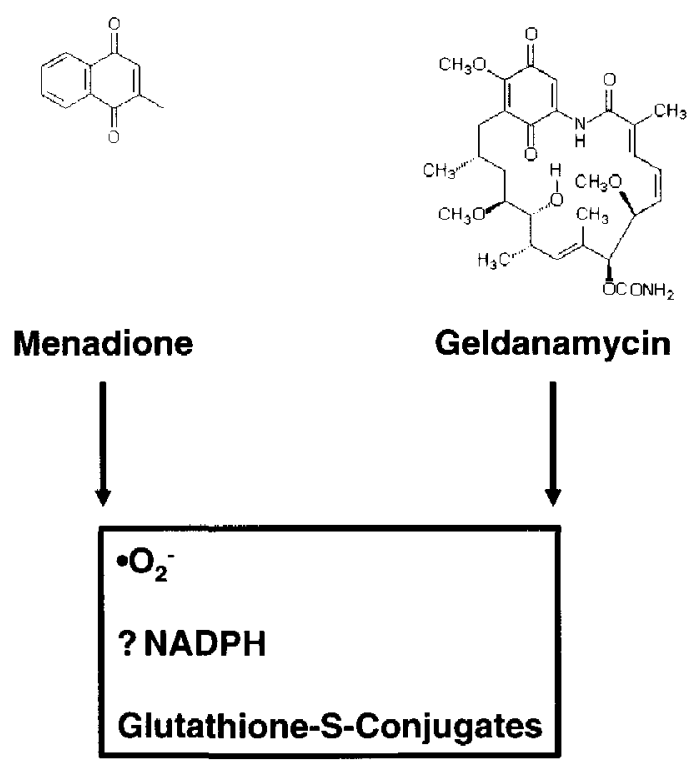

Figure 5. The classical quinone MEN is similar to GA. Both compounds harbor one reactive quinone group, that produces ROS in cells, decreases NADPH, and non-enzymatically forms covalent conjugates with glutathione. 
thereby stabilizes the survival kinases Akt and Raf-1 and binds to their co-chaperone, Cdc37 [39, 64, 92-97]. Disruption of Akt binding to Hsp90 by Hsp90 inhibitors leads to Akt degradation and cell death [63]. Hsp90 binds to and regulates the folding of multiple additional proteins, among them many cell cycle regulating proteins and proteins associated with cancer $[39,98]$. In cancer cells, the expression of $\mathrm{Hsp} 90$ and of its binding proteins is upregulated. Thus, several inhibitors of Hsp90 binding, currently in clinical cancer trials, may induce cell death and disrupt the cell cycle, by decreasing the expression of and activity of Hsp90 and Hsp90-binding proteins, including survival kinases, transcription factors, and steroid hormone receptors [59,99-105]. Although Hsp90 acts as an anti-apoptotic factor by sequestering pro-apoptotic proteins and by activating anti-apoptotic proteins, $\mathrm{Hsp} 90$ has also been shown to promote apoptosis by associating with a cyclin-dependent kinase [106-108]. The balance between Hsp90 interactions with these pro- and anti-apoptotic pathways determines cellular fate.

Hsp90 binding to Akt and Raf-1 may play a role in cell survival because these kinases are involved in survival signaling responses. Both the PI3K (phosphoinositide 3kinase)/Akt and the Ras/Raf (Ras-activated factor)/MAPK (mitogen-activated protein kinase) pathways have been implicated in cell survival and regulation of apoptosis $[6$, 109-111].

The growth factor-mediated PI3K/Akt pathway is implicated in neuronal cells survival to hypoxia and to a variety of injuries $[9,10]$. In addition, Akt is implicated in three hallmarks of cancer: self-sufficiency in growth signals, evasion of apoptosis, and sustained angiogenesis [52]. Akt prevents cell death by interacting with several signaling pathways. Akt plays roles in NFkB-induced transcription of anti-apoptotic genes, and in 
regulating forkhead pathways, that induce transcription of pro-apoptotic genes [6]. In addition, Akt phosphorylates Bad, which reduces pro-apoptotic mitochondrial cytochrome $\mathrm{c}$ release, cytosolic apoptosome assembly, and the caspase cascade [6, 112]. Furthermore, Akt has been shown to directly inhibit activation of caspase 9 in vitro [6].

\section{Hsp90 binding to kinases}

Hsp90 binds to the kinase domains of its kinase binding proteins, and this docking of Hsp90 onto kinase domains may protect kinases from dephosphorylation by phosphatases and from proteosomal degradation, and may also regulate the onset of kinase activation $[38,113,114]$. Hsp90 binding to PDK1 promotes stabilization and signaling of PDK1 by preventing the proteosomal degradation of PDK1 [115]. In addition, Hsp90 binding also prevents proteasome-dependent degradation of Integrinlinked kinase (ILK), another upstream kinase that phosphorylates Akt [113]. Hsp90 binding to the tyrosine kinase $\mathrm{pp} 60^{\mathrm{v}-\mathrm{src}}$ stabilizes this kinase and lowers its tyrosine kinase activity [116]. While bound to Hsp90, cytosolic pp60 $60^{\mathrm{v}-\mathrm{src}}$ is unphosphorylated and inactive, whereas dissociated and plasma membrane bound $\mathrm{pp} 60^{\mathrm{v}-\mathrm{src}}$ has active tyrosine kinase activity [116].

Hsp90 binding to Akt is essential for Akt phosphorylation and protects Akt from dephosphorylation by protein phosphatase 2A (PP2A) and from degradation (Figure 6) [63, 114]. In addition, Akt needs Hsp90 for its conformational maturation [52, 114]. Deletion mutagenesis studies identified an Akt binding site on Hsp90 $\alpha$ (amino acids 335 - 348) and Hsp90ß (amino acids 327 - 340), and the Akt kinase domain (amino acids 229 


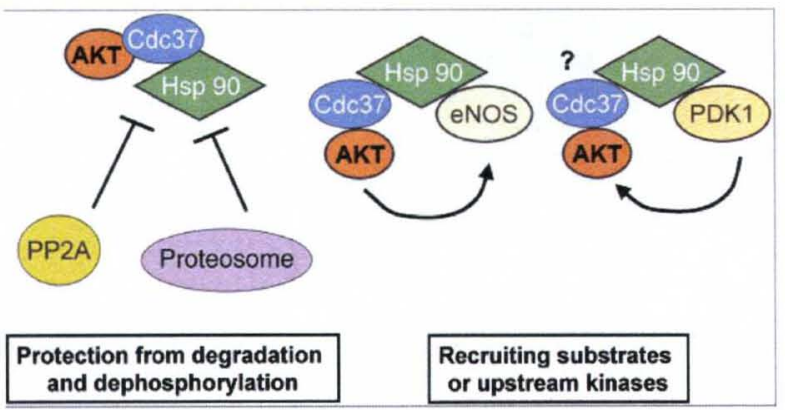

Modified from Brazil et. al., 2002

Figure 6. Akt is regulated by binding to Hsp90 and $\mathrm{Cdc} 37$ and by dephosphorylation and phosphorylation. 
- 309) was shown to bind to Hsp90 (Figure 7) [114]. Although Akt is phosphorylated when bound to Hsp90, phosphorylation of Akt is not a requirement for Akt binding to Hsp90 [114]. Several studies report that Akt binding to Hsp90 is required for Akt stability and for its activation in human and mouse cancer cell lines and in BALB/3T3 and human 293T cells, stabilizing phospho-Akt levels and Akt kinase activity [63, 113 , 114]. However, in vitro studies showed no Hsp90 effect on Akt kinase activity [63, 113 , 114]. This suggests that Hsp90 is not the only determinate of Akt activity, and additional proteins may regulate Akt activity.

Since the Akt kinases PDK1 and ILK also bind to Hsp90, Hsp90 may serve as a scaffold protein [63], bringing PDK1 and ILK close to Akt to allow for Akt activation by these upstream kinases (Figure 6). Akt-Hsp90 complexes, PDK1-Hsp90 complexes, and Akt-PDK1 complexes have been shown in several cell types by immunoprecipitation studies $[63,114,115,117,118]$. In addition, Akt-Hsp90 binding requires additional cochaperone proteins, and the stoichiometry and regulation of Akt-Hsp90 binding by these co-chaperones is unclear [21].

Hsp90 also modulates the Raf/MEK/ERK kinase survival pathway by binding to the upstream kinase Raf-1 and to Cdc37, a co-chaperone that regulates Akt and Raf-1 [96, 119]. The Cdc37 amino acid region $181-200$ binds to Raf-1 and is within the Hsp90-binding domain, located near the Akt binding domain [120-122]. Thus, Cdc37 and Hsp90 are scaffold proteins that may facilitate crosstalk between the Akt and Raf-1 signaling pathways [123-128]. Cdc37 is critical for Hsp90 binding to kinases [120, 121], and the ternary Raf-1-Cdc37-Hsp90 complex is essential to Raf-1 activity in Sf9 cells and stabilizes Raf-1 [96]. 


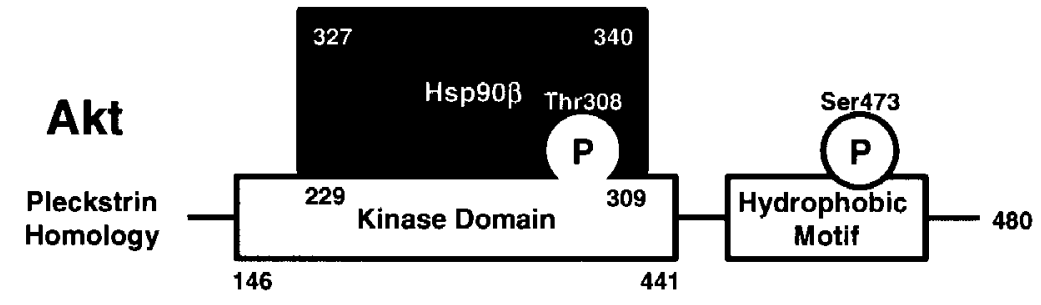

Figure 7. The stability and activity of Akt is positively regulated by binding of the Akt kinase domain to Hsp90. 


\section{Role of Hsp90 in cell survival responses to hypoxia}

By interacting with its binding proteins, Hsp90 may play a general role in survival and or a role in survival to hypoxia and to other stressors following hypoxic exposure. Recently, Hsp90 was shown to play a role in hypoxic pre-conditioning induced protection of cardiomyocytes [36]. Chiosis et. al. first hypothesized that stressful conditions including hypoxia and cancer may increase the binding of proteins to the Hsp90 complex [49]. The protein interactions of these multi-protein Hsp90 complexes that may form in response to hypoxia may play roles in cellular responses to hypoxia. Indeed, recently Hsp90 has also been shown to stabilize the survival kinase Integrin-linked kinase (ILK) in hypoxic endothelial cells [129], and Hsp90 and Cdc37 binding to and stabilization of ILK has been demonstrated previously in normoxic cells [113]. Integrin-linked kinase (ILK), a serine/threonine kinase involved in cell adhesion, proliferation, and cell survival, interacts with beta-integrins and growth factor receptors in response to extracellular signals [113]. In response to hypoxia, ILK protein levels and kinase activity increase and ILK phosphorylates survival kinases Akt and ERK, resulting in vasculogenesis and hypoxia inducible factor $1 \alpha(\mathrm{Hif}-1 \alpha)$ signaling [129]. In addition, Hsp90 binds to and regulates Hif-1 $\alpha$ [130], a transcription factor that regulates hypoxia-induced apoptosis [131], metabolic adaptation of cells to hypoxia [132], and hypoxic tumor cell growth and invasion [133]. Hsp90 binding to Hif-1 $\alpha$ positively regulates the Hif-1 $\alpha$ signaling pathway by stabilizing Hif-1 $\alpha[134,135]$, and playing roles in hypoxia-induced activation of [136] and DNA binding of Hif-1 $\alpha$ [137], and transcription of vascular endothelial growth factor (VEGF) [138]. In addition to stabilizing HIF-1 $\alpha$, Hsp90 increases phosphorylation of the pro-survival transcription factor CREB [136]. Hsp90 
also positively regulates the hypoxia-induced signaling pathway of c-Jun / activatorprotein 1 (AP-1), that upregulates transcription of protective genes in colon adenocarcinoma cells [137]. Furthermore, in a model of myocardial ischemia, Hsp90 binds to eNOS, thereby facilitating eNOS phosphorylation by Akt and increasing resistance to myocardial ischemia $[37,139]$. In conclusion, previous studies by others suggest that the protein interactions of $\mathrm{Hsp} 90$ may play a role in cellular responses to hypoxia.

\section{Regulation of the Hsp90 complex by phosphorylation}

In response to hypoxia, Akt phosphorylation increases in $\mathrm{PC}-12$ cells. Whether Akt phosphorylation affects the formation of Hsp90 complexes in response to hypoxia is currently unknown. Phosphorylation of Hsp90 and of its binding proteins by kinases may regulate the binding of proteins to the Hsp90 complex. Hsp90 and the Hsp90-binding proteins Raf-1 and Hsp70 are known substrates of Akt, and Hsp90 and Cdc37 have putative Akt phosphorylation sites [140-142].

The phosphorylation state of Hsp90 complexes may regulate Hsp90 binding. Hsp90 is phosphorylated by Akt as well as several other kinases [143] (PKA, CKII, GSK3- $\alpha$, AK), and several phosphorylated forms of Hsp90 have been identified [144]. Tyrosine phosphorylation of Hsp90 has been shown at the plasma membrane, but not in the cytosol of HEK293 cells, associating with and regulating P2X7 receptor function [145] and in HUVEC cells, associated with VEGF receptor [146]. Futhermore, Hsp90 autophosphorylates in yeast, E.coli, Brassica napus, rat, and pig [143, 147-149], and phosphorylates histones and casein in Brassica napus [149]. Autophosphorylation of Hsp90 is not altered by GA in porcine testis [143]. However, phosphatase associations 
and dissociations from Hsp90 complexes may influence phosphorylation of Hsp90 and Hsp90-bound kinases, thereby regulating kinase-Hsp90 interactions. Dissociation of protein phosphatase 1 ( $\mathrm{PPl}$ ) from $\mathrm{Hsc} 70 / \mathrm{Hsp} 90 / \mathrm{PP} 1$ complexes results in dephosphorylation of $\mathrm{Hsc70}$ and dissociation of $\mathrm{Hsp90}$ from $\mathrm{Hsc70}$ [48].

Hsp90 binding is also regulated by phosphorylation of the binding protein $\mathrm{Cdc} 37$. Phosphorylation of Cdc37 at Ser13 by Casein kinase II positively regulates Cdc37 binding to Hsp90 and to Akt and Raf-1, and stabilizes and activates Hsp90-dependent kinases in rabbit reticulocyte lysates and in $\operatorname{COS} 7$ cells $[121,150,151]$. Furthermore, Cdc37 phosphorylation by CK II in yeast positively regulates the signaling pathways of multiple GA-sensitive Cdc37- and Hsp90-binding kinases by activating Cdc37 in a positive feedback loop [152]. In addition, dephosphorylation of Hsp90-bound Cdc37 at Ser 13 by overexpression of protein phosphatase 5 (PP5/Ppt 1 ) decreases expression of CRaf and phosphorylation of ERK1/2 in the human colon carcinoma cell line, HCT116 [153]. In summary, phosphorylation and dephosphorylation of Hsp90 complex proteins may alter the activity of and stability of Hsp90 binding proteins.

\section{Regulation of the Hsp90 complexes in diseases}

However, it is unclear how Akt phosphorylation and dephosphorylation and Aktdependent phosphorylation of $\mathrm{Hsp} 90$ and its co-chaperones may affect the protein interactions of $\mathrm{Hsp} 90$ complexes in normal cells and cancer cells [49]. Understanding the regulation of Hsp90 protein interactions by Akt at physiologic and pathological conditions may be important in the development of novel treatments for a variety of medical conditions. Indeed, Hsp90 inhibitors that disrupt the Hsp90 complex are in clinical trials for metastatic stages of melanoma and prostate cancers and multiple 
myeloma [76, 154-159]. In addition, the Hsp90 inhibitor 17-(dimethylaminoethylamino)17-demethoxygeldanamycin (DMAG) has anti-tumor activity in animal models of breast, pancreatic, and small cell lung cancer $[100,102]$, and increases the sensitivity of lymphoma cells to doxorubicin chemotherapy [160]. Thus, it may be worthwhile to further develop Hsp90 inhibitors as adjuvants to conventional chemotherapies and radiotherapies, that hypoxic cancer cells often develop resistant against. Furthermore, studies with another GA analog, 17-allylamino-17-demethoxygeldanamycin (17-AAG), in a mouse model of spinal and bulbarmuscular atrophy (SBMA) suggest that Hsp90 inhibitors may also be useful in the treatment of neurodegenerative diseases [161]. However, the regulation of normoxic and hypoxic Hsp90 complexes and their roles in neuronal and cancer cell survival, resistance to chemotherapies, vasculogenesis, cancer metastases, and wound healing remain under investigation $[129,161,162]$.

\section{Hypothesis}

Therefore, the central hypothesis of this study is that the Hsp90 signaling complex regulates PC-12 cell survival and is modulated by phosphorylation of Hsp90.

\section{Specific Aim 1}

In Specific Aim 1, Hsp90-binding proteins were identified in normoxic and hypoxic cell lysates, and the roles of these proteins in cell survival were examined.

\section{Specific Aim 2}

The purpose of Specific Aim 2 was to determine whether Akt and Akt-dependent phosphorylation events regulate cell survival and protein binding to normoxic and hypoxic Hsp90 complexes. 


\section{CHAPTER II: MATERIAL AND METHODS}

\section{General Experimental Approach}

The interactions between Hsp90 and its various binding proteins and their role in PC-12 cells survival to normoxia (RA) or sustained hypoxia $\left(0.1 \% \mathrm{O}_{2} ; \mathrm{SH}\right)$ were studied, using a custom-designed chamber maintained at an atmospheric oxygen level of $0.1 \% \mathrm{O}_{2}$. In Specific Aim 1, proteomics strategies were implemented to identify critical signaling protein interactions with Hsp90 that mediate survival during normoxia and hypoxia (Figure 8). Protein-protein interactions were characterized using co-immunoprecipitation and mass spectrometry analysis of immunoprecipitates. In Specific Aim 2, the focus was on Akt-dependent regulation of Hsp90 binding in response to hypoxia (Figure 9).

\section{Materials}

All reagents were from Sigma (St Louis, MO) unless otherwise specified. Cell culture media and additives and materials for protein separation were from Invitrogen (Carlsbad, CA), unless otherwise specified. Trypan Blue (0.4\%; J. T. Baker Chemical Company, Phillipsburg, NJ) and 3-(4, 5-methylthiazol-2-yl)-2, 5-diphenyltetrazolium bromide (MTT; Calbiochem, San Diego, CA) were dissolved in phosphate buffered saline (PBS). Geldanamycin (GA; LC Laboratories, Inc., Woburn, MA), Menadione (MEN), MG-132 (Calbiochem), 2',7'-dichlorofluorescin (DCF; Molecular Probes, Eugene, OR), Bafilomycin A (BAF; Calbiochem), and Akti1/2 (Akt Inhibitor VIII; Calbiochem) were dissolved in sterile DMSO. N-acetyl cysteine (NAC) was dissolved in RPMI1640, to which $10 \%$ horse serum, $5 \%$ fetal bovine serum, and $1 \%$ antibiotics/antimycotics was 
1A. Identify Hsp90-binding proteins at hypoxia and at normoxia:

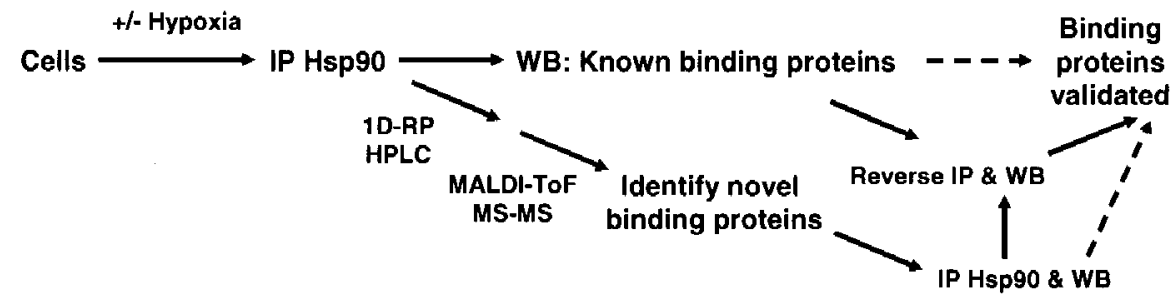

1B. Effects of Hsp90-binding protein dissociations on expression of binding proteins and cell survival:

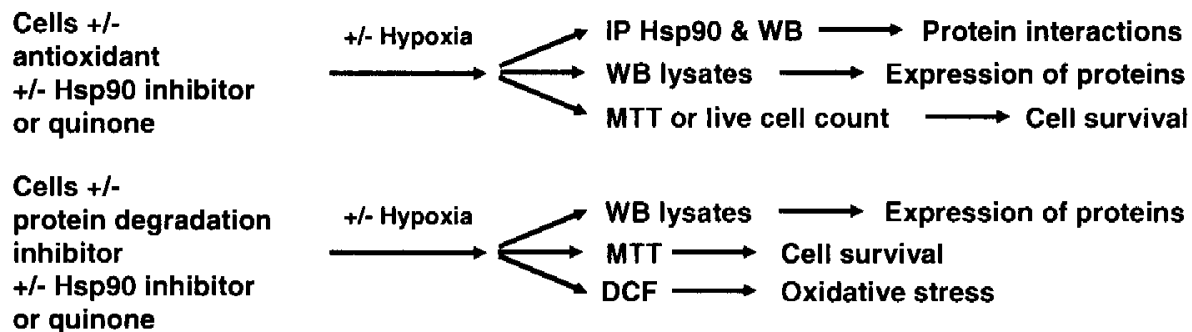

Figure 8. Overview of methods for Specific Aim 1. 


\section{A. Hsp90 phosphorylation}

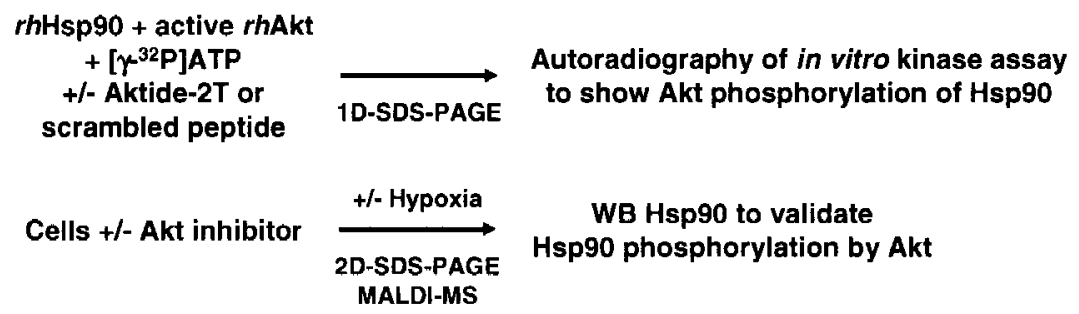

2B. Identify role of Akt in cell survival to hypoxia:

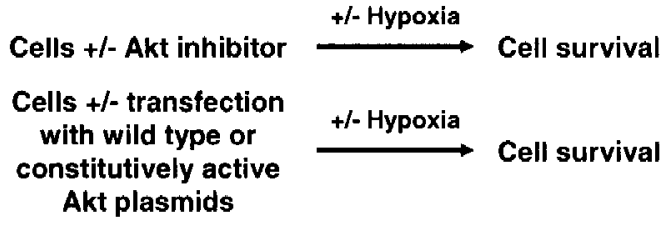

2C. Effect of Akt activation on Hsp90 associations with binding proteins

Celis +/- Akt inhibitor $\stackrel{+ \text { - Hypoxia }}{\longrightarrow}$ IP Hsp90 $\longrightarrow \begin{aligned} & \text { Immunoblot for } \\ & \text { Hsp90-binding proteins }\end{aligned}$

Figure 9. Overview of methods for Specific Aim 2. 
added following $\mathrm{pH}$ adjustment and filter sterilization. Protein A-conjugated Agarose beads and Fugene HD Transfection Reagent were from Roche Applied Science (Indianapolis, IN). Empty vector pUSE Amp DNA plasmids and wild type Akt (WT Akt)- and constitutively active myristoylated Akt (CA Akt)-encoding pUSE Amp DNA plasmids, protein phosphatase 2A (PP2A), and PP2A buffer were from Millipore/Upstate (Billerica, MA). Lab-Tek II Chamber Slides were from Nalge Nunc International (Rochester, NY) and DAPI (4', 6-diamidino-2-phenylindole dihydrochloride) was from Sigma.

\section{Cell culture}

Rat pheochromocytoma PC-12 cells (American Type Culture Collection, Manassas, VA), were cultured on rat tail collagen-coated plates in RPMI1640 medium supplemented with $10 \%$ horse serum, $5 \%$ fetal bovine serum, and $1 \%$ antibiotics/antimycotics, at $37^{\circ} \mathrm{C}$ in $5 \% \mathrm{CO}_{2}$ incubators. Experiments were performed at similar starting cell confluence that was estimated by light microscopy and MTT assay. Pre-treatments of cells with or without MG-132 were initiated at $40 \%-50 \%$ starting confluence. Cell exposures to NAC, MEN, GA, BAF, and Akti 1/2 were initiated at $70 \%$ $80 \%$ starting confluence.

\section{Exposures of cells to drugs}

To establish the dose-dependent time course of GA cytotoxicity, cells were treated for $1 \mathrm{~h}, 3 \mathrm{~h}, 6 \mathrm{~h}, 9 \mathrm{~h}, 12 \mathrm{~h}$, or $24 \mathrm{~h}$ with 10 or $20 \mu \mathrm{M}$ GA or DMSO vehicle. For antioxidant studies, cells were pre-treated $1 \mathrm{~h}$ with $1 \mathrm{mM}$ NAC or vehicle, followed by $1 \mathrm{~h}$, $6 \mathrm{~h}$, or $24 \mathrm{~h}$ treatments with $20 \mu \mathrm{M}$ MEN, $20 \mu \mathrm{M} \mathrm{GA}$, or vehicle. To determine if Hsp90 binding protects proteins from proteasomal degradation, cells were pre-treated for $21 \mathrm{~h}$ 
with DMSO or $150 \mathrm{nM}$ MG-132, and treated for $1 \mathrm{~h}$ with DMSO or $20 \mu \mathrm{M}$ GA at normoxia, or treated with DMSO, $20 \mu \mathrm{M}$ MEN, or $20 \mu \mathrm{M}$ GA starting at $3 \mathrm{~h}$ prior to exposures to $6 \mathrm{~h}$ or $24 \mathrm{~h}$ of normoxia or hypoxia. To determine if $\mathrm{Hsp} 90$ binding protects proteins from lysosomal degradation, cells were pre-treated 30 min with DMSO or up to $750 \mathrm{nM}$ Bafilomycin $\mathrm{A}_{1}(\mathrm{BAF})$, and treated with DMSO, $20 \mu \mathrm{M}$ MEN, or $20 \mu \mathrm{M}$ GA for 6h at RA. To determine if phosphorylation of Akt regulates cell survival to hypoxia by regulating Hsp90 complexes, cells were pre-treated with DMSO vehicle or $1 \mu \mathrm{M}$ or $20 \mu \mathrm{M}$ Akti1/2 for $3 \mathrm{~h}$, prior to exposures to normoxia or hypoxia.

\section{Exposures of cells to hypoxia}

PC-12 cells were exposed to $6 \mathrm{~h}$ or $24 \mathrm{~h}$ of normoxia $\left(\mathrm{RA} ; 21 \% \mathrm{O}_{2}, 5 \% \mathrm{CO}_{2}\right)$ or to sustained hypoxia ( $\mathrm{SH} ; 0.1 \% \mathrm{O}_{2}, 5 \% \mathrm{CO}_{2}$, and balanced $\mathrm{N}_{2}$ ), using computer-controlled incubation chambers linked to an external $\mathrm{O}_{2}-\mathrm{CO}_{2}$ computer-driven controller (Biospherix, Redfield, $\mathrm{NY}$ ). Chamber $\mathrm{O}_{2}, \mathrm{~N}_{2}$, and $\mathrm{CO}_{2}$ gas levels were continuously monitored, recorded, and adjusted according to the desired programmed profile, using an AD-controller interface and software (Biospherix).

\section{Transfections}

Cells $60-70 \%$ confluent were transfected in serum free medium with Fugene HD Transfection Reagent pre-incubated with $2 \mu \mathrm{g}$ of DNA plasmids and RPMI1640 medium for $15 \mathrm{~min}$ at room temperature. Cells were transfected with either empty vector plasmids or c-Myc tagged wild type Akt (WT Akt)- or constitutively active Akt (CA Akt)encoding plasmids. Transfected cells were incubated at $37^{\circ} \mathrm{C}$ for $5 \mathrm{hrs}$. Serum concentrations were restored prior to overnight incubation. At $24 \mathrm{~h}$ post-transfection, cells were exposed to 24h of RA or SH. Transfection experiments were repeated twice. 


\section{Cell viability}

Viability was measured by MTT or Trypan blue exclusion assays. MTT assay was performed by adding the formazan dye MTT (3-(4, 5-methylthiazol-2-yl)-2, 5-

diphenyltetrazolium bromide) to cells at $1 \mathrm{~h}$ before collection. Cell pellets were washed with PBS to remove excess MTT, and the reduced formazan products were solubilized with DMSO. Optical density was measured at $450 \mathrm{~nm}$ by an Original Multiskan EX plate reader (Thermo Electron Corporation). Trypan blue exclusion assay was performed by counting Trypan blue stained cells on a hemacytometer, using a light microscope connected to a digital camera and computer with Motic imaging software. Cells that did not absorb blue dye were counted as live cells.

\section{Reactive oxygen species (ROS) production}

1h prior to collection, $5 \mu \mathrm{M}$ DCF was added to cells. Cells were centrifuged, resuspended in PBS, and transferred to black 96-well plates (Greiner Bio-One, Monroe, $\mathrm{NC}$ ). Fluorescence kinetics was measured for $60 \mathrm{~min}$ at $485 \mathrm{~nm}$ excitation and $535 \mathrm{~nm}$ emission wavelengths using a fluorescent microplate reader (TECAN SPECTRAFLUOR Plus).

\section{In vitro kinase assays}

Recombinant human active Akt (400 ng), $1 \mu \mathrm{g}$ recombinant human Hsp90 $\alpha$ (Stressgen, Victoria, BC, Canada) or Hsp90 $\beta$ (Medical and Biological Laboratories, Woburn, MA) and $10 \mu \mathrm{Ci}\left[\gamma_{-}^{-32} \mathrm{P}\right] \mathrm{ATP}$ in $30 \mu \mathrm{L}$ of kinase buffer $(20 \mathrm{mM}$ HEPES, $10 \mathrm{mM} \mathrm{MgCl}, 10 \mathrm{mM} \mathrm{MnCl} 2$ ) were incubated for $45 \mathrm{~min}$ at $25^{\circ} \mathrm{C}$, in the presence or absence of Aktide-2T ( $200 \mu \mathrm{M})$ or scrambled peptide $(200 \mu \mathrm{M})$, separated by SDS-PAGE and revealed by autoradiography [140]. 


\section{PP2A treatment of lysates}

Prior to 2-D SDS PAGE separation, lysates were treated with or without 0.5 units of protein phosphatase $2 \mathrm{~A}$ for $1.5 \mathrm{~h}$ at $30^{\circ} \mathrm{C}$ in PP2A buffer. Samples were then processed as described below for 2D gel electrophoresis.

\section{Antibodies}

Primary antibodies used for immunoblotting were purchased from Santa Cruz (Santa Cruz, CA; Akt, phospho-Ser 473 Akt, ERK1, Cdc37, Raf-1, SOD-1), antiphospho-Ser473 Akt, Akt, and anti-Myc-Tag (9B11) were from Cell Signaling Technology (Danvers, MA), anti-Hsp90 $\alpha / \beta$ was from Assay Designs/Stressgen (Ann Arbor, MI), and anti-ubiquitin and anti- $\beta$-actin were from Sigma. Secondary antibodies were anti-rat IgG HRP from Assay Designs, anti-rabbit HRP from Cell Signaling Technology, and goat anti-mouse IgG HRP, Exacta Cruz anti-mouse and anti-rabbit HRP-conjugates were from Santa Cruz. For immunoprecipitations, Hsp $90 \alpha / \beta$ antibody was from Santa Cruz and anti-Akt (Catalog No. 9272) was from Cell Signaling Technology. For immunostaining, the primary antibodies rabbit anti-Akt1/2, rabbit antiGRIP1, mouse anti- Hsp90 $\alpha / \beta(\mathrm{F}-8)$, and normal mouse and rabbit IgG isotype controls were from Santa Cruz, and the secondary fluorochrome antibodies (Jackson Immunoresearch Laboratories, West Grove, PA) were donkey anti-rabbit TRITC (with rhodamine red fluorescence) and donkey anti-mouse FITC (with green fluorescence).

\section{Collection of cells}

Cells were detached by pipetting up and down and collected by centrifugation at $900 \mathrm{rpm}$ for $4 \mathrm{~min}$ at $4^{\circ} \mathrm{C}$. Pellets were washed with PBS and centrifuged at 4,000 rpm for 
5 min at $4^{\circ} \mathrm{C}$, and supernatant was aspirated. Pellets were stored at $-80^{\circ} \mathrm{C}$ prior to use, or were immediately resuspended in lysis buffer.

\section{Preparation of cell lysates}

Cell lysates (NP-40 soluble lysates fractions) were prepared by resuspending pellets in lysis buffer $(0.4 \% \mathrm{NP}-40,1 \%$ glycerol, $50 \mathrm{mM}$ tris at $\mathrm{pH} 7.5,1 \mathrm{mM} \mathrm{Na}$ orthovanadate, $150 \mathrm{mM} \mathrm{NaCl}, 10 \mathrm{mM}$ EDTA, $100 \mathrm{mM} \mathrm{NaF}, 20 \mathrm{mg} / \mathrm{mL}$ leupeptin, $10 \mathrm{mg} / \mathrm{mL}$ aprotinin, $0.5 \mathrm{mM}$ PMSF). Resuspended cells were incubated on ice for $10 \mathrm{~min}$, and then sonicated using a Fischer Scientific Sonic Dismembrator 60 set at 3 (5X for $1 \mathrm{sec}, 1 \mathrm{X}$ for $5 \mathrm{sec}$, and again $5 \mathrm{X}$ for $1 \mathrm{sec}$ ), and centrifuged at $4^{\circ} \mathrm{C}$ at $14,000 \mathrm{rpm}$ $(18,000 \mathrm{rcf})$ for $15 \mathrm{~min}$. Total protein concentrations were determined in the supernatant by DC Bio-Rad protein assay (Bio-Rad, Hercules, CA).

\section{Immunoprecipitation}

Lysates were incubated with Protein A-conjugated Agarose beads (Roche) and either primary immune antibody or non-immune isotype control antibody in lysis buffer with $0.4 \%$ NP-40. Immunoprecipitates were washed in lysis buffer without NP-40. For Hsp90 immunoprecipitations, mouse monoclonal $\operatorname{IgG}_{2 \mathrm{a}}$ anti-Hsp90 $\alpha / \beta$ (F-8) antibody (Santa Cruz) was used, and normal mouse IgG antibody (Santa Cruz) served as an isotype control. Compared to four other anti-Hsp90 antibodies tested, this anti-Hsp90 antibody immunoprecipitated the highest quantities of Hsp90 and co-immunoprecipitated the highest quantities of the kinase co-chaperone $\mathrm{Cdc} 37$ (data not shown). Therefore, the above anti-Hsp90 antibody was selected to study Hsp90 interactions with hypoxiainducible kinases. Protein $A$ beads were selected over protein $G$ and protein $A / G$ beads for their lesser non-specific protein binding. 


\section{Immunoblotting}

Lysate fractions were separated by SDS PAGE using $4-12 \%$ tris-glycine gels for 1-dimensional (1-D) gel immunoblotting, or by 2-dimensional SDS PAGE, using non-linear pH 3 -10 ZOOM immobilized $\mathrm{pH}$ gradient (IPG) strips rehydrated overnight with lysates in urea/thiourea solubilization/rehydration buffer (Proteomic Research Services, Inc.). IPG strips were washed with Equilibration buffers 1 and 2 (Proteomic Research Services, Inc.). Proteins were separated by isoelectric focusing (IEF) using a ZOOM IPG Runner Mini-Cell connected to a Thermo Electron 6000P Power Supply, set at a step voltage program (200V for $20 \mathrm{~min}, 450 \mathrm{~V}$ for $15 \mathrm{~min}, 750 \mathrm{~V}$ for $15 \mathrm{~min}$, and $2000 \mathrm{~V}$ for $105 \mathrm{~min}$ ). Following IEF, proteins in IPG strips were separated by molecular weight. IPG strips were applied to $1 \mathrm{~mm}$ wide NuPAGE Novex 4 - 12\% Bis-Tris ZOOM gels, and gels were run at $200 \mathrm{~V}$ for $\mathrm{lh}$ in $1 \mathrm{X}$ NuPAGE MOPS SDS Running Buffer with NuPAGE antioxidant. Proteins separated by 1-D and by 2-D SDS PAGE were transferred onto nitrocellulose membranes and immunoblotted. Transfer efficiency and protein loading were verified by Ponceau-S staining of the membranes. Proteins were detected by overnight incubation with primary antibody and visualized using horseradish peroxidaseconjugated secondary IgG antibodies and the enhanced chemiluminescence reagent ECL-Plus (General Electric, Niskayuna, NY). Immunoblots of lysates and of immunoprecipitates were repeated three or more times.

\section{Densitometry analysis of immunoblots}

Protein bands on films of immunoblotted immunoprecipitates were quantified by densitometry analysis, using Adobe Photoshop CS2 Version 9.0.2. Protein bands were 
selected with the lasso tool. The mean luminescence and pixel sizes of selected areas were used to calculate the densitometry units $\left(\mathrm{Y}_{\mathrm{DU}}\right)$ of each protein band.

Equation for calculating $\mathrm{Y}_{\mathrm{DU}}$ of a protein:

$\mathrm{Y}_{\text {DU Protein }}=$ Pixels $x(255-$ Mean Luminescence $)$

The densitometry units of co-immunoprecipitated proteins were normalized by dividing these values by the densitometry units of the immunoprecipitated proteins. The binding of co-immunoprecipitated proteins to the immunoprecipitated protein in inhibitor-treated or SH samples was compared to that of vehicle-treated or RA samples, by expressing the normalized protein densitometry units of the inhibitor-treated or SH sample as a percentage of the normalized protein densitometry units of the vehicle or RA immunoprecipitates.

Equation for calculating \% of binding relative to vehicle:

$$
\begin{aligned}
\%= & 100 \times\left(\mathrm{Y}_{\mathrm{DU} \text { Co-IP protein in inhibitor sample }} / \mathrm{Y}_{\mathrm{DU} \text { IP protein in inhibitor sample }}\right) \\
& \div\left(\mathrm{Y}_{\mathrm{DU} \text { Co-IP protein in vehicle sample }} / \mathrm{Y}_{\mathrm{DU}}\right. \text { IP protein in vehicle sample }
\end{aligned}
$$

\section{Mass spectrometry analysis}

To confirm the presence of $\mathrm{Hsp} 90$ in the $90 \mathrm{kDa}$ protein spots cross-reacting with Hsp90 antibody, gel plugs containing protein spots were excized, proteins were in-gel trypsin digested, and digested peptides were analyzed by matrix assisted laser desorption/ionization time-of-flight (MALDI-ToF) mass spectrometry.

To determine the effect of basal Akt phosphorylation on Hsp90 binding, we performed 1-dimensional reverse phase liquid chromatography mass spectrometry-mass spectrometry (LC-MS-MS) analysis of trypsin digested eluted anti-Hsp90 and isotype control immunoprecipitates. Hsp90 was immunoprecipitated from the lysates of PC-12 
cells pre-treated with DMSO vehicle or $20 \mu \mathrm{M}$ Akti $1 / 2$ for $3 \mathrm{~h}$ and exposed to $6 \mathrm{~h}$ of RA or SH. Immunoprecipitated proteins were eluted off of the beads by incubating the beads for $35 \mathrm{~min}$ with $20 \mathrm{mM}$ glycine at $\mathrm{pH} 2.4$, and eluants were neutralized with $1 \mathrm{M}$ triethyl ammonium bicarbonate (TEABC) at $\mathrm{pH}$ 8.5. LC-MS-MS analysis of equally immunoprecipitated anti-Hsp90 samples or isotype controls showed few proteins in isotype control samples, while Hsp90 immunoprecipitates were enriched in Hsp90. Thus, efficient immunoprecipitations were performed and peptide samples were of high quality, permitting identification of proteins specifically bound to Hsp90.

Proteins were identified by peptide mass fingerprinting of tryptic peptides by searching the Mascot protein database (http://www.matrixscience.com), using various search stringency criteria, to generate a list of proteins ranked in order of greatest significant probability for true positive identification. The MASCOT search engine analyzed the entire MSDB, NCBI, and SwissProt protein databases. Peptides were assumed to be monoisotopic, oxidized at methionine residues, and carbamidomethylated at cysteine residues. Up to 1 missed trypsin cleavage was allowed. Mass tolerance of $100 \mathrm{ppm}$ was the window of error allowed for matching the peptide mass values. Probability based MOWSE scores estimated the significances of peptide identifications by comparing the calculated peptide masses for each entry in the sequence databases with our experimental data. These probability based scores were reported as $-10 * \mathrm{LOG}_{10}(\mathrm{P})$, where $\mathrm{P}$ is the probability that the observed match was a random event. Protein identifications were significant if they were expected to occur at random with a frequency of less than $5 \%$. 


\section{Immunocytochemistry}

PC-12 cells at $80 \%$ confluence were cultured on Lab-Tek II Chamber Slides, and exposed to $6 \mathrm{~h}$ RA or $\mathrm{SH}$ in the presence or absence of $20 \mu \mathrm{M} \mathrm{Akti1} / 2$, and then fixed with $3.7 \%$ paraformaldehyde for $30 \mathrm{~min}$ at $4^{\circ} \mathrm{C}$. Fixed cells were washed twice with $\mathrm{KREBS}^{+}$(Krebs-Ringer phosphate buffer, $\mathrm{pH} 7.2$ ), permeabilized with $2 \%$ saponin for 10 min at room temperature, and washed twice with $0.02 \%$ saponin in $\mathrm{KREBS}^{+}$. Cells were incubated overnight with primary antibody in $2.5 \% \mathrm{BSA}, 2 \%$ donkey serum, $0.02 \%$ saponin in $\mathrm{KREBS}^{+}$at $4^{\circ} \mathrm{C}$ while shaking. Cells were washed twice with $0.02 \%$ saponin in $\mathrm{KREBS}^{+}$, and incubated with secondary antibody in $2.5 \%$ BSA, $2 \%$ donkey serum, $0.02 \%$ saponin in $\mathrm{KREBS}^{+}$for $2 \mathrm{~h}$ in the dark at $4^{\circ} \mathrm{C}$. Cells were incubated with the nuclear stain DAPI for $10 \mathrm{~min}$, washed once with $\mathrm{KREBS}^{+}$and were imaged using a Zeiss Axiovert $100 \mathrm{M}$ confocal microscope with LSM510 software.

\section{Statistical analysis}

Immunoblotting and immunoprecipitation experiments shown are representative of three or more experiments, unless otherwise noted. Measurements of cell viability and ROS production were repeated five or more times, unless otherwise noted. Statistical analysis was performed using the computer program, Statistical Package for the Social Sciences, Version 14.0 (SPSS). Data were analyzed by one-way and or two-way ANOVA, followed by Tukey HSD post-hoc t-tests or independent t-tests. 


\section{CHAPTER III: SPECIFIC AIM 1 RESULTS}

\section{Overview}

In Specific Aim 1, Hsp90-binding proteins were identified in normoxic and hypoxic cell lysates, and the role of these proteins in $\mathrm{PC}-12$ cell survival were examined using Geldanamycin (GA), an Hsp90 inhibitor that disrupts Hsp90 binding to proteins. Hsp90 was shown to regulate cellular survival by binding to the kinase co-chaperone Cdc37 and to the kinases, Akt and Raf-1.

\section{Effect of Hsp90 inhibition by Geldanamycin (GA) on PC-12 cell survival}

Hsp90 $\beta$ silencing by siRNA has been infrequently used in the published literature to study Hsp90 chaperone function. Although siRNA silencing of Hsp90ß was attempted during this study, this method was abandonned due to poor siRNA transfection efficiency and high expression of Hsp90 in PC-12 cells. Therefore, to study the role of Hsp90 interactions in $\mathrm{PC}-12$ cell survival, Hsp90 was pharmacologically inhibited using the classical benzoquinone ansamycin Hsp90 ATPase inhibitor, Geldanamycin (GA). Cells were exposed to 10 or $20 \mu \mathrm{M}$ GA or vehicle alone (DMSO) for up to $24 \mathrm{~h}$, and cell survival was assessed by MTT assay. No significant cytotoxicity occurred at $1 \mathrm{~h}$ and $3 \mathrm{~h}$ of treatment, however GA induced cell death by $6 \mathrm{~h}$. While both 10 and $20 \mu \mathrm{M} \mathrm{GA}$ induced cell death at $24 \mathrm{~h}$, cell toxicity induced by $20 \mu \mathrm{M}$ GA was significantly higher when compared to the lower dose. These data suggest that GA inhibition of Hsp90 induces cell death in a time and dose-dependent manner (Figure 10). 


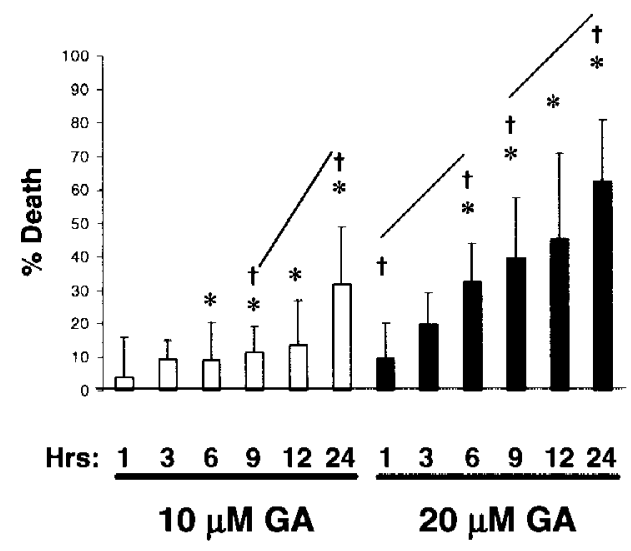

Figure 10. By 6h, GA induced dose- and time-dependent cell death, measured by MTT assay. Cells were exposed to DMSO vehicle, $10 \mu \mathrm{M}$ GA, or $20 \mu \mathrm{M}$ GA for the indicated times. The percentage of cell death was expressed as \% of control MTT OD values of GA-treated cells $v s$. vehicle treated cells at the same time point. $*=p<.01$ for $10 \mu \mathrm{M}$ GA vs. $20 \mu \mathrm{M}$ GA at same time point, $\dagger=\mathrm{p}<.05$ for same dose of GA at different time points, two-way ANOVA followed by Tukey HSD post-hoc t-tests, error bars = standard deviations $(\mathrm{n} \geq 5)$. 


\section{Effect of GA on cell survival to hypoxia}

To determine if Hsp90 regulates cell survival to hypoxia, cells pre-treated with 20 $\mu \mathrm{M}$ GA or with vehicle (DMSO) for $3 \mathrm{~h}$, were exposed to $6 \mathrm{~h}$ or $24 \mathrm{~h}$ of normoxia (RA) or

$0.1 \% \mathrm{O}_{2}$ sustained hypoxia $(\mathrm{SH})$, and cell survival was assessed by MTT assay. Exposure to $6 \mathrm{~h}$ SH did not alter cell survival, although $24 \mathrm{~h} \mathrm{SH}$ resulted in hypoxic cell death. Pretreatment with GA induced similar cell death in normoxic and hypoxic cells by $6 \mathrm{~h}$ of exposure, and this was confirmed by measuring cell viability by Trypan Blue Exclusion assay in parallel with MTT assay (Figure 11A). Cells pre-treated with a lower concentration of GA $(10 \mu \mathrm{M})$ died later by $24 \mathrm{~h} \mathrm{RA}$ and SH (data not shown). Thus, the effect of GA on cell survival is concentration dependent, and is not altered by SH. These data suggest that Hsp90 plays a general role in cellular survival rather than a role in cellular survival to hypoxia, and that cellular responses to $6 \mathrm{~h} \mathrm{SH}$ do not protect against or exacerbate GA cytotoxicity.

\section{Effect of GA on reactive oxygen species (ROS) production and ROS-mediated} cytotoxicity

GA disrupts Hsp90 function by interfering with its ATPase function. However, GA harbors a quinone group that may contributes to its cytotoxicity. To determine the effect of this oxidative group on GA-induced cell death, ROS production was assessed, using the DCF assay, in GA-treated cells and compared to ROS produced by the classical quinone menadione (MEN; a positive control for non-specific quinone stress) at $1 \mathrm{~h}, 6 \mathrm{~h}$, and 24h. While GA increased ROS at $1 \mathrm{~h}$, returning to baseline at 9h (Figure 12A; data 
(A)

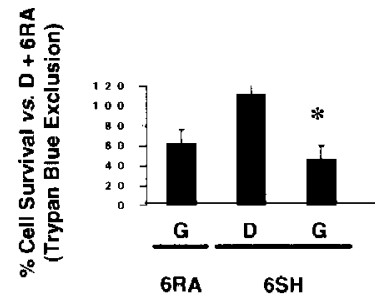

(B)

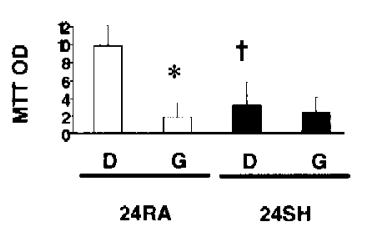

Figure 11. Cell survival at $6 \mathrm{~h}(\mathrm{~A})$ and $24 \mathrm{~h}(\mathrm{~B})$ of RA and SH in presence of DMSO (D) and $20 \mu \mathrm{M}$ GA (G). Cell viability at $6 \mathrm{~h}$ was measured by MTT and by Trypan Blue Exclusion assays. Cell viability at $24 \mathrm{~h}$ was measured by MTT assay. $*=p<.005$ for MTT OD or \% cell survival of GA-treated cells vs. DMSO-treated cells at the same exposure and time point, $\dagger=\mathrm{p}<.001$ for MTT OD of DMSO-treated 24h SH cells $v$ s. DMSO-treated $24 \mathrm{~h}$ RA cells, exposure to $6 \mathrm{~h}$ SH did not significantly alter survival in the presence of GA, one-way ANOVA followed by Tukey post-hoc t-tests, error bars = standard deviations $(\mathrm{n}>5)$. 
(A) $1 \mathrm{~h}$

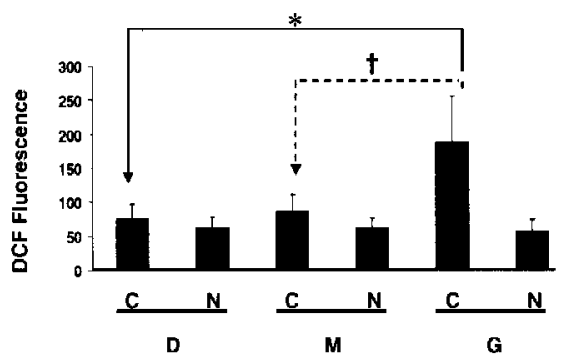

(B) $6 \mathrm{~h}$

(C) $24 \mathrm{~h}$
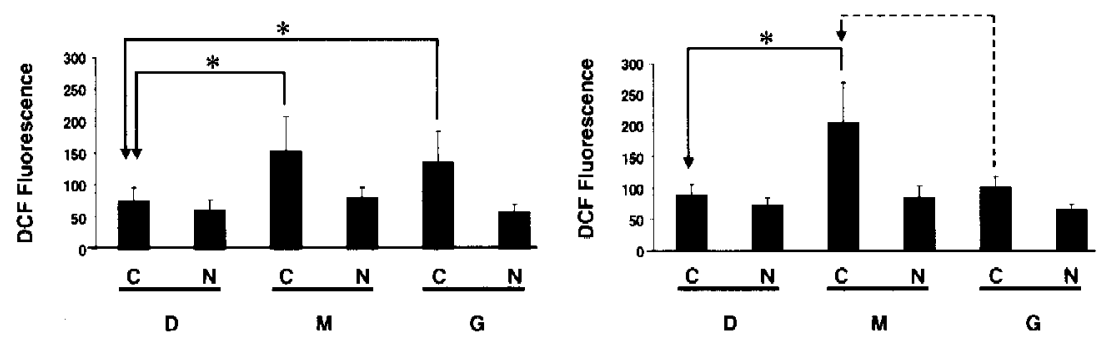

Figure 12. GA and MEN induced ROS production was inhibited by $1 \mathrm{mM} \mathrm{NAC.} 1 \mathrm{~h}(\mathbf{A})$, 6h (B), or 24h (C) with DMSO, $20 \mu \mathrm{M}$ MEN, or $20 \mu \mathrm{M}$ GA. ROS production was measured by DCF fluorescence assay. Pre-treatments: $\mathrm{C}=\mathrm{Control}, \mathrm{N}=\mathrm{NAC}$;

Treatments: $\mathrm{D}=\mathrm{DMSO}, \mathrm{M}=\mathrm{MEN}, \mathrm{G}=\mathrm{GA} .{ }^{*}=\mathrm{p}<.001$ for Control $\rightarrow$ DMSO $v s$. other conditions, $\uparrow=p<.05$ for Control $\rightarrow$ GA $v s$. Control $\rightarrow$ MEN, one-way ANOVA followed by Tukey post-hoc t-tests, error bars = standard deviations $(n>5)$. 
not shown), MEN increased ROS starting at $6 \mathrm{~h}$ (Figure 12B), persisting at $9 \mathrm{~h}, 24 \mathrm{~h}$, and 27h (Figure 12; data not shown). Pre-treatment with the glutathione precursor, N-acetyl cysteine (NAC), decreased GA- and MEN-induced DCF fluorescence to baseline levels at all time points (Figure 12). Cell survival, assessed by Trypan Blue exclusion assay, showed no GA cytotoxicity at $1 \mathrm{~h}$ (Figure 13A). Thus, the increase in cellular ROS at $\mathrm{lh}$ of GA treatment was insufficient to induce cell death at this early time point. However, significant cell death started at 6h (Figure 13B) and increased by $24 \mathrm{~h}$ (Figure 13C). Pre-treatment with NAC prevented both GA- and MEN-induced cell death (Figures 13B and 13C). In addition, NAC also similarly prevented GA cytotoxicity in cells exposed to 6h SH, showing that ROS production is also required for GA cytotoxicity in hypoxic cells (data not shown). Therefore, GA-induced oxidative stress plays a role in the cytotoxicity of GA.

\section{Effect GA on the activation of and stability of Hsp90 binding proteins}

To determine the effect of GA on the activation and expression of the survival kinases Akt and ERK1/2 and of Raf-1 and Cdc37, cell lysates were separated and immunoblotted using specific antibodies to these proteins and to their phosphorylated forms. Both GA and MEN increased phosphorylation of Akt and ERK1/2 at $1 \mathrm{~h}$ treatment, and these phosphorylations were inhibited by NAC, while total expression of these kinases was not altered by GA, MEN, and NAC. Therefore, these drugs may induce an early stress response prior to cell death (Figure 14A). Increased phosphorylation of ERK1/2, but not of Akt was sustained at 6h treatment, coinciding with the onset of cell death, while total expression of Akt and Raf-1 was reduced (Figure 14B). Later at 24h, protein expression further decreased, as the effects of GA and of MEN became less 
(A) 1h

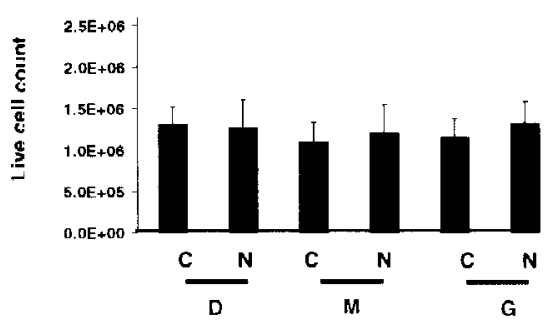

(B) $6 \mathrm{~h}$

(C) $24 \mathrm{~h}$
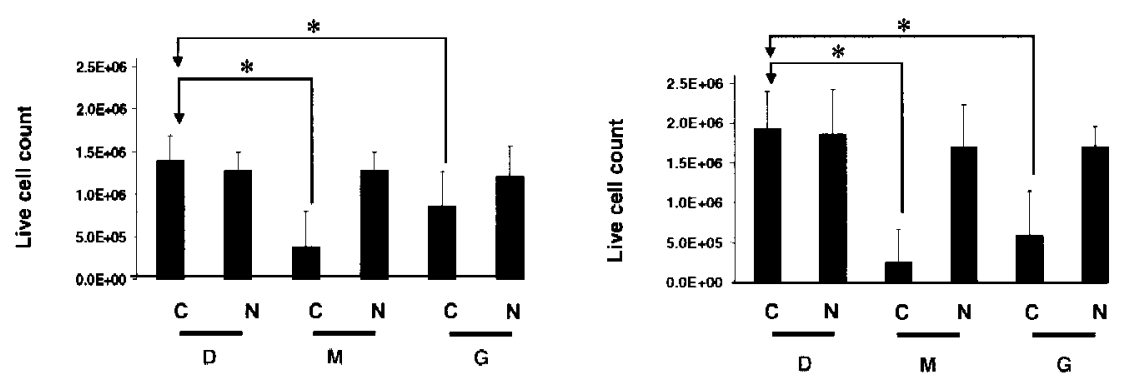

Figure 13. GA and MEN induced cell death was inhibited by $1 \mathrm{mM}$ NAC. $1 \mathrm{~h}(\mathbf{A}), 6 \mathrm{~h}$ (B), or $24 \mathrm{~h}$ (C) with DMSO, $20 \mu \mathrm{M} \mathrm{MEN}$, or $20 \mu \mathrm{M}$ GA. Cell survival was measured by Trypan blue exclusion assay. Pre-treatments: $\mathrm{C}=$ Control, $\mathrm{N}=\mathrm{NAC}$; Treatments: $\mathrm{D}=\mathrm{DMSO}, \mathrm{M}=\mathrm{MEN}, \mathrm{G}=\mathrm{GA} .{ }^{*}=\mathrm{p}<.05$ for Control $\rightarrow 6 \mathrm{~h}$ DMSO vs. other $6 \mathrm{~h}$ treated cells, $*=\mathrm{p}<.001$ for Control $\rightarrow 24 \mathrm{~h}$ DMSO vs. other $24 \mathrm{~h}$ treated cells, one-way ANOVA followed by Tukey post-hoc $t$-tests, error bars $=$ standard deviations $(n>5)$. 
(A) $1 \mathrm{~h}$

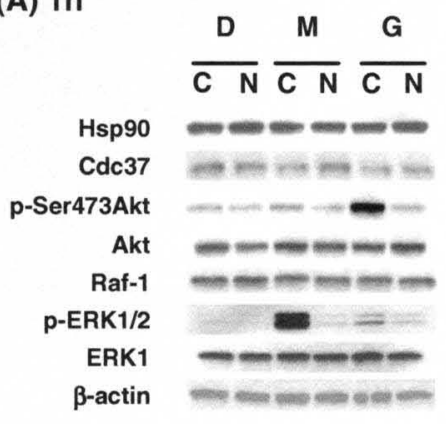

(B) $6 \mathrm{~h}$

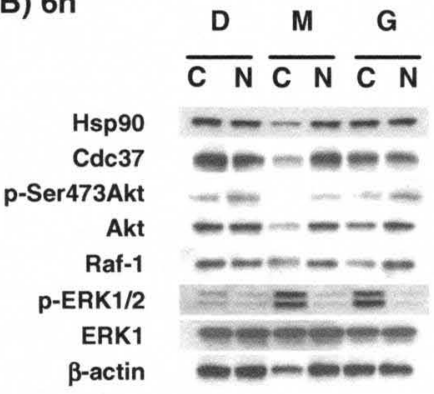

(C) $24 \mathrm{~h}$

\begin{tabular}{|c|c|c|}
\hline D & $\mathbf{M}$ & G \\
\hline$N$ & C 1 & $\mathrm{CN}$ \\
\hline 8 & - & 10 \\
\hline$\theta$, & & 20 \\
\hline$=$ & $x$ & $=$ \\
\hline is & 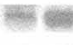 & W" \\
\hline-4 & $\operatorname{sen}$ & $=$ \\
\hline $8=$ & $-5=$ & $=$ \\
\hline & & \\
\hline
\end{tabular}

Figure 14. NAC (1 mM) inhibited GA- and MEN-induced decreases in the expression of Hsp90-binding proteins and other proteins. 1h (A), 6h (B), or 24h (C) with DMSO, $20 \mu \mathrm{M}$ MEN, or $20 \mu \mathrm{M}$ GA. Lysates were immunoblotted for Hsp90, Cdc37, phospho-Ser473 Akt, Akt, Raf-1, phospho-ERK1/2, ERK1, and $\beta$-actin. Pre-treatments: $\mathrm{C}=$ Control, $\mathrm{N}=\mathrm{NAC}$; Treatments: $\mathrm{D}=\mathrm{DMSO}, \mathrm{M}=\mathrm{MEN}, \mathrm{G}=\mathrm{GA}(\mathrm{n} \geq 3)$. 
specific, affecting proteins that may not bind to the Hsp90 complex, such as $\beta$-actin and ERK I (Figure 14C). These GA- and MEN-induced phosphorylation increases, suggestive of activation of kinases, as well as total protein degradation, were inhibited by NAC, suggesting that oxidative stress plays a role in GA- and MEN-induced protein degradation (Figure 14). These data suggest that GA-induced quinone stress increases protein oxidation that may enhance protein ubiquitination and degradation.

\section{GA- and MEN-induced ubiquitination and degradation of proteins}

Both GA and MEN similarly increased total protein ubiquitination at $1 \mathrm{~h}$ and $6 \mathrm{~h}$, indicating that the onset of protein ubiquitination occurs prior to the decrease in protein expression (Figure 15). NAC inhibited these increases in ubiquitination (Figure 15), suggesting that oxidative stress induced by these quinones increases protein ubiquitination.

\section{Effects of SH on GA-induced degradation of Hsp90-binding proteins}

In addition to its effect on proteins function and stability in normoxic cells, Hsp90 may also regulate the activation and stability of its binding proteins in hypoxic cells. To investigate the effects of Hsp90 function on the stabilization of its binding proteins in $\mathrm{SH}$, cells were pre-treated with $20 \mu \mathrm{M}$ GA or DMSO for $3 \mathrm{~h}$, and exposed to $6 \mathrm{~h}$ or $24 \mathrm{~h}$ of RA

or SH. Inhibition of Hsp90 increased protein ubiquitination by $6 \mathrm{~h}$, particularly at RA, and induced protein degradation at $6 \mathrm{~h}$ and $24 \mathrm{~h}$ of RA and SH (Figure 16), that correlated with comparable levels of cell death at RA and SH (Figures 10 and 11). Exposure to $6 \mathrm{~h} \mathrm{SH}$ induced an increase in Ser473 Akt phosphorylation that was not affected by GA pre-treatment (Figure 16), although GA decreased total Akt expression. In contrast, GA decreased phospho-Akt levels at 6h RA. Thus, while Akt degradation is similar in 
(A) $1 \mathrm{~h}$

$\frac{D}{C N} \frac{M}{C N} \frac{G}{C N}$

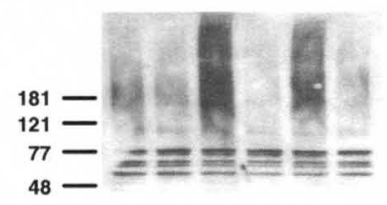

(B) $6 \mathrm{~h}$

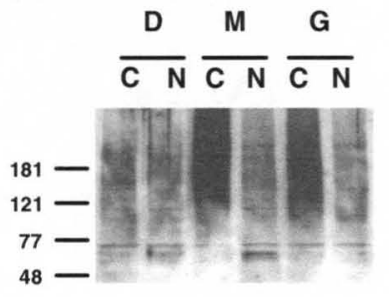

Figure 15. NAC (1 mM) inhibited GA- and MEN-induced ubiquitination of proteins.

1h (A) or 6h (B) with DMSO, $20 \mathrm{mM}$ MEN, or $20 \mathrm{mM}$ GA. Lysates were immunoblotted for ubiquitin. Pre-treatments: $\mathrm{C}=$ Control, $\mathrm{N}=\mathrm{NAC}$; Treatments: $\mathrm{D}=\mathrm{DMSO}$, $\mathrm{M}=\mathrm{MEN}, \mathrm{G}=\mathrm{GA}(\mathrm{n} \geq 3)$. 


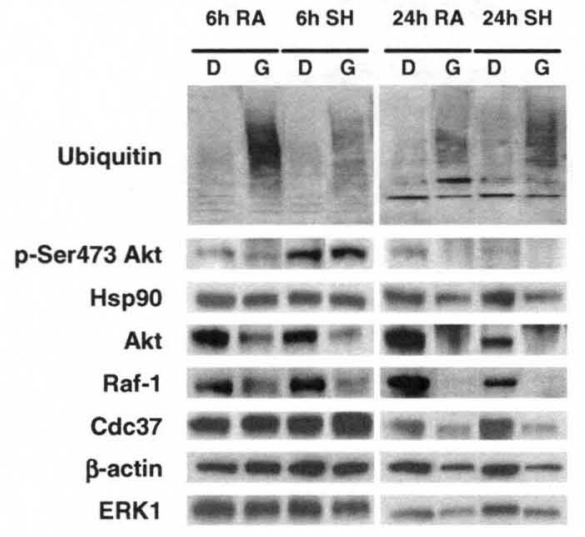

Figure 16. Representative immunoblots of lysates show the effects of DMSO vehicle, $20 \mu \mathrm{M}$ GA, and $6 \mathrm{~h}$ and $24 \mathrm{~h}$ RA or SH on phosphorylation of Akt and expression of ubiquitinated proteins, Hsp90 complex proteins, ERK1, and $\beta$-actin. $\mathrm{D}=\mathrm{DMSO}, \mathrm{G}=\mathrm{GA}$ $(n \geq 3)$. 
GA-treated normoxic and hypoxic cells, GA does not prevent SH-induced Akt phosphorylation. These results suggest that, although in normoxic cells GA lowers Akt phosphorylation, 6h SH induces Akt phosphorylation independently from Hsp90 function. Total expression of Akt and Raf- 1 decreased with GA at $6 \mathrm{~h} \mathrm{RA}$ and $\mathrm{SH}$, while Hsp90, Cdc37, $\beta$-actin, and Erk1 expressions were only affected at 24h (Figure 16). Except for its effects on phospho-Akt, SH did not otherwise alter GA-induced changes in the expression Hsp90 complex proteins, although 24h SH decreased expression of Akt and Raf-1 in DMSO-treated cells.

\section{Role of proteasomal degradation in GA-induced cytotoxicity}

Hsp90 has been reported to protect its binding proteins from proteasomal degradation. Therefore, the effects of GA on proteasomal degradation of normoxic and hypoxic $\mathrm{Hsp} 90$ complex proteins were investigated, using the proteasome inhibitor MG-132 (150 nM for 24h), followed by $20 \mu \mathrm{M} \mathrm{GA}$, or $20 \mu \mathrm{M}$ MEN, or DMSO for $3 \mathrm{~h}$. Following treatments, cells were exposed to $6 \mathrm{~h}$ or $24 \mathrm{~h}$ of RA or SH. In addition, as GA induces ROS as early as $1 \mathrm{~h}$, cells were pre-treated with MG-132 or DMSO and treated $1 \mathrm{~h}$ with $20 \mu \mathrm{M}$ GA or DMSO at RA to detect early stages of protein degradation. Cell lysates were immunoblotted for ubiquitin, Hsp90, Hsp90-binding proteins, ERK1, $\beta$-actin, and the endogenous cytosolic antioxidant, superoxide dismutase 1 (SOD-1). Immunoblots of SOD-1 showed that $150 \mathrm{nM} \mathrm{MG-132} \mathrm{did} \mathrm{not} \mathrm{alter} \mathrm{the} \mathrm{expression} \mathrm{of}$ SOD-1 (Figure 17; data not shown), although $100 \mathrm{nM}$ MG-132 is known to increase expression of the cellular antioxidants SOD-1, SOD-2, and catalase by 2 weeks in undifferentiated PC-12 cells [163]. Thus, the effects of 150 nM MG-132 on protein degradation are likely not due to changes in these antioxidants. 
(A)

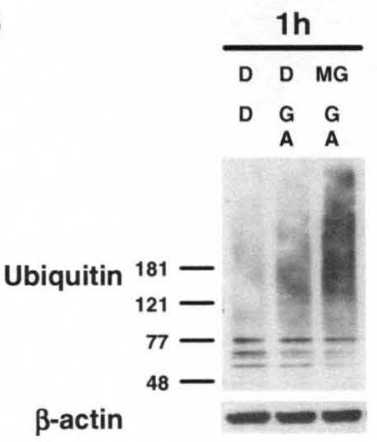

(B)

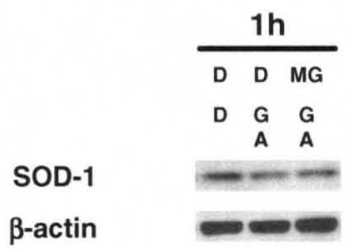

Figure 17. Representative immunoblots of lysates show that MG-132 and GA increase the expression of ubiquitinated proteins (A) without altering expression of the cytosolic antioxidant superoxide dismutase 1 (SOD-1) (B) and $\beta$-actin (A and B). Cells were exposed to $21 \mathrm{~h}$ pre-treatments with DMSO or $150 \mathrm{nM} \mathrm{MG}-132$ and treated for $1 \mathrm{~h}$ with DMSO or $20 \mu \mathrm{M}$ GA $(\mathrm{n}=3)$. 
MEN and GA increased protein ubiquitination, and MG-132, by preventing proteasomal degradation of these ubiquitinated proteins, further increased their accumulation (Figures 17 and 18). Both GA and MEN enhanced the degradation of Hsp90-binding proteins in RA and SH (Figure 18). Although both compounds are quinones, MEN and GA differ in that only GA disrupts Hsp90-binding. In addition, MEN-induced decreases in Hsp90, Cdc37, Akt, Raf-1, ERK1, and $\beta$-actin expression were inhibited by MG-132, demonstrating that MEN induces proteasomal degradation of these proteins (Figure 18). In contrast, GA-induced decreases in the expression of Hsp90, Cdc37, Akt, Raf-1, ERK1, and $\beta$-actin were not altered by MG-132 (Figure 18). Thus, disruption of Hsp90 binding by GA allows for the degradation of proteins by a proteasome-independent pathway.

Therefore, we examined whether GA induces lysosomal degradation of Akt, Raf-1, and Hsp90, by pre-treating cells for 30 min with DMSO or $750 \mathrm{nM}$ Bafilomycin $\mathrm{A}_{1}(\mathrm{BAF})$, prior to $6 \mathrm{~h}$ treatments with DMSO, $20 \mu \mathrm{M} \mathrm{MEN}$, or $20 \mu \mathrm{M}$ GA. Immunoblots of cell lysates suggest that lysosomes are not involved in the degradation of Akt, Raf-1, and ubiquitinated proteins (data not shown). The role of $\mathrm{Hsp} 90$ binding in regulating protein degradation by the calpain and caspase cysteine protease pathways has not been examined. Thus, future studies may focus on the role of $\mathrm{Hsp} 90$ binding in these alternative protein degradation pathways.

To determine whether GA- and MEN-induced decreases in the expression of Hsp90 complex proteins correlates with cell death, the effects of MEN and GA on cell survival were assessed by MTT assay. MEN and GA cytotoxicities correlated with decreased expression of Hsp90 complex proteins at $6 \mathrm{~h}$ and $24 \mathrm{~h}$ of RA and SH, indicating that these proteins play a role in survival (Figures 18 -20). Both GA and MEN induced 


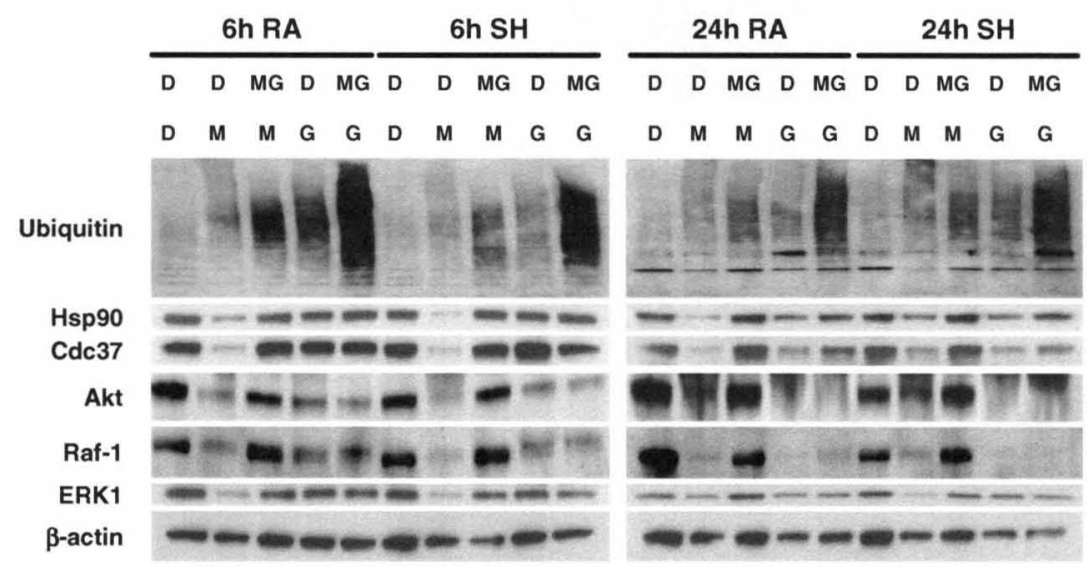

Figure 18. Representative immunoblots of lysates show the effects of MG-132, MEN,

GA, and SH on expression of ubiquitinated proteins, Hsp90 complex proteins, ERK1, and $\beta$-actin. $\mathrm{D}=\mathrm{DMSO}$ vehicle, $\mathrm{MG}=\mathrm{MG}-132, \mathrm{M}=\mathrm{MEN}, \mathrm{G}=\mathrm{GA}(\mathrm{n}=3)$. 


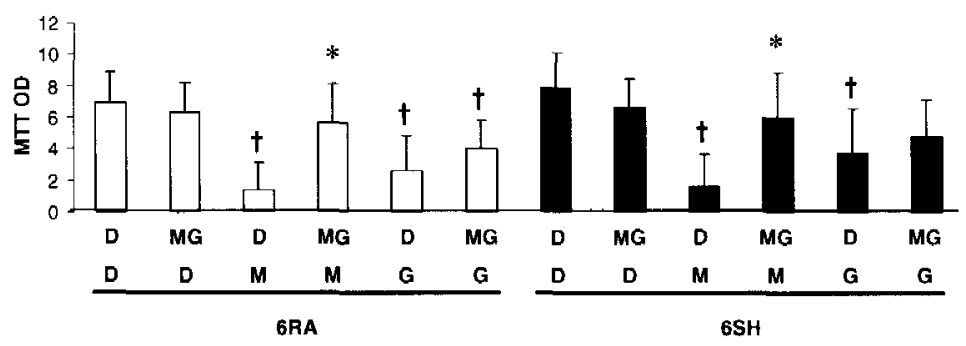

Figure 19. Cell survival at 6h RA and SH in the presence or absence of DMSO, MEN, and GA. Cell viability was measured by MTT assay. $\mathrm{D}=\mathrm{DMSO}$ vehicle, $\mathrm{MG}=\mathrm{MG}-132$, $\mathrm{M}=\mathrm{MEN}, \mathrm{G}=\mathrm{GA} .{ }^{*}=\mathrm{p}<.005$ for MTT OD of DMSO-pre-treated vs. MG-132pre-treated cells with same treatment at the same exposure, $\dagger=p<.05$ for MTT OD of DMSO + DMSO-treated cells vs. cells at the same exposure, one-way ANOVA followed by Tukey post-hoc t-tests, error bars $=$ standard deviations $(n>5)$. 


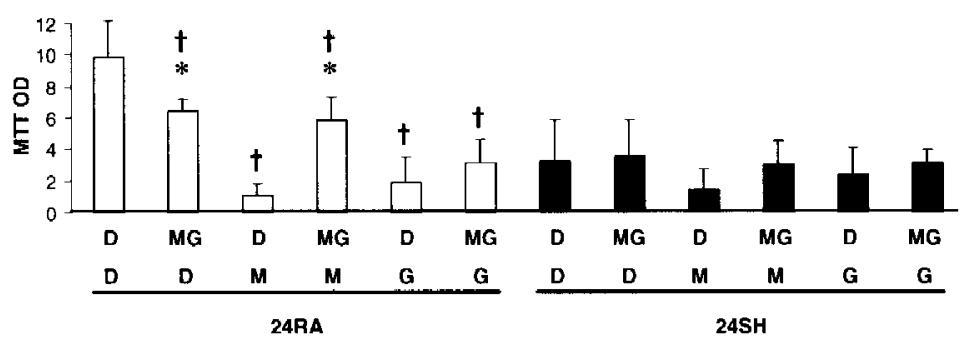

Figure 20. Cell survival at $24 \mathrm{~h} \mathrm{RA}$ and $\mathrm{SH}$ in the presence or absence of DMSO, MEN, and GA. Cell viability was measured by MTT assay. D = DMSO vehicle, $\mathrm{MG}=\mathrm{MG}-132$, $\mathrm{M}=\mathrm{MEN}, \mathrm{G}=\mathrm{GA} .{ }^{*}=\mathrm{p}<.01$ for MTT OD of DMSO-pre-treated $v s$. MG-132pre-treated cells with same treatment at the same exposure, $\dagger=p<.01$ for MTT OD of DMSO + DMSO-treated cells vs. cells at the same exposure, one-way ANOVA followed by Tukey post-hoc t-tests, error bars $=$ standard deviations $(n>5)$. 
protein degradation, although the mechanisms mediating degradation and cell death appeared to be different. To determine whether proteasomal degradation of proteins results in ROS induction, DCF fluorescence levels were determined in cells treated with the proteasome inhibitor MG-132, prior to their exposure to GA or MEN, and compared to controls. MG-132 increased accumulation of ubiquitinated proteins (Figures 17 and 20) and prevented MEN-induced increases in ROS (Figure 21 and 22), protein degradation, and cell death (Figures 19 and 20). In contrast, MG-132 did not alter GA-induced ROS (data not shown), decreases in expression of Hsp90, Cdc37, Akt, Raf-1, ERK1, and $\beta$-actin (Figure 18), and GA cytotoxicity (Figures 19 and 20). These findings suggest MEN induces oxidative stress, resulting in proteasomal protein degradation, that increases ROS and cytotoxicity, without disrupting Hsp90 binding. In contrast, GA cytotoxicity involves disruption of $\mathrm{Hsp} 90$ binding and requires oxidative stress. Furthermore, accumulation of ubiquitinated proteins when proteasomal degradation was inhibited in GA-exposed cells (Figures 17 and 18), may be attributed to proteasomal degradation of proteins unrelated to the Hsp90 complex. GA may induce degradation of Hsp90-binding proteins by a non-proteasomal degradation pathway.

\section{Effect of GA on Hsp90 binding to client proteins}

To determine whether oxidative stress, that induces protein degradation, plays a role in GA-induced disruption of the Hsp90 complex, Hsp90 was immunoprecipitated from lysates of cells treated with GA, MEN, or the vehicle DMSO, with or without NAC pre-treatment. Immunoblots of Hsp90 immunoprecipitates show that 1 h GA treatment decreased Cdc37 and Raf-1 binding to Hsp90, while MEN did not affect their binding (Figure 23). However, NAC, shown to inhibit ROS formation at this time point (Figure 


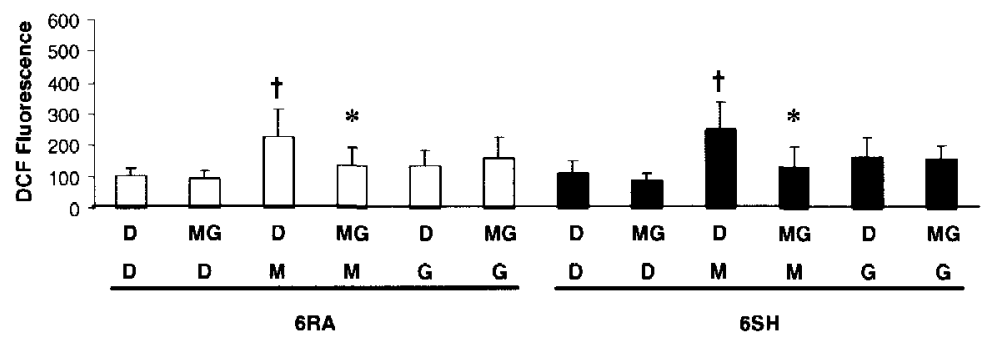

Figure 21. Reactive oxygen species (ROS) production at $6 \mathrm{~h}$ RA and SH in the presence or absence of DMSO, MEN, and GA. ROS production was measured by DCF fluorescence assay. $\mathrm{D}=\mathrm{DMSO}$ vehicle, $\mathrm{MG}=\mathrm{MG}-132, \mathrm{M}=\mathrm{MEN}, \mathrm{G}=\mathrm{GA} . *{ }^{*}=\mathrm{p}<.05$ for DCF fluorescence of DMSO-pre-treated $v s$. MG-132-pre-treated cells with same treatment at the same exposure, $\uparrow=\mathrm{p}<.001$ for DCF of DMSO + DMSO-treated cells $v s$. cells at the same exposure, one-way ANOVA followed by Tukey post-hoc t-tests, error bars $=$ standard deviations $(\mathrm{n}>5)$. 


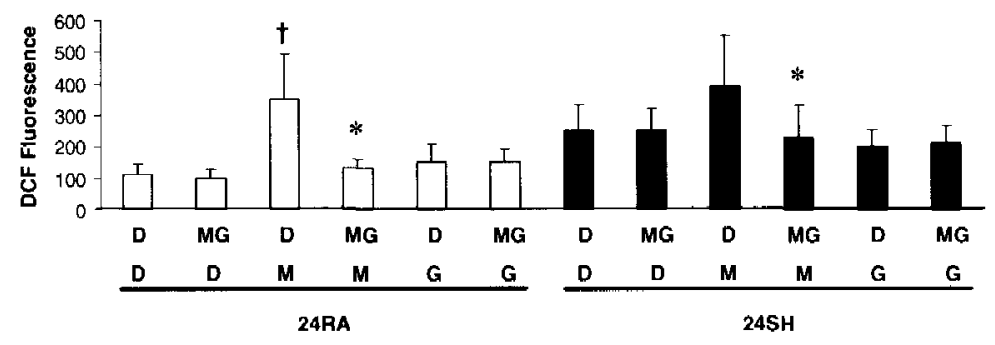

Figure 22. Reactive oxygen species (ROS) production at 24h RA and SH in the presence or absence of DMSO, MEN, and GA. ROS production was measured by DCF fluorescence assay. $\mathrm{D}=\mathrm{DMSO}$ vehicle, $\mathrm{MG}=\mathrm{MG}-132, \mathrm{M}=\mathrm{MEN}, \mathrm{G}=\mathrm{GA} .{ }^{*}=\mathrm{p}<.05$ for DCF fluorescence of DMSO-pre-treated vs. MG-132-pre-treated cells with same treatment at the same exposure, $\uparrow=\mathrm{p}<.001$ for DCF of DMSO + DMSO-treated cells vs. cells at the same exposure, one-way ANOVA followed by Tukey post-hoc t-tests, error bars $=$ standard deviations $(n>5)$. 
12A), did not reverse the 1 h GA-induced disruption of Hsp90 binding to Raf- 1 and Cdc37 (Figure 23). Thus, GA-induced disruption of Hsp90 binding appears independent from its effect on cellular oxidative status at this early time point, as NAC did not prevent this dissociation. These findings were confirmed by immunoprecipitation of Hsp90-binding proteins, followed by immunoblotting for Hsp90 and Hsp90-binding proteins. Cdc37 dissociated from Hsp90 and Akt by 1 h of GA treatment independently of oxidative stress, as demonstrated by immunoblots of $\mathrm{Cdc} 37$ and Akt immunoprecipitates (data not shown). In addition, GA dissociated Akt from Hsp90 by 24 h (data not shown). Longer GA treatments increased dissociation of the Hsp90 complex, while MEN still failed to affect protein binding (Figure 24). Therefore, while sufficient to induce cell death starting at $6 \mathrm{~h}$, oxidative stress alone, as induced by MEN, does not disrupt Hsp90 complexes. NAC did not prevent GA-induced early protein dissociation, but allowed re-association of proteins with $\mathrm{Hsp} 90$ by $24 \mathrm{~h}$.

\section{Effect of hypoxia on Hsp90 binding and expression of binding proteins in hypoxia}

During SH, Hsp90 binding may be altered and may regulate the expression of Akt and of other Hsp90-binding proteins. Therefore, we examined the effects of GA on Hsp90 binding by immunoprecipitating Hsp90 from the lysates of cells treated with DMSO or $20 \mu \mathrm{M}$ GA for $3 \mathrm{~h}$ and exposed to $6 \mathrm{~h}$ or $24 \mathrm{~h}$ of RA or SH. Hsp90 immunoprecipitates were immunoblotted for Akt, Raf-1, Cdc37, and Hsp90. Immunoblots of Hsp90 immunoprecipitates show that Akt, Raf-1, and Cdc37 bind to normoxic and hypoxic Hsp90 complexes (Figure 25). Densitometry analysis of these immunoprecipitates demonstrated that GA disrupted Hsp90 binding to Raf-1 and Cdc37 


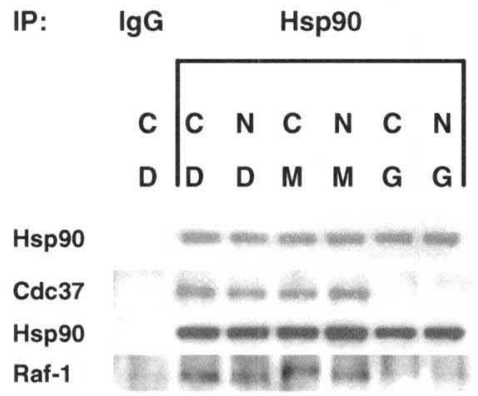

Figure 23. Representative immunoblots of Hsp90 immunoprecipitates show that at $1 \mathrm{~h}$ of treatment, GA-induced disruption of $\mathrm{Cdc} 37$ and of Raf-1 binding to Hsp90 was not modified by NAC, while MEN did not disrupt Hsp90 binding. Pre-treatments:

$\mathrm{C}=$ Control, $\mathrm{N}=\mathrm{NAC}$; Treatments: $\mathrm{D}=\mathrm{DMSO}, \mathrm{M}=\mathrm{MEN}, \mathrm{G}=\mathrm{GA} . \mathrm{IgG}=$ control immunoprecipitation with non-immune isotype control antibody $(n=3)$. 


\begin{tabular}{|c|c|c|c|c|c|c|c|c|c|c|c|c|c|c|}
\hline \multirow{3}{*}{ IP: } & \multicolumn{7}{|c|}{$6 \mathrm{~h}$} & \multicolumn{7}{|c|}{$24 \mathrm{~h}$} \\
\hline & $\lg G$ & & & Hsp & & & & $\lg G$ & & & Hsp & & & \\
\hline & C & C & $\mathbf{N}$ & C & $\mathrm{N}$ & C & $\mathrm{N}$ & C & C & $\mathrm{N}$ & C & $\mathbf{N}$ & C & $\mathbf{N}$ \\
\hline & D & lD & D & $M$ & $\mathbf{M}$ & $\mathbf{G}$ & G & D & lD & D & M & $M$ & G & G I \\
\hline Hsp90 & & 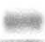 & 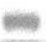 & mas & 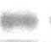 & $=$ & $\omega$ & & nese & (5es & mes & $m$ & (6) & $\Leftrightarrow$ \\
\hline Cdc37 & & 1. & 6 & 60 & 6 & $8=$ & & & & . & 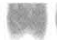 & 길 & Nis & 6 \\
\hline Raf-1 & & Exis & 작 & 6 & 6 & Fis & Eat & & Wiato & Ex & 대 & $6=$ & $\pi$ & 5 \\
\hline
\end{tabular}

Figure 24. Representative immunoblots of Hsp90 immunoprecipitates show the effects of control growth medium or $1 \mathrm{mM} \mathrm{NAC}$ pre-treatments and $6 \mathrm{~h}$ and $24 \mathrm{~h}$ treatments with DMSO, $20 \mu \mathrm{M}$ MEN, or $20 \mu \mathrm{M}$ GA on Hsp90 binding. Pre-treatments: C = Control, $\mathrm{N}=$ NAC; Treatments: $\mathrm{D}=\mathrm{DMSO}, \mathrm{M}=\mathrm{MEN}, \mathrm{G}=\mathrm{GA} . \mathrm{IgG}=$ control immunoprecipitation with non-immune isotype control antibody $(\mathrm{n} \geq 3)$. 


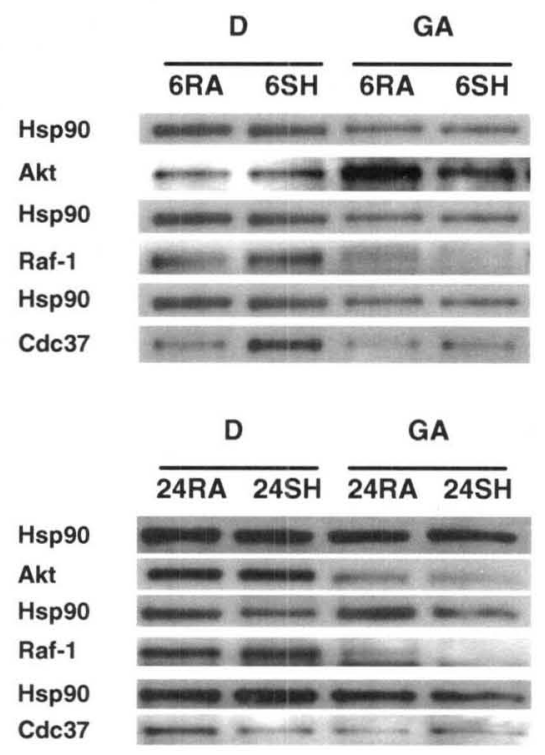

Figure 25. Representative immunoblots of Hsp90 immunoprecipitates show Akt, Raf-1, and $\mathrm{Cdc} 37$ bind to normoxic (RA) and hypoxic (SH) Hsp90 complexes. PC-12 cells were pre-treated with DMSO or $20 \mu \mathrm{M}$ GA for $3 \mathrm{~h}$ and exposed to $6 \mathrm{~h}$ or $24 \mathrm{~h}$ of RA or SH.

Hsp90 was immunoprecipitated from lysates, and immunoprecipitates were immunoblotted for Hsp90, Cdc37, Akt, and Raf-1. D = DMSO vehicle, $\mathrm{GA}=$ Geldanamycin $(\mathrm{n} \geq 3)$. 
in 6h RA and SH cells, while Akt binding to Hsp90 was disrupted later by $24 \mathrm{~h} \mathrm{RA}$ and SH.

As the expression of Hsp90-binding proteins decreases in $\mathrm{SH}$, we examined whether SH disrupts Akt, Raf-1, and Cdc37 binding to Hsp90, and whether disruption of Hsp90 binding by GA increases SH-induced protein degradation. GA affected Akt binding to Hsp90 differently at RA and SH (Figure 25). Pre-treatment with GA at 6h RA increased Akt binding to Hsp90, while this binding was disrupted at $6 \mathrm{~h} \mathrm{SH.} \mathrm{Additionally,}$ GA increased protein ubiquitination peaking at $6 \mathrm{~h}$, particularly at RA and induced protein degradation at $6 \mathrm{~h}$ and $24 \mathrm{~h}$ of RA and SH (Figure 18), that correlated with cell death (Figures 19 and 20). Total expression of Akt and Raf-1 decreased with GA at 6h RA and $\mathrm{SH}$, while Cdc37, $\beta$-actin, and Erk1 expressions were affected at 24h (Figure 18). Therefore, Hsp90 binding may stabilize Raf-1 and Cdc37, as disruption of their binding to Hsp90 correlates with decreased expression of these proteins. Akt expression also decreased in GA-treated cells at 6h RA, despite its increased binding to Hsp90. While 6h SH increases Akt binding to Hsp90, combining GA treatment with hypoxic stress results in disruption of Akt binding and its degradation. This disruption of Akt binding by GA combined with hypoxic stress, may allow for an increase in Akt phosphorylation that is decreased at 6h RA (Figures 16 and 25).

In conclusion, Hsp90 regulates binding protein stability similarly at RA and SH. Hsp90 stabilization of its binding proteins positively regulates cellular survival independently of molecular oxygen levels, and Hsp90 inhibition by GA induces cell death by disruption of Hsp90 binding (Figure 26). In addition, oxidative stress induced by the quinone moiety of GA plays an essential, previously unknown role in GA cytotoxicity 


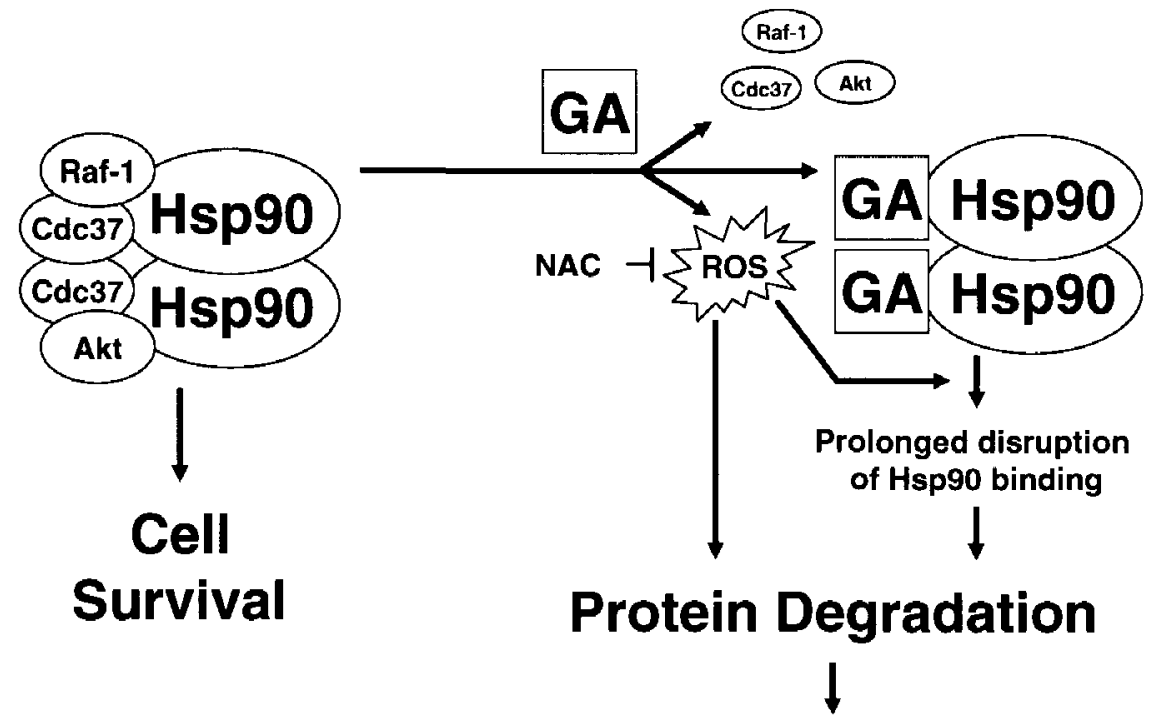

Cell Death

Figure 26. Hsp90 binding regulates PC-12 cell survival by regulating the degradation of Hsp90-binding proteins. We used the exogenous antioxidant precursor $\mathrm{N}$-acetyl cysteine (NAC) to show that GA induces cell death by oxidative stress and by disrupting Hsp90 binding. The degradation of proteins that is increased by this oxidative stress and by disruption of Hsp90 binding may contribute to cell death. 
(Figure 26). Furthermore, these studies also suggest that proteins that are dissociated from $\mathrm{Hsp} 90$ by GA are degraded by a proteasome-independent degradation pathway (Figure 27). 


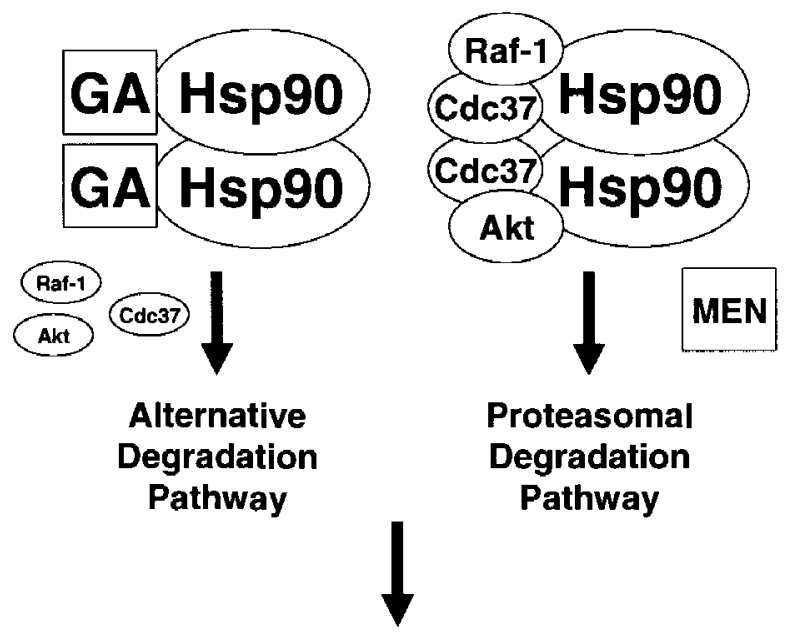

Cell Death

Figure 27. Hsp90 binding may regulate PC-12 cell survival by regulating the nonproteasomal degradation of Hsp90 complex proteins. MEN, which did not disrupt Hsp90 binding, induced cytotoxicity via oxidative stress and proteasomal degradation. In contrast, disruption of Hsp90 binding by GA allowed proteins to be degraded by an alternative pathway. Inhibiting proteasomal degradation did not alter GA cytotoxicity, suggesting that the non-proteasomal pathway contributes to cell death. 


\section{CHAPTER IV: SPECIFIC AIM 2 RESULTS}

\section{Overview}

Specific Aim 2 examined whether Akt and Akt-dependent phosphorylation events regulate protein binding to the Hsp90 complex and cell survival. Basal Akt phosphorylation was shown to positively regulate cell survival. In response to hypoxia, Akt phosphorylates Hsp90 and Hsp90 binding to Akt, Raf-1, and Cdc37 increases. However, this study cannot confirm that these hypoxia-induced changes in the Hsp90 complex play a role in cellular survival to hypoxia. Additional factors besides Akt expression and phosphorylation may be critical to survival to hypoxia. Increased Akt phosphorylation is not sufficient for survival to hypoxia

Exposure of PC-12 cells to $6 \mathrm{~h}$ of $0.1 \% \mathrm{O}_{2}$ sustained hypoxia $(\mathrm{SH})$ increased Akt phosphorylation (Figure 28A), without inducing significant cell death (Figures 28B). Later by $24 \mathrm{~h}, \mathrm{SH}$ induced cell death (Figure $28 \mathrm{~B}$ ), that coincided with decreased Akt expression and phosphorylation (Figure 28A). Equal loading of proteins was verified by Ponceau-S staining of nitrocellulose membranes and by immunoblotting these membranes for $\beta$-actin.

Survival kinases are activated in response to stress to promote survival pathways. To determine whether increased Akt phosphorylation at $6 \mathrm{~h} \mathrm{SH}$ is critical for cell survival to $\mathrm{SH}$, cells were pre-treated with the Akt inhibitor, Akti1/2 $(1 \mu \mathrm{M})$, prior to exposures to $6 \mathrm{~h}$ or $24 \mathrm{~h}$ of normoxia (RA) or SH. At this dose, Akti1/2 inhibited the $6 \mathrm{~h}$ SH-induced phosphorylation of Akt, and only minimally altered basal phosphorylation of Akt (Figure 
(A)
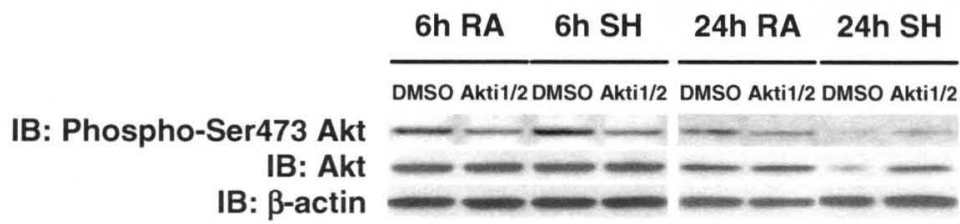

(B)

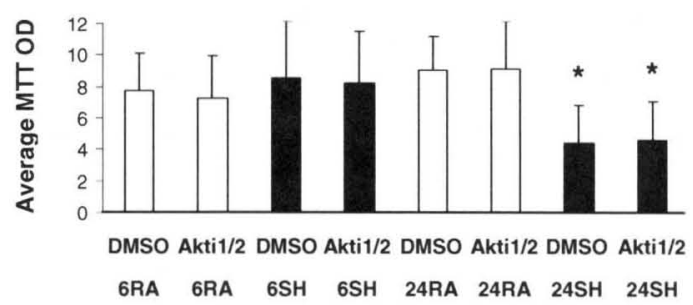

Figure 28. Inhibition of $6 \mathrm{~h} \mathrm{SH}$-induced phosphorylation of Akt by a low dose of Akti1/2 did not alter PC-12 cell survival. Cells were pre-treated with DMSO vehicle or $1 \mu \mathrm{M}$ Akti $1 / 2$ for $3 \mathrm{~h}$, and exposed to $6 \mathrm{~h}$ or $24 \mathrm{~h}$ of normoxia (RA) or $0.1 \% \mathrm{O}_{2}$ sustained hypoxia (SH). (A) Representative immunoblots of cell lysates show expression of phospho-Ser473 Akt, Akt, and $\beta$-actin. (B) Cell viability was measured by MTT assay. $*=\mathrm{p}<.05$ for MTT optical density (OD) of 24h RA vs. 24h SH, two-way ANOVA followed by Tukey post-hoc t-tests, error bars $=$ standard deviations $(n \geq 5)$. 
28A). Preventing the increase in Akt phosphorylation at $6 \mathrm{~h} \mathrm{SH}$ neither resulted in significant cell death, nor altered Akt and $\beta$-actin expression (Figure 28). Additionally, inhibition of increased Akt phosphorylation at $6 \mathrm{~h} \mathrm{SH}$ did not increase cell death at $24 \mathrm{~h}$ SH (Figure 28). Thus, the SH-induced increase in Akt phosphorylation at $6 \mathrm{~h} \mathrm{SH}$ does not appear to improve survival to SH, but may nonetheless promote the onset of a stress response. Alternatively, activation of additional pathways may compensate for the inability of cells to increase Akt activity at $6 \mathrm{~h} \mathrm{SH}$.

\section{Basal Akt phosphorylation is critical for survival}

We examined whether complete inhibition of Akt kinase activity with a higher dose of Akti 1/2 inhibitor $(20 \mu \mathrm{M})$ would affect survival. The inhibitor at this dose completely abrogated Ser473 phosphorylation of Akt, while being still specific to Akt. The phosphorylation of ERK1/2 and the expression of Akt, $\beta$-actin (Figure 29A), Hsp90, and Hsp90-binding proteins were not altered by Akti1/2 (data not shown). Cell survival was drastically decreased by $20 \mu \mathrm{M} \mathrm{Aktil} / 2$ at RA and SH, and SH did not alter the cytotoxicity of Aktil/2 (Figure 29B), demonstrating that basal phosphorylation of Akt is required for cell survival regardless of molecular oxygen levels.

\section{Sustained Akt activation is not sufficient to protect against hypoxic cell death}

Loss of function experiments indicated that the increase in Akt phosphorylation at 6h SH did not appear to underlie cell survival to SH, but that Akt activity was still essential to PC-12 cell survival. Therefore we examined whether gain of function experiments, inducing sustained Akt activity at $24 \mathrm{~h} \mathrm{SH}$, would rescue the cells from $\mathrm{SH}$-induced cell death. Cells were transfected with empty vector plasmids or with c-Myc-tagged wild type Akt (WT Akt)- or with c-Myc-tagged constitutively active 
(A)

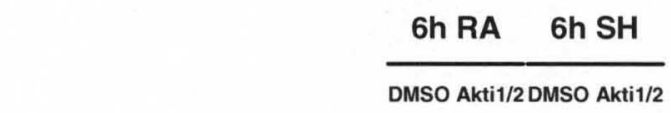

IB: Phospho-Ser473 Akt

IB: Akt

MSO Akti1/2 DMSO Akti1/2

IB: $\beta$-actin

(B)

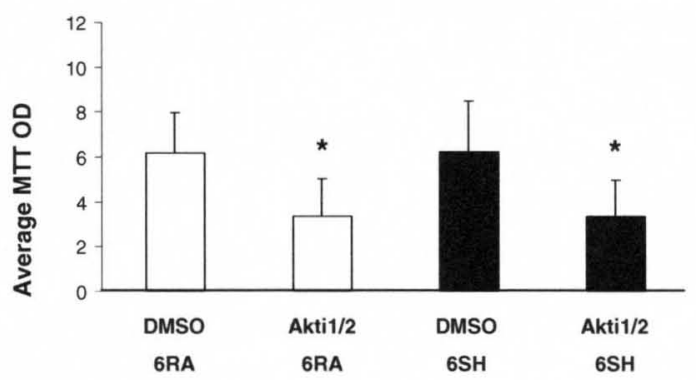

Figure 29. Inhibition of basal phosphorylation of Akt by a high dose of Akti1/2 decreased PC-12 cell survival to $6 \mathrm{~h} \mathrm{RA}$ and SH. Cells were pre-treated with DMSO vehicle or $20 \mu \mathrm{M}$ Akti1/2 for 3h, and exposed to $6 \mathrm{~h}$ of RA or SH. (A) Representative immunoblots of cell lysates show expression of phospho-Ser473 Akt, Akt, and $\beta$-actin. (B) Cell viability was measured by MTT assay. $*=\mathrm{p}<.05$ for MTT OD of DMSOtreated vs. Akti1/2-treated cells at the same exposure, one-way ANOVA followed by Tukey post-hoc t-tests, error bars $=$ standard deviations $(n>5)$. 
myristoylated Akt (CA Akt)-encoding plasmids, and exposed to 24h of RA or SH. Transfection efficiency was verified by immunoblotting for phospho-Ser473 Akt, Akt, and c-Myc tag (Figure 30A). Overexpression of WT Akt and CA Akt did not rescue cells from hypoxic cell death at $24 \mathrm{~h}$ (Figure 30B). These data suggest that while Akt activation is required for survival, it is not sufficient to maintain survival after a long duration of oxygen deprivation, and that additional cellular responses may be required to rescue the cells at this time point. Indeed, after $24 \mathrm{~h} \mathrm{SH}$, cellular respiration may be critically impaired and cytotoxic reactive oxygen species may be released that may damage proteins beyond repair. Indeed, protein expression after $24 \mathrm{~h}$ was lower in SH than in RA, even after cell transfection to overexpress Akt constructs (Figure 30A).

\section{Hypoxia induces a transient increase in protein binding to Hsp90 that correlates with increased phosphorylation of Akt}

To determine whether hypoxia alters Hsp90 binding to Akt, Raf-1, and Cdc37, Hsp90 immunoprecipitates from cells exposed to $6 \mathrm{~h}$ and $24 \mathrm{~h}$ of RA or SH were immunoblotted for these binding proteins. SH first increased the binding of Akt, Raf-1, and $\mathrm{Cdc} 37$ to Hsp90 at 6h (Figure 25). Akt immunoprecipitation confirmed increased Akt binding to $\mathrm{Hsp} 90$ in response to $6 \mathrm{~h} \mathrm{SH}$, and increased co-localization of Akt with $\mathrm{Hsp} 90$ at $6 \mathrm{~h} \mathrm{SH}$ was also visualized by immunocytochemistry (Figure 31 ). However, binding of Akt and Raf- 1 approached baseline normoxic levels by $24 \mathrm{~h} \mathrm{SH}$, while Cdc37 binding was below baseline by $24 \mathrm{~h}$ SH (Figure 25).

\section{Akt phosphorylates Hsp90 in vitro and ex vivo}

Akt phosphorylation at $6 \mathrm{~h} \mathrm{SH}$ coincides with increased Hsp90 binding to its client proteins (Figures 25 and 28). Therefore, we investigated whether Hsp90 is an Akt 
(A)

$$
\begin{array}{cccccccc}
\text { TR } & \text { V } & \text { WT } & \text { CA } & \text { TR } & \text { V } & \text { WT } & \text { CA } \\
& & \text { Akt } & \text { Akt } & & & \text { Akt } & \text { Akt } \\
\text { RA } & \text { RA } & \text { RA } & \text { RA } & \text { SH } & \text { SH } & \text { SH } & \text { SH }
\end{array}
$$

IB: phospho-Akt

IB: Akt

IB: c-Myc

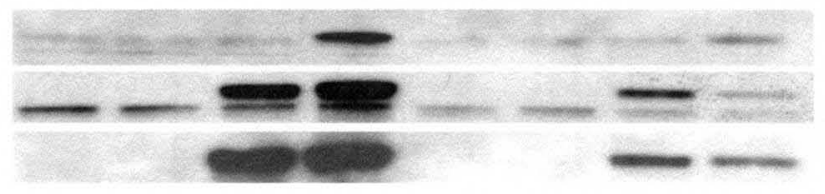

(B)

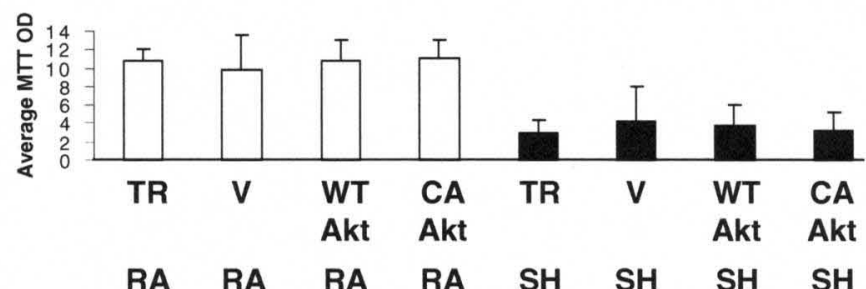

Figure 30. Transfection of PC-12 cells with c-Myc tagged wild type Akt (WT Akt) or constitutively active Akt (CA Akt)-encoding DNA plasmids did not rescue cells from 24h SH-induced cell death. Transfection conditions: TR = mock transfection with transfection reagent, $\mathrm{V}=$ transfection of empty vector plasmids, WT Akt $=$ transfection of wild type Akt plasmids, CA Akt = transfection of constitutively active Akt plasmids; Exposures: $\mathrm{RA}=24 \mathrm{~h}$ RA, $\mathrm{SH}=24 \mathrm{~h} \mathrm{SH}$. (A) Representative immunoblots of cell lysates show expression of phospho-Ser473 Akt, Akt, and c-Myc tag, demonstrating efficient transfection. (B) MTT assay measured cell viability, and the average MTT OD was calculated using data from two representative exposures. 
6h RA

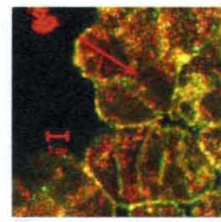

6h SH
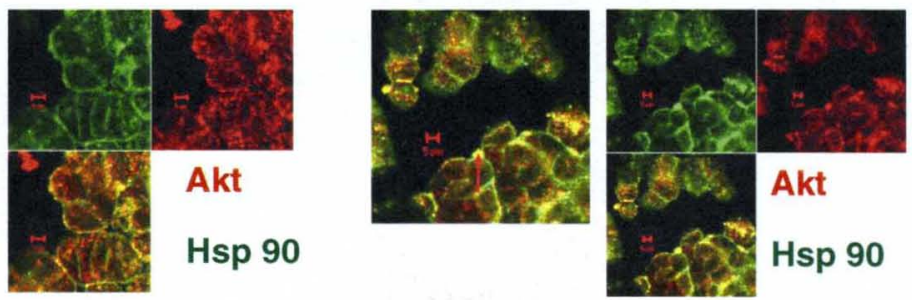

IP: IgG

RA $\overline{\text { 6RA } 6 \mathrm{SH}}$

Akt

Hsp90

Figure 31. Confocal microscopy images of PC-12 cells co-immunostained for Akt (red) and Hsp90 (green) show that 6h SH increases Akt co-localization with Hsp90 at the cell periphery, which is in agreement with Akt immunoprecipitation data. 
substrate in vitro as well as in PC-12 cells. Autoradiographs of 1-D SDS PAGE separated in vitro kinase assays showed that recombinant active human Akt autophosphorylates and phosphorylated recombinant human $\mathrm{Hsp} 90 \beta$ (Figure 32A). The Akt inhibitory peptide Aktide-2T $(200 \mu \mathrm{M})$ and not a scrambled peptide $(200 \mu \mathrm{M})$, inhibited these phosphorylations (Figure 32A). To verify that Akt phosphorylation of Hsp90 may occur in PC-12 cells, cells were transfected with empty vector, wild type Akt (WT Akt), or constitutively active myristoylated Akt (CA Akt)-encoding DNA plasmids. Cell lysates were separated by 2-D SDS PAGE and immunoblotted for Hsp90 in order to detect an Akt-dependent acidic shift in the isoelectric point of Hsp90 in CA Akt transfected cells. Overexpression of CA Akt induced an acidic shift in Hsp90 isoelectric point, suggestive of Akt-dependent phosphorylation of Hsp90 (Figure 32B).

To determine whether hypoxia induces a similar Akt-dependent phosphorylation

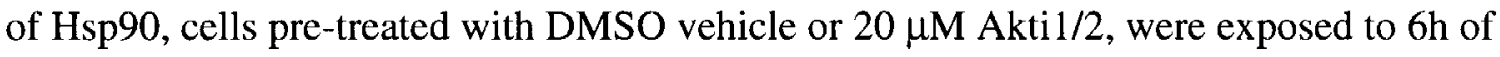
RA or SH, to induce increased Akt phosphorylation at SH. Cell lysates were separated by 2-D SDS PAGE and immunoblotted for Hsp90 and Akt. Exposure to $6 \mathrm{~h}$ SH increased Akt-dependent phosphorylation of Hsp90, Akt, and Ser473 Akt, as shown by a shift of these proteins towards more acidic isoelectric points, that was reversed by protein phosphatase 2A (PP2A) treatment or by Akti1/2 pre-treatment (Figure 33). Thus, Hsp90 is phosphorylated by Akt at $6 \mathrm{~h} \mathrm{SH}$.

\section{Akt-dependent phosphorylation regulates Hsp90 binding at hypoxia}

We next examined whether Akt-dependent phosphorylation of Hsp90 regulates protein binding to Hsp90. Hsp90 was immunoprecipitated from the lysates of cells pretreated with vehicle or $20 \mu \mathrm{M}$ Akti $1 / 2$ and exposed to $6 \mathrm{~h}$ RA or SH. Immunoblots of 
(A)

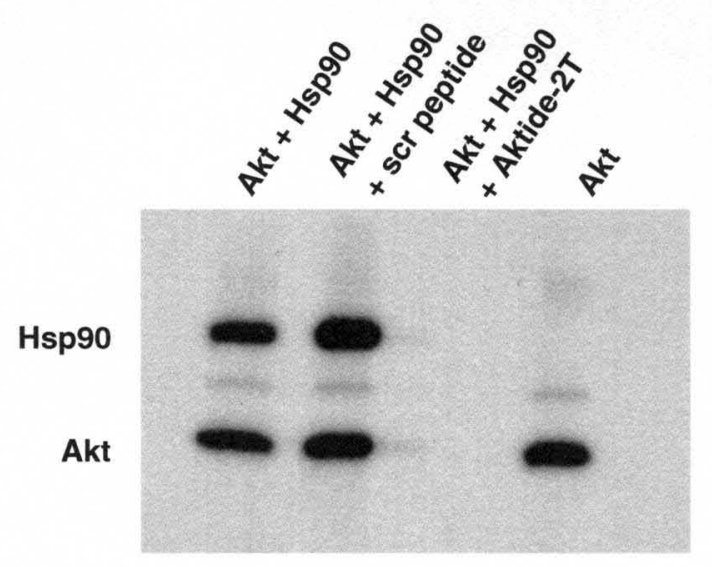

(B)

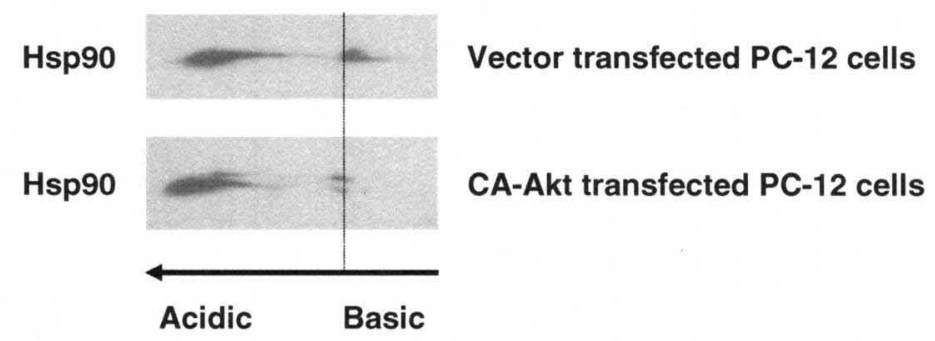

Figure 32. Hsp90 is phosphorylated by Akt in vitro and in the lysates of PC-12 cells transfected with constitutively active Akt (CA Akt)-encoding plasmids.

(A) A representative autoradiograph of an in vitro kinase assay shows in vitro Akt phosphorylation of recombinant human Hsp90 and autophosphorylation of Akt.

Phosphorylations were inhibited by the Akt phosphorylation inhibitory peptide Aktide-2T, and not by a scrambled peptide. (B) Representative Hsp90 immunoblots of 2-D SDS PAGE separated PC-12 lysates show transfection with CA Akt induced an acidic shift in the isoelectric points of Hsp90. 
(A)

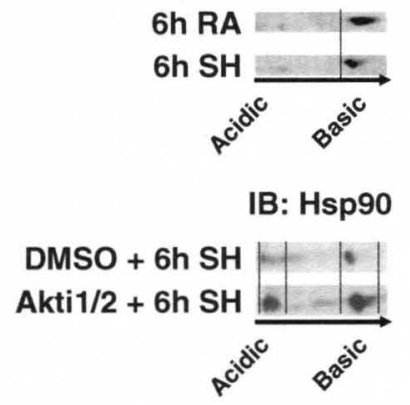

IB: Hsp90

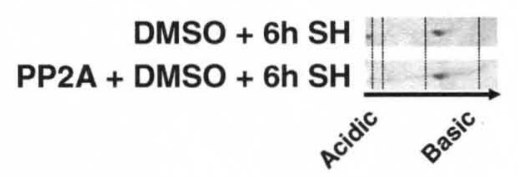

(B)

IB: P-Akt IB: Akt

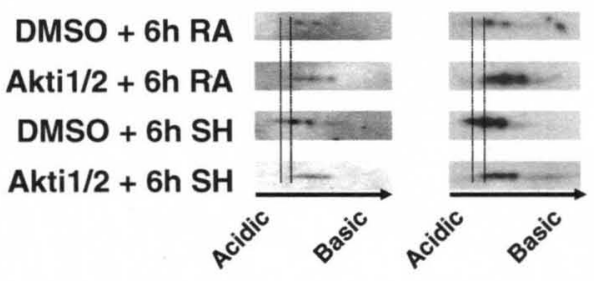

IB: Akt

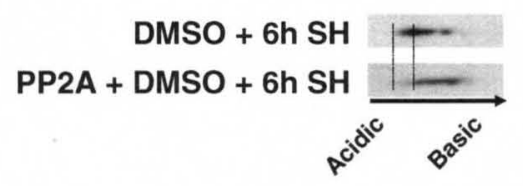

Figure 33. Representative immunoblots of 2-D SDS PAGE separated lysates show 6h SH induces acidic shifts in Hsp90, Akt, and phospho-Ser473 Akt, that are inhibited by Akti1/2 and by protein phosphatase 2A (PP2A). PC-12 cells were pre-treated with DMSO vehicle or $20 \mu \mathrm{M}$ Akti1/2 and exposed to 6 h of RA or SH. Prior to 2-D separation, lysates were treated with or without PP2A. (A) Hsp90 immunoblots. Hsp90 was identified in two overlapping dark spots (to the right of the dashed line) at the predicted isoelectric point of $\sim 5$, by MALDI-ToF mass spectrometry.

(B) Phospho-Ser473 Akt and Akt immunoblots. 
Hsp90 and Akt immunoprecipitates show that inhibition of Akt at $6 \mathrm{~h} \mathrm{SH}$ by Akti1/2 decreases Akt, Raf-1, and Cdc37 binding to Hsp90 (Figure 34). Therefore, Akt phosphorylation may promote Hsp90 binding to Cdc37, Akt, and Raf-1 at 6h SH. In contrast, decreased Akt phosphorylation at $24 \mathrm{~h}$ results in decreased $\mathrm{Cdc} 37$ binding to Hsp90 and in cell death, and minimally affected Akt and Raf-1 binding to Hsp90 compared to 24h RA levels (Figure 25).

LC-MS-MS analysis of anti-Hsp90 and isotype control immunoprecipitates from 6h RA and SH exposed PC-12 cells pre-treated with DMSO or $20 \mu \mathrm{M}$ Akti1/2 uncovered additional known and novel putative Hsp90 complex protein interactions that may be regulated by Akt phosphorylation. Equal immunoprecipitation was verified by Hsp90 immunoblotting of the immunoprecipitates prior to further analysis (data not shown). Few proteins were identified in isotype control immunoprecipitates, while Hsp90 immunoprecipitates were enriched in Hsp90. Thus, efficient immunoprecipitations were performed and peptide samples were of high quality, permitting reliable identification of proteins specifically bound to Hsp90. Putative Hsp90 complex-binding proteins were identified by searching the Mascot protein database, using various search stringency criteria, to generate a list of proteins ranked in order of greatest significant probability for true positive identification. Many of the identified Hsp90 complex proteins associated and dissociated from $\mathrm{Hsp} 90$ in response to $6 \mathrm{~h} \mathrm{SH}$, suggesting that Hsp90 protein binding was altered by SH. A total of 81 proteins were identified among the $6 \mathrm{~h} \mathrm{RA}+\mathrm{DMSO}$ and $6 \mathrm{~h} \mathrm{SH}+$ DMSO Hsp90 immunoprecipitates. $40 \%$ of these proteins were identified only in normoxic Hsp90 complexes and $44 \%$ of proteins were identified only in hypoxic Hsp90 complexes, while only $16 \%$ of proteins were bound to Hsp90 in both normoxia 


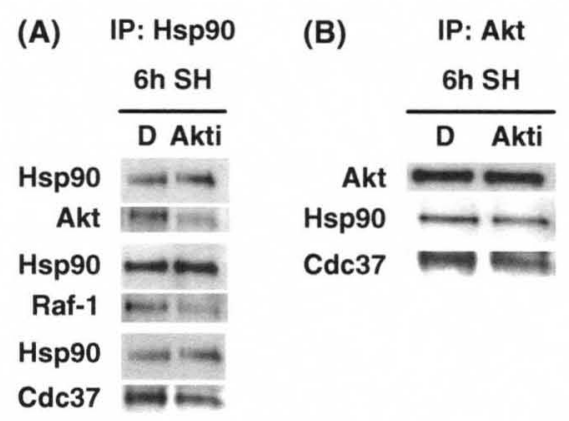

Figure 34. Representative immunoblots of Hsp90 (A) and Akt (B) immunoprecipitates show inhibition of basal Akt phosphorylation by Akti1/2 decreases binding of proteins to Hsp90 at $6 \mathrm{~h} \mathrm{SH} . \mathrm{D}=\mathrm{DMSO}$, Akti1/2 $=20 \mu \mathrm{M}$ Akti1/2 $(\mathrm{n}=3)$. 
and hypoxia (Figure 35A). Identified Hsp90-binding proteins included proteins regulating processes that are altered by SH such as transport of proteins, calcium-dependent exocytosis, and glycolysis (Figure 35). Alterations in these protein interactions with Hsp90 by SH and or by Akt activation may play a role in cellular response to hypoxia. The motor transport protein, cytosolic dynein heavy chain (Dynein) has previously been reported to interact with Hsp90 complexes [164-166] and was identified only in SH samples (Figure 35A). Thus, SH may positively regulate the Dynein-Hsp90 complex interaction. Additional proteins that may be recruited to the complex in response to $6 \mathrm{~h}$ $\mathrm{SH}$, included the voltage-dependent L-type calcium channel, Rab3 interacting molecule 1 (Rab3-IM1), and the trafficking protein Ras-related protein (Rab2), that transports proteins from the endoplasmic reticulum to the Golgi complex [167] (Figure 35A). Multiple proteins were released from $\mathrm{Hsp} 90$ complexes in response to $6 \mathrm{~h} \mathrm{SH}$, such as SNAP25-interacting protein (SNIP) and Rab3-interacting molecule 2 (Rab3-IM2), both regulators of calcium-dependent exocytosis $[168,169]$ (Figure 35A). In addition, a potassium voltage-gated channel and the glycolytic enzymes phosphofructokinases PFK1 and PFK2, known to be activated by hypoxia, were released from Hsp90 binding in response to $6 \mathrm{~h} \mathrm{SH}$ (Figure 35A).

Overall, a grand total of 90 different proteins were identified in Hsp90 immunoprecipitates from lysates obtained from our four experimental conditions. The majority ( $84 \%$ ) of these proteins may be regulated by both SH and Akt phosphorylation, suggesting that Akt phosphorylation plays a role in SH-induced alterations in Hsp90 binding (Figure 35B). Recruitment of proteins to $\mathrm{Hsp} 90$ complexes in response to $\mathrm{SH}$ was altered by Akti1/2. The aforementioned Dynein-Hsp90 complex interaction was not 


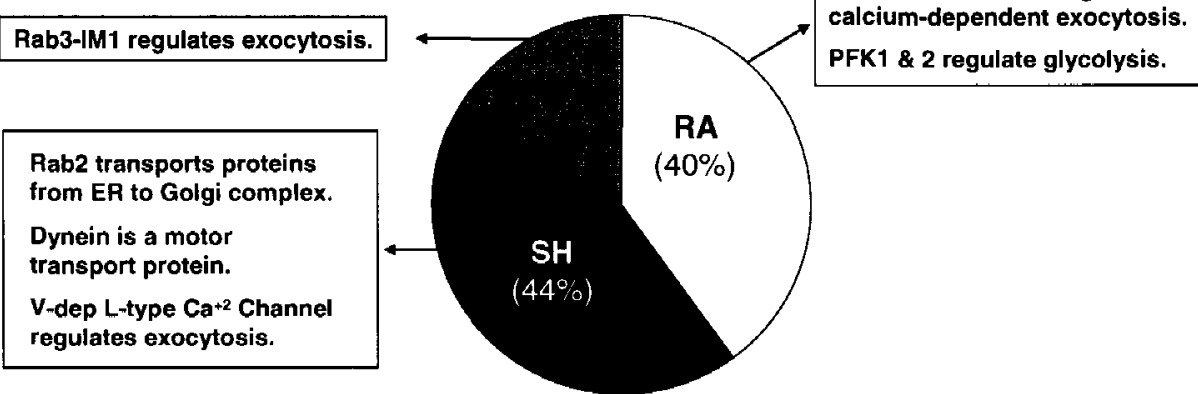

(B) Regulation of Hsp90 binding by Akt phosphorylation

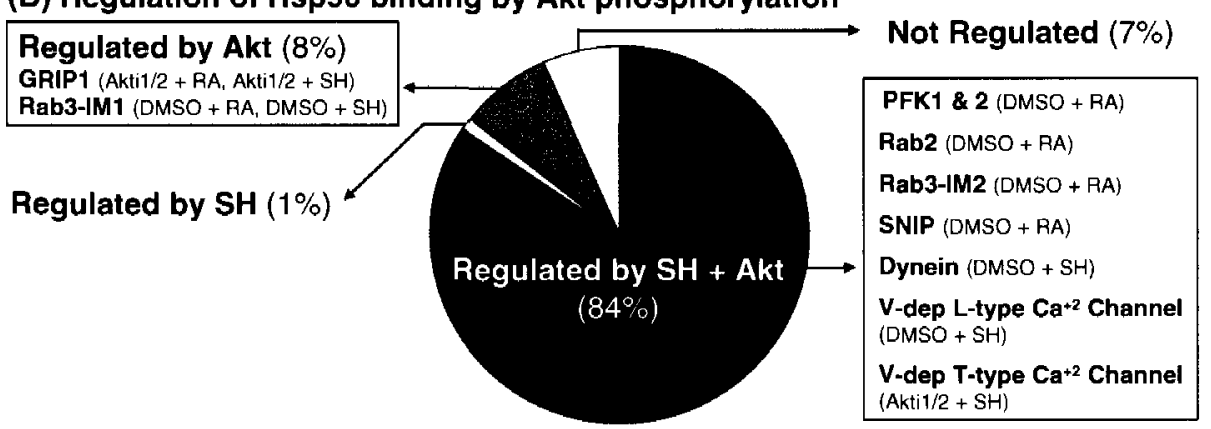

Figure 35. Binding of proteins to Hsp90 complexes at RA and at SH may be globally regulated by Akt phosphorylation. Cells were pre-treated with DMSO vehicle or $20 \mu \mathrm{M}$ Akti1/2 for 3h, and exposed to $6 \mathrm{~h}$ of RA or SH. Hsp90 was immunoprecipitated from lysates. Putative Hsp90 complex-binding proteins were identified by reverse phase 1-D LC-MS-MS analysis of Hsp90 immunoprecipitates. GRIP1 = glutamate receptor interacting protein 1; Rab2 = Ras-related protein; V-dep = voltage dependent; Rab3-IM1 \& Rab3-IM2 = Rab3 interacting molecules $1 \&$ 2; SNIP = SNAP25-interacting protein; PFK1 \& $2=$ phosphofructukinases $1 \& 2$. (A) Proteins associated and dissociated from Hsp90 in response to $6 \mathrm{~h} \mathrm{SH}$. A total of 81 proteins were identified in DMSO + RA and DMSO + SH Hsp90 immunoprecipitates. $40 \%$ of these identified proteins may bind to Hsp90 only at RA, and $44 \%$ of proteins may bind to Hsp90 only at SH. Only $16 \%$ of proteins were detected in both DMSO + RA and DMSO + SH Hsp90 complexes.

(B) Akti1/2 altered protein interactions of RA and SH Hsp90 complexes. The majority of 
identified putative Hsp90-binding proteins may be regulated by Akt and hypoxia. 
detected in the presence of Akti1/2 at $6 \mathrm{~h} \mathrm{SH}$, suggesting that this interaction requires Akt phosphorylation (Figure 35B). In addition, we identified the glutamate receptor interacting protein (GRIP1) as a protein of high stringency hit significance that associated with Hsp90 complexes only in Akti1/2-treated samples independently from hypoxia, suggesting GRIP1 binds to Hsp90 when Akt phosphorylation is decreased (Figure 35B). Immunblots for GRIP1 showed expression of GRIP1 in PC-12 cell lysates was not altered by Aktil/2 (Figure 36), and preliminary immunochemistry of Hsp90 and GRIP1 suggest co-localization of GRIP1 with Hsp90, particularly at the cell periphery (data not shown). The majority of $\mathrm{Hsp} 90$ binding proteins at RA or $\mathrm{SH}$, dissociated in response to Akti1/2, suggesting that Akt phosphorylation globally regulates the association of proteins with Hsp90 complexes, and modulates cellular responses to SH. In summary, Akt phosphorylation regulates the protein interactions of normoxic and hypoxic Hsp90 complexes, but this study cannot confirm that Akt phosphorylation regulates survival to hypoxia (Figure 37). 

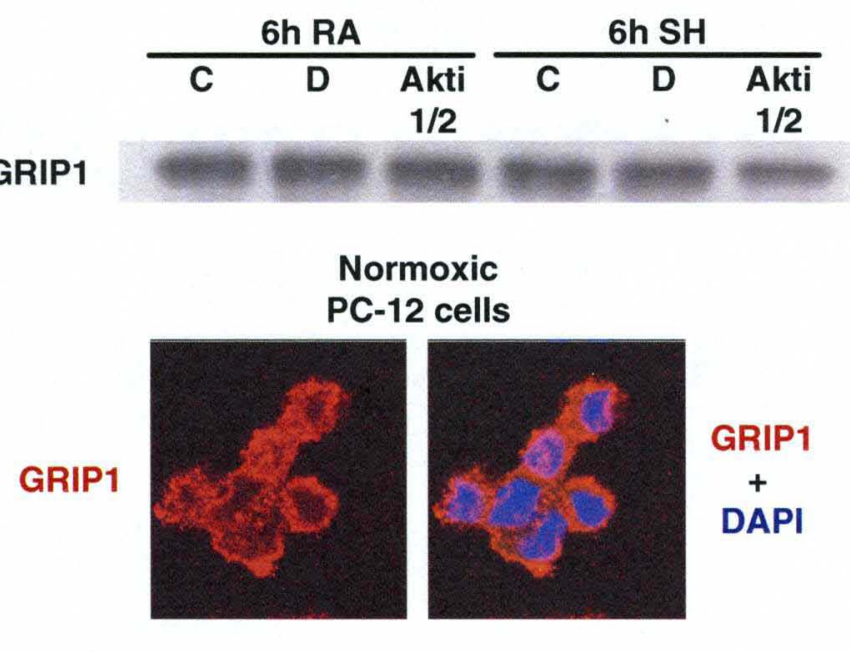

Figure 36. The putative Hsp90-binding protein GRIP1 is expressed in PC-12 cells. Representative immunoblots show that GRIP1 expression in lysates is not altered by 6h SH or by $20 \mu \mathrm{M}$ Akti1/2. Confocal microscopy images of PC-12 cells co-immunostained for GRIP1 and DAPI show GRIP1 chiefly localizes to the cell periphery, but also occurs deeper in the cell. 

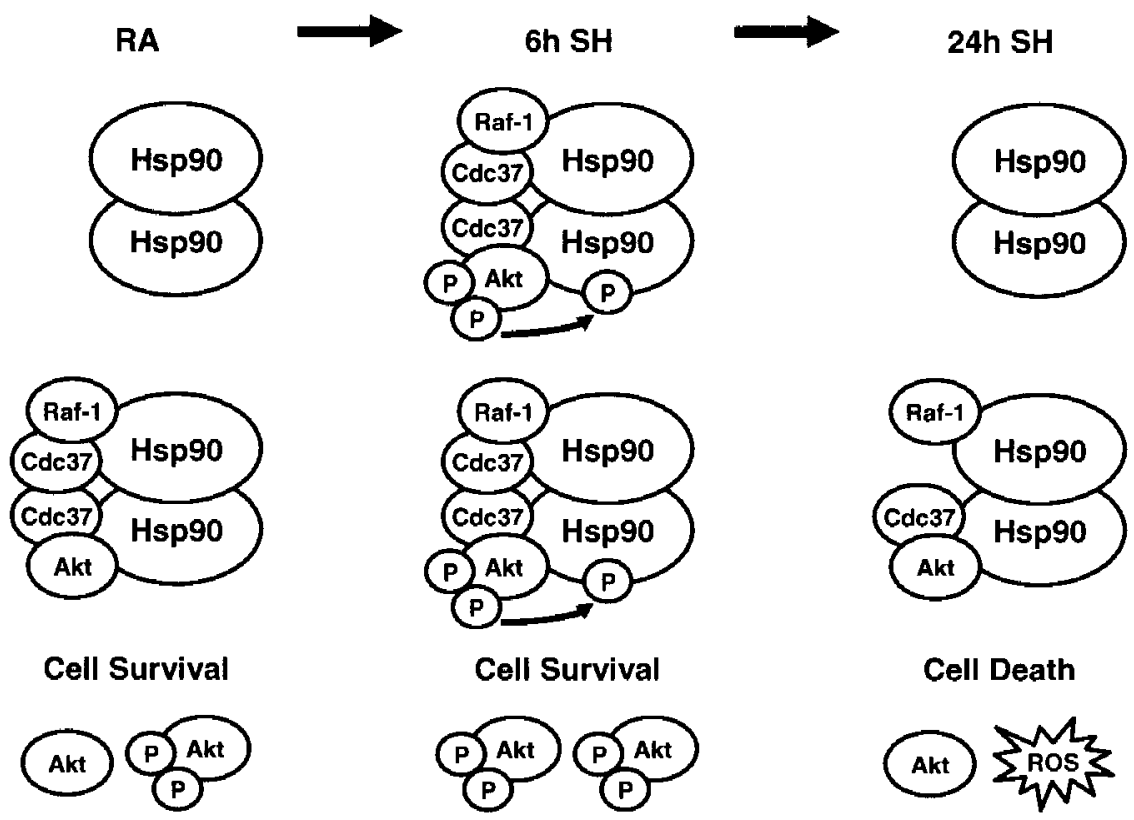

Figure 37. Akt phosphorylation of Hsp90 regulates Hsp90 binding to Akt, Raf-1, and Cdc37. Although Akt phosphorylation of Hsp90 and increased Hsp90 binding correlate with PC-12 cell survival to hypoxia at $6 \mathrm{~h}$, this study cannot confirm that Akt phosphorylation and Hsp90 binding play roles in the cellular survival responses to hypoxia. Instead, this study demonstrates that Akt phosphorylation and $\mathrm{Hsp} 90$ binding play roles in general cellular survival. 


\section{CHAPTER V: DISCUSSION}

\section{Specific Aim 1 overview}

The protein interactions of Hsp90 complexes have been implicated in cell survival. Hsp90 binding has been previously shown to be required for stability and activation of the survival kinase Akt, and disruption of Hsp90 binding to Akt induces apoptosis $[63,114]$. Additional Hsp90-binding proteins that may regulate cell survival are the kinase Raf-1 and the kinase co-chaperone Cdc37, that is critical for Hsp90 binding to kinases $[107,120,121]$. Indeed, the Raf-1-Cdc37-Hsp90 complex is essential to Raf-1 activity and stabilization [96]. This study shows that Hsp90-dependent stabilization of Akt and Raf-1 regulates survival of PC-12 cells.

\section{The mechanisms of GA cytotoxicity}

We used the classical Hsp90 inhibitor Geldanamycin to show that Hsp90 binding to Akt, Raf-1, and Cdc37 positively regulates cell survival by stabilizing Akt and Raf-1. GA induces PC-12 cell death, suggesting a role for Hsp90 interactions in survival of these cells. Our findings show that GA cytotoxicity correlates with decreased expression of Hsp90-binding proteins. Later on, at $24 \mathrm{~h} \mathrm{SH}$, a general decrease in protein expression, including proteins that do not bind to Hsp90, occurred. GA cytotoxicity has been attributed to its disruption of Hsp90 binding [77]. However, the benzoquinone moiety of GA is a source of oxidant radicals, and the role of oxidative stress in the drug's 
cytotoxicity and in distuption of Hsp90 binding has not been previously examined. Thus, using an antioxidant strategy and comparing the GA effect to that of MEN, a classical quinone that does not bind Hsp90, this study determined the role of oxidative stress in GA-induced cell death and in disruption of protein binding. Our comprehensive study of Hsp90 binding demonstrates for the first time a role for oxidative stress in these two effects of GA (Figure 26). We established that while cytotoxic, MEN-induced quinone stress alone was insufficient to dissociate the Hsp90 complex. We uncovered a dual mechanism for GA-induced cell death, that may allow improved targeting of cancer cells. GA induced early disruption of the Hsp90 complex and oxidation of proteins, followed by their degradation, resulting in cytotoxicity. These data are in agreement with a recent study by Fukuyo et. al., that showed oxidative stress induced by the GA derivative 17-demethoxygeldanamycin (17-DMAG) is required to decrease the kinase activity and expression of mutant B-Raf [86]. In addition, cells treated with the GA derivative, 17-allylamino-17-demethoxy-geldanamycin (17-AAG), have been recently shown to produce ROS [170].

\section{Developing antioxidant and GA analog therapies for the treatment of cancer}

Therefore, the cytotoxicity of GA and its derivatives can be modulated using antioxidant compounds, so that Hsp90 binding can be transiently disrupted without altering cellular redox state, allowing for the targeting of $\mathrm{Hsp} 90$ and its binding proteins in Hsp90 and kinase over-expressing cancer cells [72], while potentially minimizing toxicity to non-cancerous cells. However, this strategy needs to be modulated to fit the variability of cancer cell tolerance to oxidative stress. Indeed, some cancer cells are sensitive to oxidative stress while others, especially metastatic cancer cells, are resistant 
to oxidative stress [171]. High levels of the endogenous antioxidant peptide glutathione (GSH) and Hsp25, which positively regulates GSH levels, are associated with the resistance of cancer cells to GA cytotoxicity [172]. Additionally, GSH levels regulate cancer cell resistance to radiation therapy [171]. Although GA was initially discovered as an Hsp90-targeting drug, GA and MEN are among several anticancer drugs known to also decrease GSH $[83,84]$. Furthermore, adding the antioxidant NAC may increase cancer cell proliferation [173] and decrease GA analog toxicity in cancer cells. However, more advantageous antioxidants may instead sensitize cancer cells to hepatotoxic GA and its analogs, while exhibiting minimal toxicity in non-cancerous cells. The metalloporphyrin manganese superoxide dismutase (MnSOD) mimetic, MnTBAP, is such an alternative antioxidant [174], that induces cancer cell death by increasing $\mathrm{H}_{2} \mathrm{O}_{2}$ [173], yet inhibits cardiotoxicity induced by the anthraquinone derivative chemotherapeutic, Doxorubicin [175], and acute liver failure [176]. In addition, the antioxidant properties of MnTBAP may be chemopreventive against esophageal adenocarcinoma [177]. Alternatively, the recent development of the Hsp90-binding non-quinone analog of GA, analog 5 of macbecin, may provide cancer therapies that are less toxic to normal cells [178]. Benzoquinone ansamycin Hsp90 inhibitors may induce cancer cell death by inducing the degradation of oxidized Hsp90-binding proteins that have dissociated from Hsp90. Whether non-quinone ansamycin Hsp90 inhibitors may induce similar toxicity in cancer cells in the absence of oxidation of dissociated binding proteins remains to be investigated. However, our current study demonstrates that increased ROS production by GA is required for its cytotoxicity. 


\section{The mechanism of quinone-induced phosphorylation of kinases}

In this study, the quinones GA and MEN induced an increase in the phosphorylation of Akt and ERK1/2 prior to a decrease in total expression of these kinases. Quinones may induce kinase phosphorylation by generating reactive oxygen species (ROS), that increase epidermal growth factor receptor (EGFR) signaling [179].

Singlet oxygen $\left({ }^{1} \mathrm{O}_{2}\right)$, an electronically excited form of molecular oxygen that reacts with free radicals, may also increase signaling of receptor tyrosine kinases by inhibiting inhibitory protein tyrosine phosphatases (PTPase) by oxidizing their active cysteines [180]. ROS induced by MEN may play a similar role in activation of EGFR and ErbB2, since NAC partially inhibited their activation in the keratinocyte cell line, HaCaT [179]. Additional mechanisms also increase phosphorylation of receptor tyrosine kinases and downstream kinases. In rat liver epithelial cells, MEN induces EGFR-dependent phosphorylation of ERK by three alternative mechanisms: (i) PTPase dephosphorylation of EGFR (by alkylating the cysteine thiols of unknown PTPases) [181, 182], (ii) by depleting cellular glutathione (by alkylation), and (iii) by redox cycling (which increases glutathione disulfide (GSSG)) [183, 184]. In contrast, MEN induces phosphorylation of Akt by an EGFR-dependent pathway in some cells and by an EGFR-independent pathway in other cells [185]. However, the Akt pathway may also be activated by reactive oxygen species (ROS) in an EGFR-dependent manner [186]. In PC-12 cells, ROS-induced signaling may be the predominant mechanism of GA- and MEN-induced increases in phosphorylation of Akt and ERK, since NAC completely inhibited these inducible phosphorylations. In addition, in PC-12 cells oxidative stress plays a role in the cytotoxicities of these two quinones. The relative roles of alkylation and oxidative stress 
in MEN-induced kinase phosphorylation and cytotoxicity may depend on cell type. In rat platelets, the primary mechanism of MEN cytotoxicity is arylation rather than oxidative stress, although MEN is a redox cycler and an arylator [187].

\section{Mechanism of decreased sensitivity of Akt phosphorylation to GA at hypoxia}

Although GA initially increased phosphorylation of Akt and ERK, the expression and phosphorylation of these kinases later decreased. Interestingly, at $6 \mathrm{~h}$ of exposure, phosphorylated Akt in hypoxic lysates was more resistant to GA-induced dephosphorylation than that of normoxic lysates. The mechanism for this persistence of Akt phosphorylation in hypoxic cells has never been investigated. Perhaps in response to hypoxia, a kinase upstream of and independent of its binding to Hsp90 phosphorylated Akt, and so that Akt phosphorylation still increased in cells exposed to $6 \mathrm{~h} \mathrm{SH}$ and persists even in the presence of GA. Indeed, the activation of the upstream kinase Src by its GA-induced dissociation from Hsp90 results in activation of Akt and ERK [188]. We speculate that Src or another kinase is dissociated from Hsp90 by hypoxia, and that this dissociation enables an increase in the duration of Akt phosphorylation at 6h SH despite the presence of GA.

\section{GA-induced protein degradation is proteasome-independent in PC-12 cells}

Disrupting Hsp90 function with $\mathrm{Hsp90}$ inhibitors has been reported to induce ubiquitination and proteasomal degradation of many of Hsp90-binding oncoproteins [77]. The present study suggests that increased protein ubiquitination may also result from protein oxidation by these quinone compounds. The chaperone function of $\mathrm{Hsp90}$ protects Akt and Raf-1 from ubiquitin-dependent proteasomal degradation in the human cancer MCF-7 and mouse fibroblast NIH3T3 cell lines, respectively $[63,64]$. 
Furthermore, lysosomal, caspase, and calpain protein degradation pathways do not play a role in the degradation of Akt and Raf-1 in these two cell lines $[63,64]$. However, these studies by Basso et. al. and Schulte et. al. did not examine the effects of proteasomal inhibition on cell viability in the presence or absence of $\mathrm{Hsp} 90$ inhibition. Our results show increased protein ubiquitination in GA- and MEN-treated PC-12 cells. Proteasomal inhibition prevented protein degradation and cell death in MEN-treated cells, although MEN did not dissociate proteins from Hsp90. In contrast, GA dissociated the Hsp90 complex and proteasomal inhibition did not prevent GA-induced cytotoxicity and the degradation of some Hsp90 complex proteins. Therefore, Hsp90 binding may potentially affect protein degradation pathways. Proteins bound to Hsp90 may be targeted to proteasomal degradation, whereas proteins dissociated from $\mathrm{Hsp} 90$ may be degraded by an alternative pathway (Figure 27). Furthermore, Hsp90 inhibition by GA has been shown to induce proteasome-dependent internalization and subsequent lysosomal degradation of the receptor tyrosine kinase ErbB2, an Hsp90-binding protein localized at the plasma membrane [66].

\section{Hsp90 may regulate chaperone-mediated autophagy}

In addition, Finn $e t$. al. propose a role for $\mathrm{Hsp} 90$ in negatively regulating chaperone mediated autophagy (CMA), a selective process that targets specific cytosolic proteins for lysosomal degradation [67]. Hsp90 inhibition by GA was shown to increase CMA [67]. Recently, Hsp90 has been shown to bind IkB kinases as well as NFkBinducing kinase, regulating NFkB activation $[68,69]$. GA disrupted the binding of these kinases, resulting in their degradation by a non-proteasomal mechanism that was identified as autophagic degradation $[68,69,189]$. These data agree with our findings 
that GA- dissociated Hsp90-binding proteins are degraded via a non-proteosomal degradation pathway. However, oxidative stress may induce CMA of oxidized proteins [70], and the role of GA-induced oxidative stress in CMA was not examined in these studies. Hsp90 binding may facilitate refolding of oxidized cytosolic proteins, preventing their translocation to lysosomes that only accept unfolded proteins [67]. Regulation of CMA by Hsp90 may play a role in cellular survival. Indeed, alterations in CMA have been shown in models of normal aging and the age-related neurodegenerative diseases, Alzheimer's Disease and Parkinson's Disease [71].

\section{GA-induced protein degradation is lysosome-independent in PC-12 cells}

Our work shows that the disruption of Hsp90 binding by GA induces chiefly proteasome-independent degradation of many cytosolic Hsp90-binding proteins, while the non-specific quinone stress of MEN induces chiefly proteasomal degradation. Thus, the lysosome inhibitor Bafilomycin $\mathrm{A}_{1}$ (BAF) was used to investigate whether lysosomal degradation is the non-proteasomal mechanism responsible for GA-induced degradation of these proteins and cell death. BAF is known to inhibit lysosome acidification at $50 \mathrm{nM}$ concentration by $25 \mathrm{~min}$ in $100 \mathrm{ng} / \mathrm{mL}$ nerve growth factor (NGF)-differentiated PC-12 cells [190]. However, up to $750 \mathrm{nM}$ BAF did not alter GA-induced degradation of Akt and Raf-1, suggesting that these proteins are not degraded by the lysosomes when Hsp90 binding is disrupted.

\section{Hsp90 binds proteins of the caspase proteolytic pathway}

Future studies will determine whether Hsp90 binding protects proteins from degradation by caspases and cells from caspase-dependent cell death. Caspases are activated in models of cerebral ischemia [191], traumatic brain injury [192], and spinal 
cord injury [193], and caspase inhibitors are neuroprotective against neuronal cell death in a model of cerebral ischemia [191]. GA induces caspase-dependent apoptosis in human glioma cells, that correlates with decreased expression of phosphorylated Akt [62]. In addition, Caspase- 3 has been identified as a binding protein of Hsp90, suggesting that Hsp90 binding may regulate caspase activation [194]. Furthermore, Hsp90 binds to the caspase-processed and unprocessed forms of CDK 11 (CDKp 110 and CDK1 1p46, respectively) [108] and regulates their proteasomal degradation, suggesting that Hsp90 may function as a scaffold for caspases and their substrates, thereby allowing substrate cleavage, or that Hsp90 may prevent caspase substrate cleavage by sequestering inactive caspases. In contrast, the broad-spectrum caspase inhibitor zVAD-fmk did not alter 17-DMAG-induced degradation of mutant B-Raf [86]. Thus, Hsp90 may affect neuropathological conditions by interacting with caspase pathways and substrates. Designing drugs that target Hsp90 may lead to the development of novel therapies for these pathological conditions involving dysregulation of caspase-dependent apoptosis pathways.

\section{Hsp90 binds proteins of the calpain proteolytic pathway}

Like caspases, calpains are involved in protein degradation and in apoptosis. However, calpains are also implicated in necrotic cell death [195]. Alterations in activation of the calpain degradation pathway are associated with hypoxia-induced retinal neuropathologies [196] and neurodegenerative diseases, including Alzheimer's, Parkinson's, and Pick's diseases [197]. Recent studies have focused on the role of calpains in necrotic neuronal cell death in hypoxic, ischemic, and excitotoxic neuronal injuries [195, 197]. In PC-12 cells, calpain is activated by nerve growth factor withdrawal 
[198], and calpain inhibition is protective against cell death (induced by exogenous ATP and iron) [199]. Hsp90 has been reported to protect several kinases and enzymes from calpain-dependent degradation. Hsp90 binding to both calpain and nitric oxide synthase (NOS) protects NOS from calpain-dependent degradation in the rat brain $[200,201]$. In addition, resistance of NOS to calpain degradation correlates with high levels of Hsp90 expression in cells $[200,201]$. Consequently, Hsp90 and calpain may regulate NOSdependent production of nitric oxide and superoxide oxidant species. The current study shows that a long duration of hypoxia may disrupt Hsp90 binding to its client proteins. Therefore, during hypoxia, NOS activity may decrease due to calpain-dependent degradation of Hsp90 and NOS (in pulmonary artery endothelial cells (PAEC)) [202]. Simultaneous production of nitric oxide and superoxide results in formation of peroxynitrite and increased toxicity [203], that may prevent the protective effect of nitric oxide and underlie hypoxic cell death (in pulmonary artery endothelial cells (PAEC)) [202]. In addition, calpain increases proteasomal degradation of proteins [204]. Calpain also decreases phosphorylation of the survival kinase Akt, without altering Akt expression or Akt binding to Hsp90 [204]. In addition, the cyclin-dependent kinase $\mathrm{Cdc} 25 \mathrm{c}$, that regulates cell cycle at the $\mathrm{G}_{2} / \mathrm{M}$ checkpoint, is degraded by calpain and not by the proteasome in GA-treated glioblastoma cell lines [205]. Therefore, calpain may degrade some proteins independently of the proteasome and process other proteins for proteasomal degradation $[204,205]$. Future studies will determine whether the chaperone Hsp90 regulates survival by protecting Akt and its other binding proteins from calpaindependent proteolytic degradation. 


\section{Hsp90 may regulate oxidative stress}

In addition, we considered whether or not Hsp90 binding regulates cell survival by regulating cellular oxidative stress. Nardai $e t$. al. proposed a role for Hsp90 in regulating the redox state of cells by reducing proteins, and show that this function of Hsp90 is blocked by sulfhydryl reagents that may target the chaperone's cysteine residues [206]. Indeed, Hsp90 siRNA studies by Conconi et. al. suggest that Hsp90 may protect the trypsin-like activity of the 20S proteasome from oxidative inactivation [207]. However, Nardai et. al. did not examine whether or not this novel putative function of Hsp90 regulates cell survival. GA and MEN may act as sulfhydryl reagents by oxidizing critical cysteine residues of Hsp90, and may thereby inhibit the ability of Hsp90 to regulate cellular oxidative stress, resulting in oxidative stress-dependent cytotoxicity. However, we cannot distinguish between the effects of disruption of Hsp90 binding by GA and the non-specific effects of the quinone moiety on cellular ROS. In PC-12 cells, undisrupted $\mathrm{Hsp} 90$ binding is not sufficient to restore baseline redox state in presence of MEN. Thus, we cannot confirm that Hsp90 regulates cellular redox state.

\section{Cancer alters the Hsp90 complex}

A variety of pathological conditions may alter Hsp90 binding and the extent to which these protein interactions control cell fate. Cancer cells are more sensitive than normal cells to the cytotoxicities of Hsp90 inhibitors, and alterations in the binding of proteins, ATP, and ADP to Hsp90 may be the mechanisms for this difference between cancer and normal cells [72, 208-210]. In cells, unbound Hsp90 monomers and Hsp90 dimer complexes binding to co-chaperones and binding proteins exist in equilibrium [49]. 
In cancer cells, this equilibrium may be shifted towards the Hsp90 complexes, increasing cancer cell sensitivity to Hsp90 inhibitors that disrupt the Hsp90 complex [49].

\section{Hypoxia alters the Hsp90 complex}

Recently, Chiosis and Neckers speculated that hypoxia may also alter the binding of proteins to Hsp90 in cancer cells may be altered by hypoxia [49]. Indeed, hypoxia has been shown to regulate Hsp90 binding in non-cancerous cells. Increased binding of Hsp90 to nitric oxide synthase 3 (NOS3) may increase resistance to myocardial ischemia by increasing NOS3-dependent production of cardioprotective nitric oxide and by decreasing production of cytotoxic superoxide [37]. Furthermore, resistance to myocardial ischemia was decreased by $10 \mu \mathrm{M} \mathrm{GA}$ [37]. In addition, alterations in the Hsp90-NOS3 complex induced by $17.8 \mu \mathrm{M}$ GA increased NOS3-dependent superoxide production in bovine coronary endothelial cells (BCEC) [211]. Thus, it is worthwhile to further explore the effects of hypoxia on Hsp90 binding in cancer cells, as hypoxia may influence cancer cell survival by regulating the Hsp90 complex.

Our hypoxia study showed that SH induces an increase in Hsp90 binding to Akt, Raf-1, and Cdc37. In contrast, Hsp90 binding to Akt and Raf-1 returned to baseline while Cdc37 binding to Hsp90 is decreased at $24 \mathrm{~h} \mathrm{SH}$, relative to RA, concomitant with hypoxic cell death. Thus, early and late stages of SH alter the extent to which these proteins bind to Hsp90. These differences may reflect a difference between the response of the Hsp90 complex to a short hypoxic stress and the response to a more sustained hypoxic stress. Furthermore, increased Hsp90 binding correlates temporally with cellular survival to hypoxia, although this study cannot confirm a role for Hsp90 in the survival response to hypoxia. 
In addition, putative Hsp90-binding proteins identified by LC-MS-MS in hypoxic Hsp90 complexes and proteins related to these proteins are known to play roles in cellular processes that are altered by hypoxia. Hypoxia alters transport of proteins, endocytosis, exocytosis, and metabolism, and also plays a key role in tumor cell survival, invasion, and metastasis. Proteins involved in these cellular functions were identified in Hsp90 immunoprecipitates, suggesting that the chaperone Hsp90 may regulate several of these functions. The Hsp90 complex may function as a scaffold protein by allowing several proteins from the same pathway to interact with one another while they are bound to Hsp90. Indeed, Hsp90 has been shown to function as a scaffold protein for signaling pathways that interact with Akt and are altered by hypoxia [139, 212].

We identified the motor transporter Dynein as an Hsp90 complex protein only in hypoxic cell lysates (Figure 35A). In response to $6 \mathrm{~h} \mathrm{SH}$, the association of the Hsp90 complex with Dynein may increase, allowing for translocation of Hsp90-binding proteins to the nucleus. Indeed, Hsp90 is known to translocate binding proteins towards the nucleus by interacting with Dynein complexes. The Dynein-Hsp90 complex interaction is known to mediate the nuclear translocations of glucocorticoid receptor and the tumor suppressor p53, a hypoxia-regulated pro-apoptotic Hsp90-binding protein (Figure 38) [164-166]. Additionally, in pulmonary artery endothelial cells, hypoxia causes Dyneindependent mitochondrial translocation to the perinuclear domain that serves to create a nuclear oxidant stress important for hypoxic signaling [213]. Interruption of the Dyneindependent molecular motor using a specific siRNA prevented both the perinuclear mitochondrial clustering and, importantly, the hypoxia-induced nuclear oxidant stress [213]. Therefore, disruption of Hsp90-Dynein interaction using Hsp90 inhibitors may 


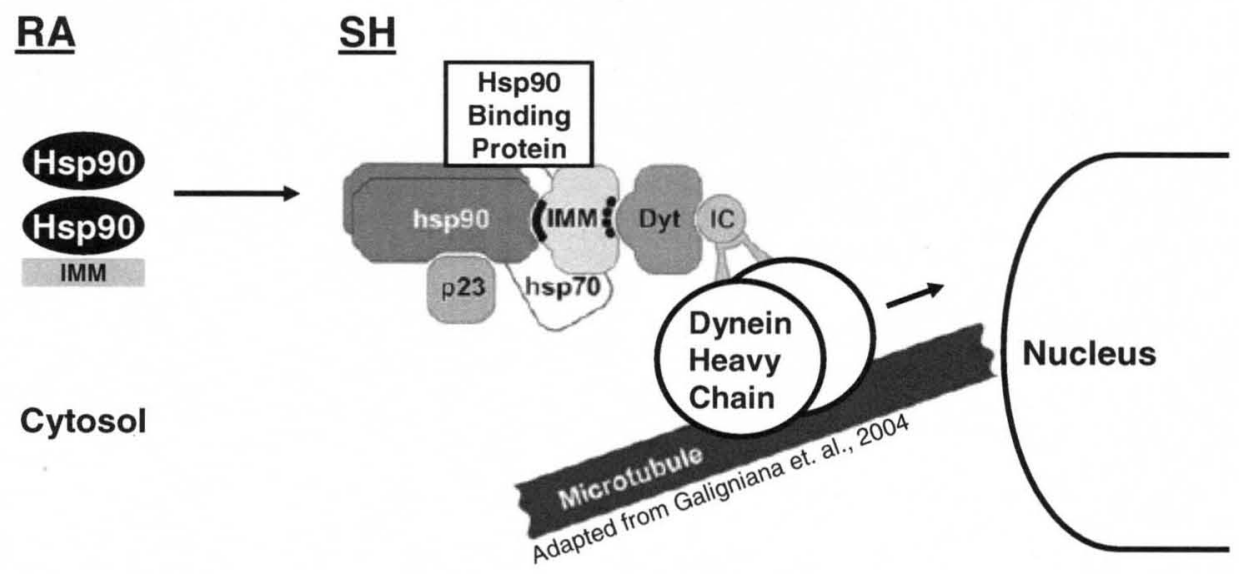

Figure 38. Cytoplasmic dynein heavy chain, identified as a putative Hsp90-binding protein only in lysates from $6 \mathrm{~h} \mathrm{SH}+$ DMSO cells, may assist Hsp90 in hypoxia-induced Akt-dependent translocation of its binding proteins to the nucleus. 
relieve the cells from hypoxia-induced nuclear oxidant stress, provided that Hsp90 inhibitor-related oxidant stress is minimal.

In addition, we showed that the Rab pathway trafficking proteins, Rab3-IM1 and Rab2, may be recruited to the Hsp90 complex in response to $6 \mathrm{~h}$ SH. The trafficking protein Rab2 transports proteins from the endoplasmic reticulum to the Golgi complex (Figure 35A) [167]. Yoon et. al. identified a related Rab vesicle trafficking protein, Rab11, as a novel target of hypoxic stimulation in breast carcinoma cells, that is important for tumor invasion, but not for regulation of apoptosis [214]. Rab11 plays a role in membrane protein recycling and in the exocytosis and translocation of proteins from the trans-Golgi network to the plasma membrane [214, 215]. Thus, Rab3-IM1 and Rab2 may also play a role in hypoxia-induced cancer cell invasion, but not in cellular survival to hypoxia. In summary, some of the Hsp90-binding proteins identified may play roles in survival, while others may play roles in cellular processes unrelated to survival that are altered by hypoxia. Ongoing proteomics studies will determine which of the novel putative Hsp90-binding proteins regulate survival.

In addition to identifying trafficking proteins, we identified putative Hsp90binding proteins involved in endocytosis. Endocytosis pathway proteins recruited to the complex in response to $6 \mathrm{~h} \mathrm{SH}$ include the voltage-dependent L-type calcium channel, which regulates calcium-dependent endocytosis pathway. Identified proteins that may be released from Hsp90 complexes in response to $6 \mathrm{~h} \mathrm{SH}$, such as SNAP25-interacting protein (SNIP) and Rab3-IM2, also regulate calcium-dependent exocytosis (Figure 35A) $[168,190]$. 
Furthermore, our data suggests that a potassium voltage-gated channel may be released from Hsp90 complexes in response to $6 \mathrm{~h} \mathrm{SH}$. Previously, hypoxia has been shown to alter potassium channel pathways [216-218], and potassium channels are involved in oxygen sensing and in regulation of apoptosis [219]. Interestingly, exocytosis of potassium voltage-gated channels to the plasma membrane is known to be regulated by Rab1 1, a relative of the putative Hsp90-binding Rab proteins that we identified (Figure 35) [215]. These potassium channels may also be regulated by the idenfied calcium channels that is involved in endocytosis. Indeed, some potassium channels depend on calcium channels for activation $[218,220]$. In addition, Dynein binding has been shown to downregulate potassium channel expression at the plasma membrane following channel internalization [221].

Hypoxia initially increases the rate of anaerobic glycolysis until ATP is depleted, resulting in decreased glycolysis and hypoxic cell death [222-225]. In hypoxic cardiac cells, the short-term increases in glycolysis are protective, but may be detrimental in the long term [226]. In addition, increased rates of glycolysis in cancer cells are responsible for promoting survival of tumor cells and for poor prognosis for cancer patients [227]. We identified the glycolysis enzymes phosphofructokinases PFK1 and PFK2 as putative Hsp90-binding proteins that may be released from Hsp90 complexes in response to $6 \mathrm{~h}$ SH (Figure 35A). PFK2 positively regulates PFK1 and glycolysis by synthesizing the allosteric positive regulator of PFK1, fructose-2,6-bisphosphate (Fru-2,6-P2). Thus, Hsp90 may function as a scaffold protein for PFK1 and PFK2 at normoxia, thereby enhancing the activation of PFK1 by the product of PFK2. However, glycolysis is slower at normoxia than at hypoxia. Alternatively, rather than act as a scaffold, Hsp90 may 
instead sequester these enzymes at normoxia, reducing their activity. Dissociation of PFK1 and PFK2 from Hsp90 in hypoxia may activate PFK1 and increase the rate of glycolysis, until the ATP that is needed for glycolysis is depleted. Cancer cells are known to have higher glycolitic rates and enhanced Hsp90 expression.

\section{Specific Aim 2 overview}

Our findings show that $6 \mathrm{~h} \mathrm{SH}$ induces Akt activation and Akt-dependent Hsp90 phosphorylation in PC-12 cells, coinciding with enhanced Akt, Raf-1, and Cdc37 binding to Hsp90. While increased Akt stimulation at $6 \mathrm{~h} \mathrm{SH}$ was not critical for cellular survival, it contributed to enhance Akt, Rafl and Cdc37 binding to Hsp90. This increase in Akt phosphorylation and in Hsp90 binding correlated temporally with survival to hypoxia. However, we were unable to confirm that Akt phosphorylation and Hsp90 binding regulate survival to hypoxia. Thus, our study concludes that Akt phosphorylation and Hsp90 binding plays a role in general survival rather than in the survival responses to hypoxia. Inhibiting baseline Akt phosphorylation resulted in protein dissociation from the hypoxic complex, and in death in normoxic and hypoxic cells. In contrast, Hsp90 binding to Akt and Raf-1 returned to baseline while Cdc37 binding to Hsp90 was decreased at 24h SH, compared to RA, concomitant with a decrease in Akt phosphorylation and cell survival. Cell transfection, to express constitutively active Akt to sustain Akt activation, was not sufficient to prevent cell death at $24 \mathrm{~h} \mathrm{SH}$, suggesting that by this time point hypoxic damage is irreversible.

\section{Akt regulates cellular functions}

Akt may regulate a broad spectrum of cellular functions that may influence survival, including glucose metabolism, gene transcription, cell proliferation, and 
apoptosis $[228,229]$. Akt regulates cellular survival of normoxic and hypoxic cells [9, 230-234]. In addition, Akt activation promotes survival during cerebral ischemia [235, 236] and ischemia/reperfusion [237-239], and protects cells from hypoxia/reoxygenation (H/R)-induced oxidative stress and apoptosis [240]. Pro-survival effects of Akt have been attributed to its regulation of and phosphorylation of the pro-apoptotic proteins Bad [240], caspases [107], and forkhead family transcription factions [241]. Furthermore, Akt prevents apoptosis by phosphorylating telomerase reverse transcriptase (TERT), an enzyme of telomerase that is critical to the synthesis and maintenance of telomere length [242]. Akt phosphorylation and TERT binding to Akt and Hsp90 is required for TERT to maintain its activity [242]. In addition, Akt may regulate the hypoxia-inducible survival pathways of vascular endothelial growth factor (VEGF) [243] and of hypoxia-inducible factor $1 \alpha(\mathrm{Hif}-1 \alpha)$ [244]. In agreement with another study [140], we found that Akt phosphorylates Hsp90. Thus, we examined whether phosphorylation of Hsp90 by Akt regulates Hsp90 binding to proteins that may affect cellular responses to hypoxia and cellular survival.

\section{The role of Akt phosphorylation in PC-12 cellular survival}

In PC-12 cells, mild sustained hypoxia $\left(5 \% \mathrm{O}_{2}\right)$ has been shown to induce phosphorylation and activation of Akt by $6 \mathrm{~h}$, that persists up to $24 \mathrm{~h}[6,245]$. In the present study, PC-12 cells were exposed to severe sustained hypoxia $\left(0.1 \% \mathrm{O}_{2}\right)$, that similarly increased Akt phosphorylation by $6 \mathrm{~h}$, but decreased Akt phosphorylation and caused hypoxic cell death by $24 \mathrm{~h}$. Thus, Akt phosphorylation temporally correlates with PC-12 cell survival to hypoxia, and the findings of our study and those of BeitnerJohnson et. al. demonstrate that the severity and duration of hypoxia differentially affect 
hypoxia-induced Akt activation [245]. In addition, activation of the phosphatidylinositol 3-kinase (PI3K)/Akt pathway has previously been shown to correlate with hypoxiainduced protection of PC-12 cells from apoptosis induced by serum withdrawal and by chemotherapy [8].Using two different doses $(1 \mu \mathrm{M}$ and $20 \mu \mathrm{M})$ of the Akt inhibitor, Aktil/2 [246], we uncovered that Akt activation regulates Hsp90 chaperone function, modulating cellular responses to $\mathrm{SH}$. Aktil/2 interacts with the pleckstrin homology domain of Akt, thereby preventing Akt translocation to the plasma membrane and its phosphorylation, without affecting its expression [246] (Calbiochem). At the doses used in our study (below $50 \mu \mathrm{M}$ ), Akti1/2 specifically targeted Akt and did not inhibit closely related AGC family kinases, PKA, PKC, and SGK $[111,247]$. The lower dose of Akti1/2 inhibited only the SH-induced increase in Akt phosphorylation, while the high dose of Akti 1/2 also inhibited basal Akt phosphorylation and affected Hsp90 protein binding, differentiating between the effect of $\mathrm{SH}$-induced and basal Akt activation. In addition, this study uniquely demonstrates that, while Akt activity is required for survival, $\mathrm{SH}-$ induced Akt activation is not critical to survival, although it may affect cellular adaptive responses to hypoxia.

DeFeo-Jones et. al. demonstrated a role for Akt in survival of normoxic prostate cancer cells using a comparable Aktil/2 dose $(5 \mu \mathrm{M})$, that sensitized tumor and not normal prostate cells to therapy-induced apoptosis [111]. Thus, Akt particularly affects tumor cells survival. In addition, Akti1/2 has been used to show that Akt phosphorylation induced by the peptide $\mathrm{Gly}^{14}$-Humanin protects against hypoxia/ischemia reperfusion injury in a mouse model of middle cerebral artery occlusion [248]. This Akti1/2 study in PC-12 cells demonstrates that basal Akt phosphorylation and not hypoxia-induced Akt 
phosphorylation is critical to survival. Many studies indicate that Akt signaling induced by a short hypoxic challenge protects cells during exposures to subsequent stressors, including reoxygenation, chemotherapy, and serum withdrawal. However, these studies did not examine cell survival during sustained hypoxia. While cell resistance to a variety of stressors may indeed dependent on prior hypoxia-induced Akt phosphorylation, cell survival during sustained hypoxia may instead require basal Akt phosphorylation, and Akt phosphorylation above baseline levels may not be critical.

\section{Sustained Akt activation is not sufficient to protect against hypoxic cell death}

In order to determine if increasing Akt phosphorylation may rescue cells from hypoxic cell death, we transfected PC-12 cells with wild type and constitutively active Akt-encoding plasmids and then exposed cells to $24 \mathrm{~h} \mathrm{SH}$. Previously, transfection of a variety of cells with constitutively active Akt was shown to protect cells from apoptosis induced by a variety of stimuli [235], and transfection of dominant negative and inactive Akt constructs inhibited growth factor-mediated cell survival $[249,250]$. However, our Akt transfection studies suggest that Akt activation is unable to rescue PC-12 cells from 24h SH. In hypoxia-sensitive cells, hypoxia irreversibly arrests mRNA translation [30, $251,252]$, an effect that may have influenced our transfections. This decreased rate of translation in hypoxic cells, may explain the lower expression levels in Akt-transfected hypoxic cells, compared to their normoxic counterparts. The lower expression of exogenous Akt was not sufficient to decrease hypoxic cell death that correlated with increased production of ROS (Figure 30 and data not shown). Therefore, greater expression of exogenous Akt and additional factors may be needed in order for cells to become resistant to hypoxia-induced cell death (204). Additional factors that regulate cell 
survival may include cellular antioxidant enzymes and other kinase pathways. Indeed, transgenic and knockout studies in mice show that the major cellular antioxidants, superoxide dismutase (SOD) and glutathione peroxidase (GPX), may protect neurons in ischemic brain injury $[235,253-255]$. By $24 \mathrm{~h}$, hypoxic cell death may occur due to a combination of energy depletion (less ATP), translation arrest, and an inability of irreversibly damaged oxidized antioxidant proteins to reduce ROS that damage proteins, DNA, and lipids.

\section{Hsp90 binds to phosphorylated and unphosphorylated Akt}

Akt binding to the Hsp90 complex is required for the stability and activation of Akt $[63,114,115,256]$. Unphosphorylated Akt may be phosphorylated by upstream kinase PDK1 [63] while bound to Hsp90, and phosphorylated Akt may evade dephosphorylation by phosphatase 2A [114] while bound to Hsp90. Indeed, ex vivo immunoprecipitation studies by Sato et. al. show kinase dead, wild type, and constitutively active Akt bind to Hsp90, demonstrating that Akt activity and phosphorylation are not required for Akt binding to Hsp90 [114]. Although GA induces a decrease in phosphorylation of Akt, few immunoprecipitation studies have determined which phosphorylation forms of Akt bind to Hsp90 in the presence of GA. Sato et. al. briefly mention that GA did not disrupt Akt binding to Hsp90 in their study [114], suggesting that unphosphorylated Akt can bind to Hsp90 even in the presence of GA. In addition, active phosphorylated Akt binds to immunoprecipitated $\mathrm{Cdc} 37$ in the presence of 17-AAG, which did not alter Akt binding to Cdc37, suggesting that phosphorylated Akt may also bind to Hsp90 in the presence of GA and its analogs [63]. Thus, the binding of GA and its analogs to Hsp90 may induce alterations in the conformation of the Akt- 
Hsp90 complex, that do not disrupt Akt binding to Hsp90, but do nonetheless decrease Akt phosphorylation and increase proteasomal degradation of Akt [63]. Perhaps, GAbound Hsp90 may shuttle phosphorylated and unphosphorylated Akt to the proteasome, where Akt is degraded.

Overexpression of Cdc37 increases Akt binding to Hsp90 [63], while siRNA silencing of Cdc37 disrupts Hsp90 binding and decreases phosphorylation of Akt [257]. In addition, $\mathrm{Cdc} 37$ immunoprecipitation studies by Basso et. al. show phosphorylated Akt also binds to $\mathrm{Cdc} 37$ [63]. Furthermore, Akt binding to immunoprecipitated $\mathrm{Cdc} 37$ was not altered by stimuli that increased (EGF; epidermal growth factor) and decreased (EGF depletion) Akt activity, and Cdc37 binding to Akt did not alter Akt activity [63]. However, this study by Basso et. al. did not immunoprecipitate $\mathrm{Hsp} 90$ in order to examine the effects of increased and decreased Akt phosphorylation on total binding of Cdc37 and Akt to Hsp90. Instead Akt binding to total Cdc37, some of which may not have been bound to Hsp90, was investigated. Therefore, in our study, Hsp90 was immunoprecipitated to examine whether Akt phosphorylation of Hsp90 alters total Hsp90 binding.

\section{Akt phosphorylates Hsp90}

Previously, Hsp90 was shown to be a substrate of Akt in mesangial cells [140], and the current study demonstrates that Hsp90 is indeed phosphorylated by Akt in vitro and in PC-12 cell lysates from normoxic and hypoxia cells. Sustained hypoxia increases Akt and Hsp90 phosphorylation that can be reversed by Akt $1 / 2$ or PP2A treatments, implicating Akt in these phosphorylations. Hsp90 is also phosphorylated by other kinases [143] (PKA, CKII, kinase FA/GSK-3 alpha, AK), can autophosphorylate, and having 
ATPase activity, may phosphorylate some of its substrates (histones and casein) [149]. Such phosphorylations and dephosphorylations of Hsp90 may regulate cellular responses to cytotoxic stimuli. For example, tyrosine kinase-dependent decreased phosphorylation of Hsp90 at residues Ser226 and Ser255 may inhibit apoptosome formation and caspase-9 activation, and thereby contribute to the resistance of leukemic cells to Imatinib (Gleevec) chemotherapy [258].

\section{Akt phosphorylation regulates normoxic and hypoxic Hsp90 complexes}

Since hypoxia alters Akt phosphorylation and Hsp90 binding, we examined whether Akt phosphorylation regulates the Hsp90 complex. Akt phosphorylation may play a role in hypoxia-induced alterations in Hsp90 binding, as the majority of identified Hsp90 binding proteins may be regulated by both hypoxia and Akt phosphorylation (Figures 35 and 38). Hsp90 binding proteins at RA or SH, mostly dissociated in response to Akti1/2, suggesting that Akt phosphorylation globally regulates the association of proteins with Hsp90 complexes, and modulates cellular responses to hypoxia. Recruitment of proteins to Hsp90 complexes in response to hypoxia was altered by Akti1/2. The aforementioned Dynein-Hsp90 complex interaction was not detected in the presence of Akti1/2 at $6 \mathrm{~h} \mathrm{SH}$, suggesting this interaction requires Akt phosphorylation (Figure 35B). Disruption of Hsp90 binding by Akti 1/2 correlated with cell death, showing the importance of Akt phosphorylation to the Hsp90 complex and to cell survival. Akt-dependent regulation of GRIP1 binding to Hsp90 without altering its total expression suggest that Hsp90 binding may alter the subcellular localization of GRIP1. GRIP1 is implicated in ionotrophic glutamate receptor subunit 2 (GluR2) and GluR2lacking AMPA receptors transport to the plasma membrane and may critically affect 
hypoxia-induced excitotoxicity [259-266]. Thus, regulation of Hsp90-GRIP1 binding may provide an additional therapeutic target in neurological diseases or traumatic CNS disorders that involve excitotoxicity. The GRIP1 binding protein Epherin B Receptor (EphBR) was also identified in an Hsp90 immunoprecipitate and not in the isotype control immunoprecipitate, suggesting that the GRIP1 expressed in our cells may indeed bind Hsp90 rather than be a false positive hit [267]. Furthermore, identification of additional GRIP1 binding proteins were identified, including EphB6R-binding Afadin (AF-6) and the kinesin-binding GABA receptor interacting fragment 1 (GRIF1) strongly suggest a role for Hsp90 in protein shuttling (Figure 39) [268-270]. However, while this may be due to the lack of a suitable antibody for immunoprecipitation, immunoblots of Hsp90 immunoprecipitates and GRIP1 immunoprecipitates failed to confirm GRIP1 binding to Hsp90 complexes. In addition, the GRIP1 binding protein GRASP1 was identified in the isotype control immunoprecipitate [271]. However, GRIP1 may nonetheless interact with Hsp90, and this putative interaction may be regulated by Akt. Indeed, Scansite revealed five putative Akt phosphorylation sites on rat GRIP1 isoform c4 - 7 [162, 163]. In summary, Akt phosphorylation regulates cellular responses to hypoxia by regulating the protein interactions of the Hsp90 complex, although this study cannot confirm that Akt phosphorylation plays a role in cellular survival to hypoxia.

\section{Conclusion}

In conclusion, our study demonstrates that Hsp90 complexes regulate the survival of PC-12 cells by binding to Akt and Raf-1. However, this study did not allow us to dissociate entirely between the two main effects of GA, dissociation of the Hsp90 complex and quinone stress. In PC-12 cells, Hsp90 binding is insufficient to protect from 


\section{GRIP1 binding proteins may bind Hsp90 complexes}

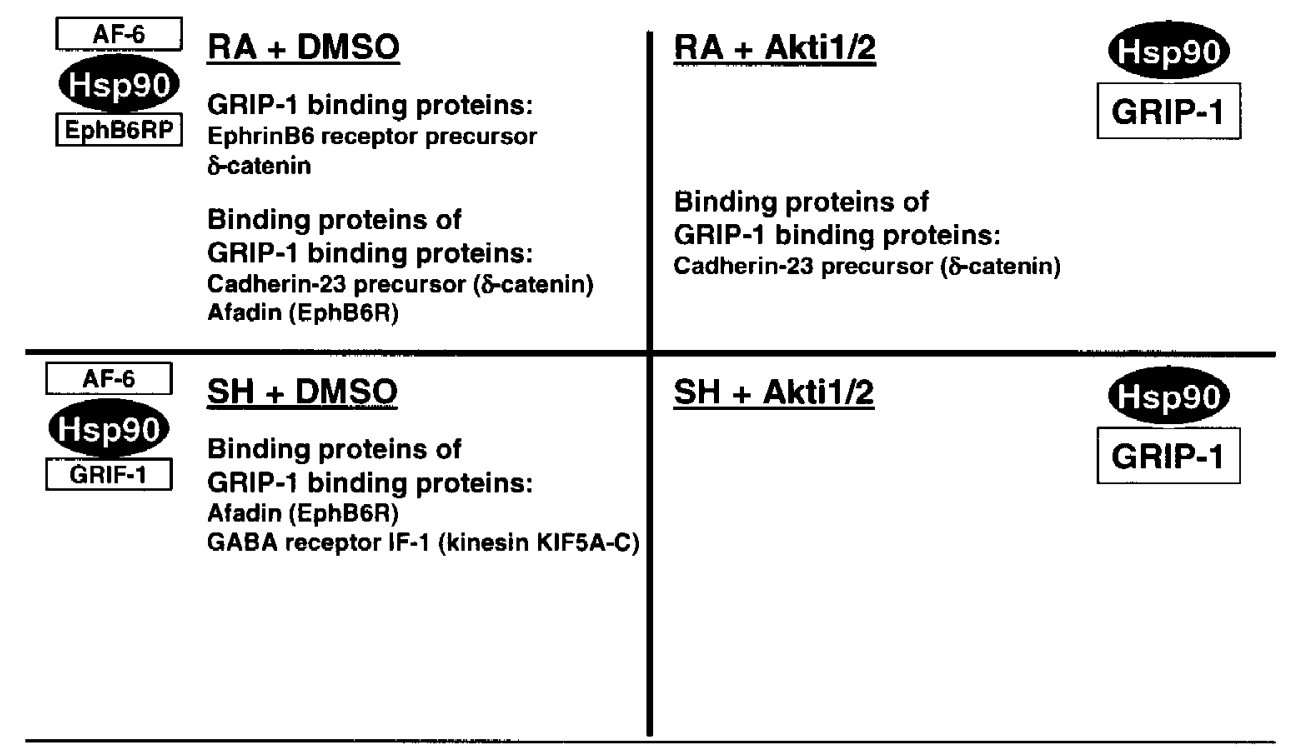

Figure 39. GRIP1 binding proteins and their other binding proteins were identified by LC-MS-MS in Hsp90 immunoprecipitates. The binding of Hsp90 complexes to these proteins may be regulated by hypoxia and or by Akt phosphorylation. 
severe oxidative stress such as MEN-induced injury. However, Hsp90 binding may protect against physiological oxidative stress.

In response to $\mathrm{SH}, \mathrm{Akt}$ is phosphorylated and phosphorylates Hsp90. Although Akt phosphorylation of Hsp90 and Hsp90 binding concomitantly increase by $6 \mathrm{~h} \mathrm{SH}$ and correlate with cellular survival, this study cannot confirm that Akt and Hsp90 play a role in the survival response to hypoxia. Instead, this study shows that Hsp90 binding and basal phosphorylation of Akt play general roles in cellular survival.

Our findings suggest that GA may target normoxic and hypoxic cancer cells that express higher levels of Hsp90 and Hsp90-binding proteins. A deeper understanding of the chaperone functions of Hsp90 and of the mechanisms of cytotoxicity of the benzoquinone ansamycin Hsp90 inhibitors may lead to the development of novel therapies for the treatment of cancers and neurological disorders. 


\section{CHAPTER VI: FUTURE STUDIES}

\section{Overview}

Although many studies demonstrate that the chaperone Hsp90 prevents the proteasomal degradation of its binding proteins $[63,64,77,88]$, results from Specific Aim 1 show that disrupting Hsp90 binding with GA targets Hsp90-binding proteins to non-proteosomal and non-lysosomal degradation. Hsp90 has been shown to interact with proteins of the calpain and caspase protein degradation pathways, and so future studies will focus on identifying the mechanism of GA-induced degradation of Hsp90-binding proteins and on the role of Hsp90 in preventing binding protein degradation by these alternative pathways [194, 200].

\section{Specific Aim 1}

Methods from Specific Aim 1 as well as inhibitors of these alternative protein degradation pathways will be used to examine Hsp90 regulation of calpain-dependent and caspase-dependent protein degradation pathways. The effects of the Hsp90 inhibitor GA on the activity of calpain [272] will be measured by a fluorescent calpain assay that detects substrate degradation (uc-Leu-Leu-Val-Tyr-AMC is a substrate; Calbiochem) [272]. In addition, caspase activation may be assessed by immunoblotting lysates for procaspases and intermediate caspases, using specific antibodies that have detected GAinduced caspase activity in other cell lines [273]. Following detection of protease activities in PC-12 cells, pharmacological studies using specific inhibitors and activators of calpain and caspases will determine the role of these proteases in the GA-induced 
degradation of dissociated Hsp90-binding proteins. Calpain may be activated by treating cells with calcium and may be inhibited by calpeptin, PD150606, and EST, inhibitors used previously to study Hsp90 function [205] (Calbiochem). In addition, the caspase inhibitor Z-VAD-FMK [205] (Calbiochem) may be used to evaluate the role of caspases in GA-induced protein degradation. The effects of these protease activators and inhibitors on the GA-induced degradation of Hsp90-binding proteins will be determineed by immunoblotting for Hsp90 complex proteins.

\section{Specific Aim 2}

Specific Aim 2 of this study showed that basal Akt phosphorylation positively regulates survival by modulating the protein interactions of the Hsp90 complex. Future studies will determine whether this Akt phosphorylation regulates cell survival by altering Hsp90-dependent shuttling of Hsp90-binding proteins to subcellular sites of degradation.

\section{Future methods}

In order to study Hsp90 shuttling of its binding proteins, methods from Specific

Aims 1 and 2 will be used in combination with co-immunostaining, confocal microscopy, and subcellular fractionation (Figure 40). The effects of $6 \mathrm{~h} \mathrm{SH}$ on co-localization of Hsp90-binding proteins with Hsp90, in the presence and absence of NAC and GA will first be examined to determine whether GA alters localization of binding proteins during RA and SH (Figure 40). After using GA to confirm that Hsp90 function modulates binding protein subcellular localization, the role of Akt phosphorylation of Hsp90 in Hsp90-dependent shuttling will be studied using the Akt phosphorylation inhibitor, Akti1/2. Use of specific antibody and dye markers for plasma membrane, cytosol, 
Effect of Hsp90 inhibition on $6 \mathrm{~h}$ hypoxia-induced Hsp90-mediated translocation of Hsp90-binding proteins

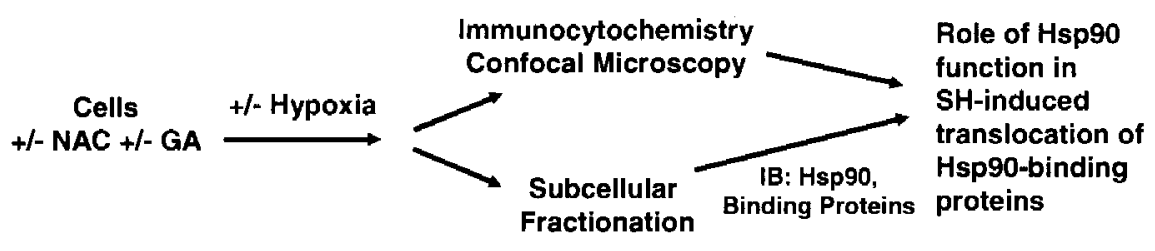

Effect of Akt phosphorylation of Hsp90 on protein translocation in response to $6 \mathrm{~h}$ hypoxia

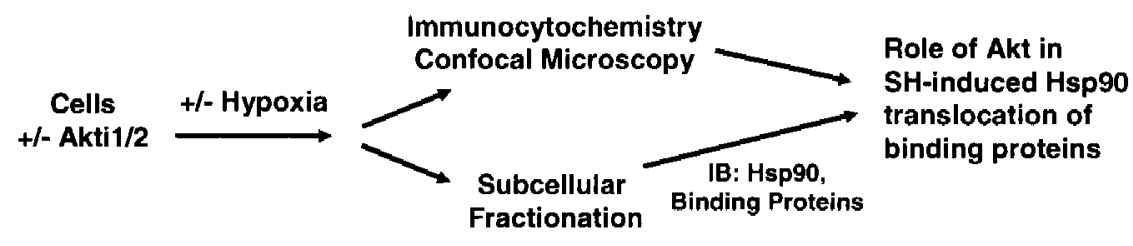

Figure 40. For future studies, methods from Specific Aims 1 and 2 in combination with immunocytochemistry, confocal microscopy, and subcellular fractionation will be used. 
perinuclear regions, nucleus, and mitochondria will allow evaluation of the purity of subcellular fractions and assist in determining the subcellular localization of $\mathrm{Hsp} 90$ complex proteins. Subcellular fractions of greatest interest include cytosolic and plasma membrane extracts, since Hsp90 and Akt are primarily cytosolic and Akt is activated at the plasma membranes. Furthermore, LC-MS-MS analysis of normoxic and hypoxic Hsp90 complexes identified many cytosolic Hsp90-binding proteins, including Dynein, PFK1, and PFK2, as well as additional Hsp90-binding proteins known to regulate exocytosis that may localize to the plasma membrane. In addition, the role of Dynein in the nuclear localization of Hsp90-binding proteins will be assessed and the effect of dirupting Hsp90-Dynein binding on hypoxia-induced transcriptional responses will be evaluated. Cells exposed to $6 \mathrm{~h}$ of RA or $\mathrm{SH}$ in the presence or absence of NAC and GA or of Aktil/2 will be fractionated and fractions immunoblotted for $\mathrm{Hsp} 90$ and Hsp90-binding proteins. Future studies are expected to show that both GA and Aktil/2 inhibit hypoxia-induced increases in Hsp90 co-localization with Akt and other binding proteins. In conclusion, future studies will focus on determining the role of Akt phosphorylation in Hsp90-dependent shuttling of proteins, that play roles in cellular survival.

\section{Conclusion}

These future studies will provide novel mechanistic insight on the role of Hsp90-Akt interactions in the pathophysiology of diseases. By regulating survival, the Hsp90-Akt complex may influence the progression of a variety of cancers and neurological diseases that are frequently associated with hypoxia. 


\section{REFERENCES}

1. Cherniack, N.S., Oxygen sensing: applications in humans. Journal of Applied Physiology, 2004. 96(1): p. 352-358.

2. Redline S, S.K., Recognition and consequences of obstructive sleep apnea hypopnea syndrome. Otolaryngol Clin North Am, 1999. 32(2): p. 303 - 331.

3. Brown, J.M., Exploiting the hypoxic cancer cell: mechanisms and therapeutic strategies. Molecular Medicine Today, 2000. 6(4): p. 157-62.

4. Chi, N.C., et al., Molecular determinants of responses to myocardial ischemia/reperfusion injury: focus on hypoxia-inducible and heat shock factors. Cardiovascular Research, 2004. 61(3): p. 437-47.

5. Renshaw, G.M., et al., Oxygen sensors and energy sensors act synergistically to achieve a graded alteration in gene expression: consequences for assessing the level of neuroprotection in response to stressors. Frontiers in Bioscience, 2004. 9: p. 110-6.

6. Seta, K.A., et al., Responding to hypoxia: lessons from a model cell line. Science's Stke [Electronic Resource]: Signal Transduction Knowledge Environment, 2002. 2002(146): p. RE11.

7. Seko, Y., et al., Hypoxia and hypoxia/reoxygenation activate Raf-1, mitogenactivated protein kinase kinase, mitogen-activated protein kinases, and S6 kinase in cultured rat cardiac myocytes. Circulation Research, 1996. 78(1): p. 82-90.

8. Alvarez-Tejado, M., et al., Hypoxia induces the activation of the phosphatidylinositol 3-kinase/Akt cell survival pathway in PCI2 cells: protective role in apoptosis. Journal of Biological Chemistry, 2001. 276(25): p. 22368-74.

9. Zhang, S.X., et al., Hypoxia induces an autocrine-paracrine survival pathway via platelet-derived growth factor (PDGF)-B/PDGF-beta receptor/phosphatidylinositol 3-kinase/Akt signaling in RN46A neuronal cells. FASEB Journal, 2003. 17(12): p. 1709-11.

10. Fukunaga, K, et al., Akt is a molecular target for signal transduction therapy in brain ischemic insult. Journal of Pharmacological Sciences, 2003. 92(4): p. 31727.

11. Luo, Y., et al., Opposing roles for ERK1/2 in neuronal oxidative toxicity: distinct mechanisms of ERKI/2 action at early versus late phases of oxidative stress. Journal of Biological Chemistry, 2006. 281(24): p. 16436-42.

12. Millhorn, D.E., et al., Regulation of ionic conductances and gene expression by hypoxia in an oxygen sensitive cell line. Advances in Experimental Medicine \& Biology, 1996. 410: p. 135-42.

13. Fishman, M.C., W.L. Greene, and D. Platika, Oxygen chemoreception by carotid body cells in culture. Proceedings of the National Academy of Sciences of the United States of America, 1985. 82(5): p. 1448-50. 
14. Gonzalez, C., et al., Effects of hypoxia on tyrosine hydroxylase activity in rat carotid body. Journal of Neurochemistry, 1979. 33(3): p. 713-9.

15. Shaw, K., W. Montague, and D.J. Pallot, Biochemical studies on the release of catecholamines from the rat carotid body in vitro. Biochimica et Biophysica Acta, 1989. 1013(1): p. 42-6.

16. Conforti, L. and D.E. Millhorn, Selective inhibition of a slow-inactivating voltage-dependent $K+$ channel in rat PC12 cells by hypoxia. Journal of Physiology, 1997. 502(Pt 2): p. 293-305.

17. Zhu, H. and H.F. Bunn, Oxygen sensing and signaling: impact on the regulation of physiologically important genes. Respiration Physiology, 1999. 115(2): p. 23947.

18. Delpiano, M.A. and J. Hescheler, Evidence for a PO2-sensitive $\mathrm{K}+$ channel in the type-I cell of the rabbit carotid body. FEBS Letters, 1989. 249(2): p. 195-8.

19. Lopez-Barneo, J., et al., Chemotransduction in the carotid body: K+ current modulated by PO2 in type I chemoreceptor cells. Science, 1988. 241(4865): p. 580-2.

20. Ellis, R.J. and R.J. Ellis, Molecular chaperones: Plugging the transport gap. Nature, 2003. 421(6925): p. 801-2.

21. Pratt, W.B. and D.O. Toft, Steroid receptor interactions with heat shock protein and immunophilin chaperones. Endocrine Reviews, 1997. 18(3): p. 306-60.

22. Samali, A. and S. Orrenius, Heat shock proteins: regulators of stress response and apoptosis. Cell Stress \& Chaperones, 1998. 3(4): p. 228-36.

23. Takayama, S., et al., Heat-shock proteins as regulators of apoptosis. Oncogene, 2003. 22(56): p. 9041-7.

24. Sreedhar, A.S., et al., Heat shock proteins in the regulation of apoptosis: new strategies in tumor therapy: a comprehensive review. Pharmacology \& Therapeutics, 2004. 101(3): p. 227-57.

25. Hatakeyama, S., et al., Interaction of U-box-type ubiquitin-protein ligases (E3s) with molecular chaperones. Genes to Cells, 2004. 9(6): p. 533-48.

26. Wen, H.C., et al., Chronic hypoxia preconditioning increases survival in rats suffering from heatstroke. Clinical \& Experimental Pharmacology \& Physiology, 2002. 29(5-6): p. 435-40.

27. Simon, R.P., et al., The temporal profile of $72-k D a$ heat-shock protein expression following global ischemia. Journal of Neuroscience, 1991. 11(3): p. 881-9.

28. Pan, Y.X., et al., Delayed cytoprotection induced by hypoxic preconditioning in cultured neonatal rat cardiomyocytes: role of GRP78. Life Sciences, 2007. 81(13): p. 1042-9.

29. Gao, Y., et al., Protein kinase C-dependent activation of P44/42 mitogenactivated protein kinase and heat shock protein 70 in signal transduction during hepatocyte ischemic preconditioning. World Journal of Gastroenterology, 2004. 10(7): p. 1019-27.

30. Liu, J., et al., Effects of heat shock protein 70 activation by metabolic inhibition preconditioning or kappa-opioid receptor stimulation on Ca2+ homeostasis in rat ventricular myocytes subjected to ischemic insults. Journal of Pharmacology \& Experimental Therapeutics, 2004. 310(2): p. 606-13. 
31. Sharp, F.R., S.M. Massa, and R.A. Swanson, Heat-shock protein protection. Trends in Neurosciences, 1999. 22(3): p. 97-9.

32. Yenari, M.A., et al., Gene therapy with HSP72 is neuroprotective in rat models of stroke and epilepsy.[see comment]. Annals of Neurology, 1998. 44(4): p. 584-91.

33. Lee, S.H., et al., Effects of hsp70.1 gene knockout on the mitochondrial apoptotic pathway after focal cerebral ischemia. Stroke, 2004. 35(9): p. 2195-9.

34. Brar, B.K., et al., Heat shock proteins delivered with a virus vector can protect cardiac cells against apoptosis as well as against thermal or hypoxic stress. Journal of Molecular \& Cellular Cardiology, 1999. 31(1): p. 135-46.

35. Heads, R.J., D.M. Yellon, and D.S. Latchman, Differential cytoprotection against heat stress or hypoxia following expression of specific stress protein genes in myogenic cells. Journal of Molecular \& Cellular Cardiology, 1995. 27(8): p. 1669-78.

36. Jiao, J.D., et al., Novel functional role of heat shock protein 90 in ATP-sensitive $K+$ channel-mediated hypoxic preconditioning. Cardiovascular Research, 2008. 77(1): p. 126-33.

37. Shi, Y., et al., Increased resistance to myocardial ischemia in the Brown Norway vs. Dahl S rat: role of nitric oxide synthase and Hsp90. Journal of Molecular \& Cellular Cardiology, 2005. 38(4): p. 625-35.

38. Csermely, P., et al., The 90-kDa molecular chaperone family: structure, function, and clinical applications. A comprehensive review. Pharmacology \& Therapeutics, 1998. 79(2): p. 129-68.

39. Richter, K. and J. Buchner, Hsp90: chaperoning signal transduction. Journal of Cellular Physiology, 2001. 188(3): p. 281-90.

40. Prodromou, C., et al., Identification and structural characterization of the ATP/ADP-binding site in the Hsp90 molecular chaperone. Cell, 1997. 90(1): p. 65-75.

41. Stebbins, C.E., et al., Crystal structure of an Hsp90-geldanamycin complex: targeting of a protein chaperone by an antitumor agent. Cell, 1997. 89(2): p. 23950.

42. Cid, C., et al., Antibodies reactive to heat shock protein 90 induce oligodendrocyte precursor cell death in culture. Implications for demyelination in multiple sclerosis. FASEB Journal, 2004. 18(2): p. 409-11.

43. Ficker, E., et al., Role of the cytosolic chaperones Hsp70 and Hsp9O in maturation of the cardiac potassium channel HERG. Circulation Research, 2003. 92(12): p. e87-100.

44. Czar, M.J., M.J. Welsh, and W.B. Pratt, Immunofluorescence localization of the 90-kDa heat-shock protein to cytoskeleton. European Journal of Cell Biology, 1996. 70(4): p. 322-30.

45. Koyasu, S., et al., Two mammalian heat shock proteins, HSP9O and HSPIOO, are actin-binding proteins. Proceedings of the National Academy of Sciences of the United States of America, 1986. 83(21): p. 8054-8.

46. Akner, G., et al., Evidence for reversible, non-microtubule and nonmicrofilament-dependent nuclear translocation of hsp 90 after heat shock in human fibroblasts. European Journal of Cell Biology, 1992. 58(2): p. 356-64. 
47. Collier, N.C. and M.J. Schlesinger, The dynamic state of heat shock proteins in chicken embryo fibroblasts. Journal of Cell Biology, 1986. 103(4): p. 1495-507.

48. Polanowska-Grabowska, R., et al., Platelet adhesion to collagen under flow causes dissociation of a phosphoprotein complex of heat-shock proteins and protein phosphatase 1. Blood, 1997. 90(4): p. 1516-26.

49. Chiosis, G., et al., Tumor selectivity of Hsp 90 inhibitors: the explanation remains elusive. ACS Chemical Biology [Electronic Resource], 2006. 1(5): p. 279-84.

50. Soti, C., et al., Comparative analysis of the ATP-binding sites of Hsp 90 by nucleotide affinity cleavage: a distinct nucleotide specificity of the C-terminal ATP-binding site. European Journal of Biochemistry, 2003. 270(11): p. 2421-8.

51. Marcu, M.G., et al., The heat shock protein 90 antagonist novobiocin interacts with a previously unrecognized ATP-binding domain in the carboxyl terminus of the chaperone. Journal of Biological Chemistry, 2000. 275(47): p. 37181-6.

52. Blagg, B.S., et al., Hsp90 inhibitors: small molecules that transform the Hsp90 protein folding machinery into a catalyst for protein degradation. Medicinal Research Reviews, 2006. 26(3): p. 310-38.

53. Oh, S.H., et al., Structural basis for depletion of heat shock protein 90 client proteins by deguelin. Journal of the National Cancer Institute, 2007. 99(12): p. 949-61.

54. Marcu, M.G., T.W. Schulte, and L. Neckers, Novobiocin and related coumarins and depletion of heat shock protein 90-dependent signaling proteins. Journal of the National Cancer Institute, 2000. 92(3): p. 242-8.

55. Soti, C., et al., Interaction of vanadate oligomers and permolybdate with the 90 $k D a$ heat-shock protein, Hsp90. European Journal of Biochemistry, 1998. 255(3): p. 611-7.

56. Soti, C., et al., A Nucleotide-dependent molecular switch controls ATP binding at the C-terminal domain of Hsp90. N-terminal nucleotide binding unmasks a Cterminal binding pocket. Journal of Biological Chemistry, 2002. 277(9): p. 706675.

57. Garnier, C., et al., Binding of ATP to heat shock protein 90: evidence for an ATPbinding site in the C-terminal domain. Journal of Biological Chemistry, 2002. 277(14): p. 12208-14.

58. Grenert, J.P., B.D. Johnson, and D.O. Toft, The importance of ATP binding and hydrolysis by hsp 90 in formation and function of protein heterocomplexes. Journal of Biological Chemistry, 1999. 274(25): p. 17525-33.

59. Rosenhagen, M.C., et al., The heat shock protein 90-targeting drug cisplatin selectively inhibits steroid receptor activation. Molecular Endocrinology, 2003. 17(10): p. 1991-2001.

60. Zhang, H., et al., Targeting multiple signal transduction pathways through inhibition of Hsp90. Journal of Molecular Medicine, 2004. 82(8): p. 488-99.

61. Georgios V. Georgakis, Y.L., Georgios Z. Rassidakis, Hector Martinez-Valdez, L. Jeffrey Medeiros and Anas Younes Inhibition of Heat Shock Protein 90 Function by 17-Allylamino-17-Demethoxy-Geldanamycin in Hodgkin's Lymphoma Cells Down-Regulates Akt Kinase, Dephosphorylates Extracellular Signal-Regulated Kinase, and Induces Cell Cycle Arrest and Cell Death. Clinical Cancer Research, 2006. 12: p. 584-590. 
62. Nomura, M., et al., Geldanamycin induces mitotic catastrophe and subsequent apoptosis in human glioma cells. Journal of Cellular Physiology, 2004. 201(3): p. 374-84.

63. Basso, A.D., et al., Akt forms an intracellular complex with heat shock protein 90 (Hsp90) and Cdc37 and is destabilized by inhibitors of Hsp90 function. Journal of Biological Chemistry, 2002. 277(42): p. 39858-66.

64. Schulte, T.W., W.G. An, and L.M. Neckers, Geldanamycin-induced destabilization of Raf-1 involves the proteasome. Biochemical \& Biophysical Research Communications, 1997. 239(3): p. 655-9.

65. Miyata, Y., et al., Specific association of a set of molecular chaperones including HSP9O and Cdc37 with MOK, a member of the mitogen-activated protein kinase superfamily. Journal of Biological Chemistry, 2001. 276(24): p. 21841-8.

66. Lerdrup, M., et al., Geldanamycin stimulates internalization of ErbB2 in a proteasome-dependent way. Journal of Cell Science, 2006. 119(Pt 1): p. 85-95.

67. Finn, P.F., et al., Effects of small molecules on chaperone-mediated autophagy. Autophagy, 2005. 1(3): p. 141-5.

68. Qing G, Y.P., Qu Z, Liu H and Xiao G, Hsp90 regulates processing of NFkappaB2 p100 involving protection of NF-kappaB-inducing kinase (NIK) from autophagy-mediated degradation. Cell Research, 2007. 17: p. 520-530.

69. Qing, G., et al., Hsp90 inhibition results in autophagy-mediated proteasomeindependent degradation of IkappaB kinase (IKK).[see comment]. Cell Research, 2006. 16(11): p. 895-901.

70. Dice, J.F. and J.F. Dice, Chaperone-mediated autophagy. Autophagy, 2007. 3(4): p. 295-9.

71. Shacka, J.J., et al., The autophagy-lysosomal degradation pathway: role in neurodegenerative disease and therapy. Frontiers in Bioscience, 2008. 13: p. 71836.

72. Kamal, A., et al., A high-affinity conformation of Hsp90 confers tumour selectivity on Hsp90 inhibitors. [see comment]. Nature, 2003. 425(6956): p. 407-10.

73. Adams, J. and P.J. Elliott, New agents in cancer clinical trials. Oncogene, 2000. 19(56): p. 6687-92.

74. Blagosklonny, M.V., et al., The Hsp90 inhibitor geldanamycin selectively sensitizes Bcr-Abl-expressing leukemia cells to cytotoxic chemotherapy. Leukemia, 2001. 15(10): p. 1537-43.

75. Neckers, L. and L. Neckers, Hsp90 inhibitors as novel cancer chemotherapeutic agents. Trends in Molecular Medicine, 2002. 8(4 Suppl): p. S55-61.

76. Ivy, P.S., et al., Clinical trials referral resource. Current clinical trials of 17-AG and 17-DMAG. Oncology (Williston Park). 18(5): p. 610.

77. Blagosklonny, M.V., Hsp-90-associated oncoproteins: multiple targets of geldanamycin and its analogs. Leukemia, 2002. 16(4): p. 455-62.

78. Tadtong, S., et al., Geldanamycin derivatives and neuroprotective effect on cultured P19-derived neurons. Bioorganic \& Medicinal Chemistry Letters, 2007. 17(10): p. 2939-43.

79. Shen, H.Y., et al., Geldanamycin induces heat shock protein 70 and protects against MPTP-induced dopaminergic neurotoxicity in mice. Journal of Biological Chemistry, 2005. 280(48): p. 39962-9. 
80. Sreedhar, A.S., et al., Hsp90 inhibition accelerates cell lysis. Anti-Hsp90 ribozyme reveals a complex mechanism of $H$ sp 90 inhibitors involving both superoxide- and Hsp90-dependent events. Journal of Biological Chemistry, 2003. 278(37): p. 35231-40.

81. Dikalov, S., et al., Geldanamycin leads to superoxide formation by enzymatic and non-enzymatic redox cycling. Implications for studies of Hsp 90 and endothelial cell nitric-oxide synthase. Journal of Biological Chemistry, 2002. 277(28): p. 25480-5.

82. Dikalov, S.I., et al., Role of quinone-iron(III) interaction in NADPH-dependent enzymatic generation of hydroxyl radicals. Biochemistry, 1992. 31(37): p. 894753.

83. Cysyk, R.L., et al., Reaction of geldanamycin and C17-substituted analogues with glutathione: product identifications and pharmacological implications. Chemical Research in Toxicology, 2006. 19(3): p. 376-81.

84. Lamson, D.W., et al., The anticancer effects of vitamin K. Alternative Medicine Review, 2003. 8(3): p. 303-18.

85. Criddle, D.N., et al., Menadione-induced reactive oxygen species generation via redox cycling promotes apoptosis of murine pancreatic acinar cells. Journal of Biological Chemistry, 2006. 281(52): p. 40485-92.

86. Fukuyo, Y., et al., Oxidative stress plays a critical role in inactivating mutant BRAF by geldanamycin derivatives. Cancer Research, 2008. 68(15): p. 6324-30.

87. Ochel, H.J., et al., The benzoquinone ansamycin geldanamycin stimulates proteolytic degradation of focal adhesion kinase. Molecular Genetics \& Metabolism, 1999. 66(1): p. 24-30.

88. Mimnaugh, E.G., C. Chavany, and L. Neckers, Polyubiquitination and proteasomal degradation of the p185c-erbB-2 receptor protein-tyrosine kinase induced by geldanamycin. Journal of Biological Chemistry, 1996. 271(37): p. 22796-801.

89. Whitesell, L., et al., Inhibition of heat shock protein HSP90-pp60v-src heteroprotein complex formation by benzoquinone ansamycins: essential role for stress proteins in oncogenic transformation. Proceedings of the National Academy of Sciences of the United States of America, 1994. 91(18): p. 8324-8.

90. Zou, J., et al., Repression of heat shock transcription factor HSFI activation by HSP90 (HSP90 complex) that forms a stress-sensitive complex with HSF1. Cell, 1998. 94(4): p. 471-80.

91. Lu, A., et al., Geldanamycin induces heat shock proteins in brain and protects against focal cerebral ischemia. Journal of Neurochemistry, 2002, 81(2): p. 35564.

92. Bo-Geon Yun, R.L.M., Hsp90 functions to balance the phosphorylation state of Akt during C2C12 myoblast differentiation. Cellular Signalling, 2005. 17: p. 1477 $-1485$

93. Dou, F., et al., Heat shock protein 90 indirectly regulates ERK activity by affecting Raf protein metabolism. Acta Biochimica et Biophysica Sinica, 2005. 37(7): p. 501-5. 
94. Schulte, T.W., et al., Disruption of the Raf-1-Hsp90 molecular complex results in destabilization of Raf-I and loss of Raf-I-Ras association. Journal of Biological Chemistry, 1995. 270(41): p. 24585-8.

95. Stancato, L.F., et al., The hsp90-binding antibiotic geldanamycin decreases Raf levels and epidermal growth factor signaling without disrupting formation of signaling complexes or reducing the specific enzymatic activity of Raf kinase. Journal of Biological Chemistry, 1997. 272(7): p. 4013-20.

96. Grammatikakis, N., et al., p50(cdc37) acting in concert with Hsp90 is required for Raf-1 function. Molecular \& Cellular Biology, 1999. 19(3): p. 1661-72.

97. Silverstein, A.M., et al., p50(cdc37) binds directly to the catalytic domain of Raf as well as to a site on hsp90 that is topologically adjacent to the tetratricopeptide repeat binding site. Journal of Biological Chemistry, 1998. 273(32): p. 20090-5.

98. Goetz, M.P., et al., The Hsp90 chaperone complex as a novel target for cancer therapy. Annals of Oncology, 2003. 14(8): p. 1169-76.

99. Basso, A.D., et al., Ansamycin antibiotics inhibit Akt activation and cyclin D expression in breast cancer cells that overexpress HER2. Oncogene, 2002. 21(8): p. 1159-66.

100. Hollingshead, M., et al., In vivo antitumor efficacy of 17-DMAG (17dimethylaminoethylamino-17-demethoxygeldanamycin hydrochloride), a watersoluble geldanamycin derivative. Cancer Chemotherapy \& Pharmacology, 2005. 56(2): p. 115-25.

101. Smith, V., et al., Comparison of 17-dimethylaminoethylamino-17-demethoxygeldanamycin (17DMAG) and 17-allylamino-17-demethoxygeldanamycin (17AAG) in vitro: effects on Hsp90 and client proteins in melanoma models. Cancer Chemotherapy \& Pharmacology, 2005. 56(2): p. 126-37.

102. Eiseman, J.L., et al., Pharmacokinetics and pharmacodynamics of 17-demethoxy 17-[[(2-dimethylamino)ethyl]amino]geldanamycin (17DMAG, NSC 707545) in C.B-17 SCID mice bearing MDA-MB-231 human breast cancer xenografts. Cancer Chemotherapy \& Pharmacology, 2005. 55(1): p. 21-32.

103. Stravopodis, D.J., et al., Drug-mediated targeted disruption of multiple protein activities through functional inhibition of the Hsp90 chaperone complex. Current Medicinal Chemistry, 2007. 14(29): p. 3122-38.

104. Schwock, J., et al., Efficacy of Hsp90 inhibition for induction of apoptosis and inhibition of growth in cervical carcinoma cells in vitro and in vivo. Cancer Chemotherapy \& Pharmacology, 2008. 61(4): p. 669-81.

105. van der Bilt, J.D., et al., Perinecrotic hypoxia contributes to ischemia/reperfusionaccelerated outgrowth of colorectal micrometastases. American Journal of Pathology, 2007. 170(4): p. 1379-88.

106. Pandey, P., et al., Negative regulation of cytochrome $c$-mediated oligomerization of Apaf-I and activation of procaspase-9 by heat shock protein 90 . EMBO Journal, 2000. 19(16): p. 4310-22.

107. Cardone, M.H., et al., Regulation of cell death protease caspase-9 by phosphorylation.[see comment]. Science, 1998. 282(5392): p. 1318-21.

108. Mikolajczyk, M., et al., Regulation of stability of cyclin-dependent kinase CDK11p110 and a caspase-processed form, CDK11p46, by Hsp90. Biochemical Journal, 2004. 384(Pt 3): p. 461-7. 
109. Frebel, K. and S. Wiese, Signalling molecules essential for neuronal survival and differentiation. Biochemical Society Transactions, 2006. 34(Pt 6): p. 1287-90.

110. Franklin, R.A. and J.A. McCubrey, Kinases: positive and negative regulators of apoptosis. Leukemia, 2000. 14(12): p. 2019-34.

111. DeFeo-Jones, D., et al., Tumor cell sensitization to apoptotic stimuli by selective inhibition of specific Akt/PKB family members. Molecular Cancer Therapeutics, 2005. 4(2): p. 271-9.

112. Adrain, C. and S.J. Martin, The mitochondrial apoptosome: a killer unleashed by the cytochrome seas. Trends in Biochemical Sciences, 2001. 26(6): p. 390-7.

113. Aoyagi, Y., et al., Stabilization of integrin-linked kinase by binding to Hsp 90 . Biochemical \& Biophysical Research Communications, 2005. 331(4): p. 1061-8.

114. Sato, S., N. Fujita, and T. Tsuruo, Modulation of Akt kinase activity by binding to Hsp90. Proceedings of the National Academy of Sciences of the United States of America, 2000. 97(20): p. 10832-7.

115. Fujita, N., et al., Involvement of Hsp90 in signaling and stability of 3phosphoinositide-dependent kinase-1. Journal of Biological Chemistry, 2002. 277(12): p. 10346-53.

116. $\mathrm{Xu}, \mathrm{Y}$. and S. Lindquist, Heat-shock protein hsp90 governs the activity of pp60vsrc kinase. Proceedings of the National Academy of Sciences of the United States of America, 1993. 90(15): p. 7074-8.

117. Sato, S., et al., Regulation of kinase activity of 3-phosphoinositide-dependent protein kinase-1 by binding to 14-3-3. Journal of Biological Chemistry, 2002. 277(42): p. 39360-7.

118. Yoshizaki, H., et al., Akt-PDKI complex mediates epidermal growth factorinduced membrane protrusion through Ral activation. Molecular Biology of the Cell, 2007. 18(1): p. 119-28.

119. Roe, S.M., et al., The Mechanism of Hsp90 regulation by the protein kinasespecific cochaperone p50(cdc37). Cell, 2004. 116(1): p. 87-98.

120. Terasawa, K., et al., Cdc37 interacts with the glycine-rich loop of Hsp 90 client kinases. Molecular \& Cellular Biology, 2006. 26(9): p. 3378-89.

121. Shao, J., et al., Phosphorylation of serine 13 is required for the proper function of the Hsp90 co-chaperone, Cdc37. Journal of Biological Chemistry, 2003. 278(40): p. 38117-20.

122. Pearl, L.H. and L.H. Pearl, Hsp90 and Cdc37 -- a chaperone cancer conspiracy. Current Opinion in Genetics \& Development, 2005. 15(1): p. 55-61.

123. Hatakeyama, M., et al., A computational model on the modulation of mitogenactivated protein kinase (MAPK) and Akt pathways in heregulin-induced ErbB signalling. Biochemical Journal, 2003. 373(Pt 2): p. 451-63.

124. Hausenloy, D.J., et al., Cross-talk between the survival kinases during early reperfusion: its contribution to ischemic preconditioning. Cardiovascular Research, 2004. 63(2): p. 305-12.

125. Mograbi, B., et al., Glial cell line-derived neurotrophic factor-stimulated phosphatidylinositol 3-kinase and Akt activities exert opposing effects on the ERK pathway: importance for the rescue of neuroectodermic cells. Journal of Biological Chemistry, 2001. 276(48): p. 45307-19. 
126. Wang, Z., et al., Hepatocyte growth factor enhances protein phosphatase Cdc25A inhibitor compound 5-induced hepatoma cell growth inhibition via Akt-mediated MAPK pathway. Journal of Cellular Physiology, 2005. 203(3): p. 510-9.

127. Wellbrock, C., et al., The RAF proteins take centre stage. Nature Reviews Molecular Cell Biology, 2004. 5(11): p. 875-85.

128. Zimmermann, S. and K. Moelling, Phosphorylation and regulation of Raf by Akt (protein kinase B). Science, 1999. 286(5445): p. 1741-4.

129. Lee, S.P., et al., Integrin-linked kinase, a hypoxia-responsive molecule, controls postnatal vasculogenesis by recruitment of endothelial progenitor cells to ischemic tissue. Circulation, 2006. 114(2): p. 150-9.

130. Zhou, J., et al,, PI3K/Akt is required for heat shock proteins to protect hypoxiainducible factor lalpha from $\mathrm{p} V H L$-independent degradation. Journal of Biological Chemistry, 2004. 279(14): p. 13506-13.

131. Sasabe, E., et al., Mechanism of HIF-lalpha-dependent suppression of hypoxiainduced apoptosis in squamous cell carcinoma cells. Cancer Science, 2005. 96(7): p. 394-402.

132. Semenza, G.L. and G.L. Semenza, Oxygen-dependent regulation of mitochondrial respiration by hypoxia-inducible factor 1. Biochemical Journal, 2007. 405(1): p. $1-9$.

133. Brahimi-Horn, M.C., et al., Harnessing the hypoxia-inducible factor in cancer and ischemic disease. Biochemical Pharmacology, 2007. 73(3): p. 450-7.

134. Katschinski, D.M., et al., Interaction of the PAS B domain with HSP9O accelerates hypoxia-inducible factor-Lalpha stabilization. Cellular Physiology \& Biochemistry, 2004. 14(4-6): p. 351-60.

135. Kurebayashi, J., et al., A radicicol derivative, KF58333, inhibits expression of hypoxia-inducible factor-Ialpha and vascular endothelial growth factor, angiogenesis and growth of human breast cancer xenografts. Japanese Journal of Cancer Research, 2001. 92(12): p. 1342-51.

136. Cen, X., et al., An analog of a dipeptide-like structure of FK506 increases glial cell line-derived neurotrophic factor expression through cAMP response elementbinding protein activated by heat shock protein 90/Akt signaling pathway. Journal of Neuroscience, 2006. 26(12): p. 3335-44.

137. Vasilevskaya, I.A. and P.J. O'Dwyer, Effects of geldanamycin on signaling through activator-protein 1 in hypoxic HT29 human colon adenocarcinoma cells. Cancer Research, 1999. 59(16): p. 3935-40.

138. Hur, E., et al., Reduction of hypoxia-induced transcription through the repression of hypoxia-inducible factor-lalpha/aryl hydrocarbon receptor nuclear translocator DNA binding by the 90-kDa heat-shock protein inhibitor radicicol. Molecular Pharmacology, 2002. 62(5): p. 975-82.

139. Fontana, J., et al., Domain mapping studies reveal that the $M$ domain of hsp 90 serves as a molecular scaffold to regulate Akt-dependent phosphorylation of endothelial nitric oxide synthase and NO release. [see comment]. Circulation Research, 2002, 90(8): p. 866-73.

140. Barati, M.T., et al., A proteomic screen identified stress-induced chaperone proteins as targets of Akt phosphorylation in mesangial cells. Journal of Proteome Research, 2006. 5(7): p. 1636-46. 
141. Scansite, (scansite.mit.edu).

142. Songyang, Z., et al., Use of an oriented peptide library to determine the optimal substrates of protein kinases. Current Biology, 1994. 4(11): p. 973-82.

143. Huang, H.C., et al., Purification and characterization of porcine testis $90-k D a$ heat shock protein (HSP90) as a substrate for various protein kinases. Journal of Protein Chemistry, 2002. 21(2): p. 111-21.

144. Garnier, C., et al., Phosphorylation and oligomerization states of native pig brain HSP90 studied by mass spectrometry. European Journal of Biochemistry, 2001. 268(8): p. 2402-7.

145. Adinolfi, E., et al., Tyrosine phosphorylation of HSP90 within the P2X7 receptor complex negatively regulates $P 2 X 7$ receptors. Journal of Biological Chemistry, 2003. 278(39): p. 37344-51.

146. Duval, M., et al., Src-mediated phosphorylation of Hsp90 in response to vascular endothelial growth factor (VEGF) is required for VEGF receptor-2 signaling to endothelial NO synthase. Molecular Biology of the Cell, 2007. 18(11): p. 465968.

147. Dougherty, J.J., et al., Identification of the $90 \mathrm{kDa}$ substrate of rat liver type II casein kinase with the heat shock protein which binds steroid receptors. Biochimica et Biophysica Acta, 1987. 927(1): p. 74-80.

148. Csermely, P. and C.R. Kahn, The 90-kDa heat shock protein (hsp-90) possesses an ATP binding site and autophosphorylating activity. Journal of Biological Chemistry, 1991. 266(8): p. 4943-50.

149. Park, M., C. Yong Kang, and P. Krishna, Brassica napus hsp90 can autophosphorylate and phosphorylate other protein substrates. Molecular \& Cellular Biochemistry, 1998. 185(1-2): p. 33-8.

150. Miyata, Y., et al., CK2 binds, phosphorylates, and regulates its pivotal substrate Cdc37, an Hsp90-cochaperone. Molecular \& Cellular Biochemistry, 2005. 274(12): p. 171-9.

151. Miyata, Y., et al., CK2 controls multiple protein kinases by phosphorylating a kinase-targeting molecular chaperone, Cdc37. Molecular \& Cellular Biology, 2004. 24(9): p. 4065-74.

152. Bandhakavi, S., et al., A positive feedback loop between protein kinase CKII and Cdc 37 promotes the activity of multiple protein kinases. Journal of Biological Chemistry, 2003. 278(5): p. 2829-36.

153. Vaughan, C.K., et al., Hsp90-dependent activation of protein kinases is regulated by chaperone-targeted dephosphorylation of Cdc37. Molecular Cell, 2008. 31(6): p. 886-95.

154. Drysdale, M.J., et al., Targeting Hsp90 for the treatment of cancer. Current Opinion in Drug Discovery \& Development, 2006. 9(4): p. 483-95.

155. Ramanathan, R.K., et al., Phase I and pharmacodynamic study of 17 (allylamino)-17-demethoxygeldanamycin in adult patients with refractory advanced cancers. [see comment]. Clinical Cancer Research, 2007. 13(6): p. 1769-74.

156. Banerji, U., et al., Phase I pharmacokinetic and pharmacodynamic study of 17allylamino, 17-demethoxygeldanamycin in patients with advanced malignancies. Journal of Clinical Oncology, 2005. 23(18): p. 4152-61. 
157. Pacey, S., et al., Hsp90 inhibitors in the clinic. Handbook of Experimental Pharmacology, 2006(172): p. 331-58.

158. Sharp, S., et al., Inhibitors of the HSP90 molecular chaperone: current status. Advances in Cancer Research, 2006. 95: p. 323-48.

159. Shadad, F.N., et al., 17-dimethylaminoethylamino-17-demethoxygeldanamycin in patients with advanced-stage solid tumors and lymphoma: a phase I study. Clinical Lymphoma \& Myeloma, 2006. 6(6): p. 500-1.

160. Robles, A.I., et al., Schedule-dependent synergy between the heat shock protein 90 inhibitor 17-(dimethylaminoethylamino)-17-demethoxygeldanamycin and doxorubicin restores apoptosis to p53-mutant lymphoma cell lines. Clinical Cancer Research, 2006. 12(21): p. 6547-56.

161. Waza, M., et al., Alleviating neurodegeneration by an anticancer agent: an Hsp 90 inhibitor (17-AAG). Annals of the New York Academy of Sciences, 2006. 1086: p. 21-34.

162. Li, W., et al., Extracellular heat shock protein-90alpha: linking hypoxia to skin cell motility and wound healing. [erratum appears in EMBO J. 2007 Jun 20;26(12):3038]. EMBO Journal, 2007. 26(5): p. 1221-33.

163. Leak, R.K., et al., Adaptation to chronic MG132 reduces oxidative toxicity by a CuZnSOD-dependent mechanism. Journal of Neurochemistry, 2008. 106(2): p. 860-74.

164. Galigniana, M.D., et al., Hsp90-binding immunophilins link p53 to dynein during p53 transport to the nucleus. Journal of Biological Chemistry, 2004. 279(21): p. 22483-9.

165. Harrell, J.M., et al., All of the protein interactions that link steroid receptor.hsp90.immunophilin heterocomplexes to cytoplasmic dynein are common to plant and animal cells. Biochemistry, 2002. 41(17): p. 5581-7.

166. Suzuki, H., A. Tomida, and T. Tsuruo, Dephosphorylated hypoxia-inducible factor lalpha as a mediator of p53-dependent apoptosis during hypoxia. Oncogene, 2001. 20(41): p. 5779-88.

167. Tisdale, E.J. and W.E. Balch, Rab2 is essential for the maturation of pre-Golgi intermediates. Journal of Biological Chemistry, 1996. 271(46): p. 29372-9.

168. Coppola, T., et al., Direct interaction of the Rab3 effector RIM with Ca2+ channels, SNAP-25, and synaptotagmin. Journal of Biological Chemistry, 2001. 276(35): p. 32756-62.

169. Chin, L.S., et al., SNIP, a novel SNAP-25-interacting protein implicated in regulated exocytosis. Journal of Biological Chemistry, 2000. 275(2): p. 1191-200.

170. Mitchell, C., et al., 17-Allylamino-17-demethoxygeldanamycin enhances the lethality of deoxycholic acid in primary rodent hepatocytes and established cell lines. Molecular Cancer Therapeutics, 2007. 6(2): p. 618-32.

171. Estrela, J.M., et al., Glutathione in cancer biology and therapy. Critical Reviews in Clinical Laboratory Sciences, 2006. 43(2): p. 143-81.

172. McCollum, A.K., et al., Up-regulation of heat shock protein 27 induces resistance to 17-allylamino-demethoxygeldanamycin through a glutathione-mediated mechanism. Cancer Research, 2006. 66(22): p. 10967-75. 
173. Laurent, A., et al., Controlling tumor growth by modulating endogenous production of reactive oxygen species.[see comment]. Cancer Research, 2005. 65(3): p. 948-56.

174. Day, B.J., I. Batinic-Haberle, and J.D. Crapo, Metalloporphyrins are potent inhibitors of lipid peroxidation. Free Radical Biology \& Medicine, 1999. 26(5-6): p. 730-6.

175. Konorev, E.A., M.C. Kennedy, and B. Kalyanaraman, Cell-permeable superoxide dismutase and glutathione peroxidase mimetics afford superior protection against doxorubicin-induced cardiotoxicity: the role of reactive oxygen and nitrogen intermediates. Archives of Biochemistry \& Biophysics, 1999. 368(2): p. 421-8.

176. Malassagne, B., et al., The superoxide dismutase mimetic MnTBAP prevents Fasinduced acute liver failure in the mouse. Gastroenterology, 2001. 121(6): p. 14519.

177. Martin, R.C., et al., Chemoprevention of carcinogenic progression to esophageal adenocarcinoma by the manganese superoxide dismutase supplementation. Clinical Cancer Research, 2007. 13(17): p. 5176-82.

178. Zhang, M.Q., et al., Optimizing natural products by biosynthetic engineering: discovery of nonquinone Hsp90 inhibitors. Journal of Medicinal Chemistry, 2008. 51(18): p. 5494-7.

179. Beier, J.I., et al., Activation of ErbB2 by 2-methyl-1,4-naphthoquinone (menadione) in human keratinocytes: role of EGFR and protein tyrosine phosphatases. FEBS Letters, 2006. 580(7): p. 1859-64.

180. von Montfort, C., et al., Singlet oxygen inactivates protein tyrosine phosphatase$1 B$ by oxidation of the active site cysteine. Biological Chemistry, 2006. 387(1011): p. 1399-404.

181. Abdelmohsen, K., et al., Signaling effects of menadione: from tyrosine phosphatase inactivation to connexin phosphorylation. Methods in Enzymology, 2004. 378: p. 258-72.

182. Klotz, L.O., et al., 2-Methyl-1,4-naphthoquinone, vitamin K(3), decreases gapjunctional intercellular communication via activation of the epidermal growth factor receptor/extracellular signal-regulated kinase cascade. Cancer Research, 2002. 62(17): p. 4922-8.

183. Abdelmohsen, K., et al., Doxorubicin induces EGF receptor-dependent downregulation of gap junctional intercellular communication in rat liver epithelial cells. Biological Chemistry, 2005. 386(3): p. 217-23.

184. Abdelmohsen, K., et al., Epidermal growth factor receptor is a common mediator of quinone-induced signaling leading to phosphorylation of connexin-43: role of glutathione and tyrosine phosphatases. Journal of Biological Chemistry, 2003. 278(40): p. 38360-7.

185. Yoshikawa, K., et al., Inhibition of PTEN and activation of Akt by menadione. Biochimica et Biophysica Acta, 2007. 1770(4): p. 687-93.

186. Barthel, A., et al., Phosphoinositide 3-kinase signaling in the cellular response to oxidative stress. Biological Chemistry, 2005. 386(3): p. 207-16.

187. Seung, S.A., et al., The relative importance of oxidative stress versus arylation in the mechanism of quinone-induced cytotoxicity to platelets. Chemico-Biological Interactions, 1998. 113(2): p. 133-44. 
188. Koga, F., et al., Hsp90 inhibition transiently activates Src kinase and promotes Src-dependent Akt and Erk activation. Proceedings of the National Academy of Sciences of the United States of America, 2006. 103(30): p. 11318-22.

189. $\mathrm{Li}, \mathrm{D}$. and $\mathrm{D}$. $\mathrm{Li}$, Selective degradation of the IkappaB kinase (IKK) by autophagy.[comment]. Cell Research, 2006. 16(11): p. 855-6.

190. Kane, M.D., et al., Inhibitors of V-type ATPases, bafilomycin $A l$ and concanamycin A, protect against beta-amyloid-mediated effects on 3-(4,5dimethylthiazol-2-yl)-2,5-diphenyltetrazolium bromide (MTT) reduction. Journal of Neurochemistry, 1999. 72(5): p. 1939-47.

191. Endres, M., et al., Attenuation of delayed neuronal death after mild focal ischemia in mice by inhibition of the caspase family. Journal of Cerebral Blood Flow \& Metabolism, 1998. 18(3): p. 238-47.

192. Yakovlev, A.G., et al., Activation of CPP32-like caspases contributes to neuronal apoptosis and neurological dysfunction after traumatic brain injury. Journal of Neuroscience, 1997. 17(19): p. 7415-24.

193. Emery, E., et al., Apoptosis after traumatic human spinal cord injury. Journal of Neurosurgery, 1998. 89(6): p. 911-20.

194. Papathanassiu, A.E., et al., F1F0-ATP synthase functions as a co-chaperone of Hsp90-substrate protein complexes. Biochemical \& Biophysical Research Communications, 2006. 345(1): p. 419-29.

195. Wang, K.K.W., Calpain and caspase: can you tell the difference? Trends in Neurosciences, 2000. 23(2): p. 20-26.

196. Azuma, M. and T.R. Shearer, The role of calcium-activated protease calpain in experimental retinal pathology. Survey of Ophthalmology, 2008. 53(2): p. 15063.

197. Vanderklish, P.W. and B.A. Bahr, The pathogenic activation of calpain: a marker and mediator of cellular toxicity and disease states. International Journal of Experimental Pathology, 2000. 81(5): p. 323-39.

198. Nath, R., et al., Non-erythroid alpha-spectrin breakdown by calpain and interleukin 1 beta-converting-enzyme-like protease(s) in apoptotic cells: contributory roles of both protease families in neuronal apoptosis. Biochemical Journal, 1996. 319(Pt 3): p. 683-90.

199. Cheng, Y., et al., Effects of extracellular ATP on $\mathrm{Fe}(2+)$-induced cytotoxicity in PC-I2 cells. Journal of Neurochemistry, 1994. 63(3): p. 895-902.

200. Averna, M., et al., In vivo degradation of nitric oxide synthase (NOS) and heat shock protein 90 (HSP90) by calpain is modulated by the formation of a NOSHSP90 heterocomplex. FEBS Journal, 2008. 275(10): p. 2501-11.

201. Averna, M., et al., Proteolytic degradation of nitric oxide synthase isoforms by calpain is modulated by the expression levels of HSP90. FEBS Journal, 2007. 274(23): p. 6116-27.

202. Su, Y. and E.R. Block, Role of calpain in hypoxic inhibition of nitric oxide synthase activity in pulmonary endothelial cells. American Journal of Physiology - Lung Cellular \& Molecular Physiology, 2000. 278(6): p. L1204-12.

203. Boczkowski, J., et al., Endogenous peroxynitrite mediates mitochondrial dysfunction in rat diaphragm during endotoxemia. FASEB Journal, 1999. 13(12): p. 1637-46. 
204. Smith, I.J., et al., Calpain activation causes a proteasome-dependent increase in protein degradation and inhibits the Akt signalling pathway in rat diaphragm muscle. Experimental Physiology, 2007. 92(3): p. 561-73.

205. Garcia-Morales, P., et al., Inhibition of Hsp 90 function by ansamycins causes downregulation of $c d c 2$ and $c d c 25 c$ and $G(2) / M$ arrest in glioblastoma cell lines. Oncogene, 2007. 26(51): p. 7185-93.

206. Nardai, G., et al., Reactive cysteines of the 90-kDa heat shock protein, Hsp90. Archives of Biochemistry \& Biophysics, 2000. 384(1): p. 59-67.

207. Conconi, M., et al., Protection from oxidative inactivation of the 20 S proteasome by heat-shock protein 90. Biochemical Journal, 1998. 333(Pt 2): p. 407-15.

208. Plescia, J., et al., Rational design of shepherdin, a novel anticancer agent. Cancer Cell, 2005. 7(5): p. 457-68.

209. Vilenchik, M., et al., Targeting wide-range oncogenic transformation via PU24FCl, a specific inhibitor of tumor Hsp90. Chemistry \& Biology, 2004. 11(6): p. 787-97.

210. Biamonte, M.A., et al., Orally active purine-based inhibitors of the heat shock protein 90. Journal of Medicinal Chemistry, 2006. 49(2): p. 817-28.

211. Pritchard, K.A., Jr., et al., Heat shock protein 90 mediates the balance of nitric oxide and superoxide anion from endothelial nitric-oxide synthase. Journal of Biological Chemistry, 2001. 276(21): p. 17621-4.

212. Shi, Y., et al., Chronic hypoxia increases endothelial nitric oxide synthase generation of nitric oxide by increasing heat shock protein 90 association and serine phosphorylation. Circulation Research, 2002. 91(4): p. 300-6.

213. Swiger B, P.M., Pastukh V, Gillespie MN and Al-Mehdi A-B Hypoxia causes perinuclear mitochondrial clustering and nuclear oxidant stress in pulmonary artery endothelial cells (PAECS) via a dynein-dependent molecular motor. FASEB Journal, 2008. 22:1174.16.

214. Yoon, S.O., et al., Hypoxia stimulates carcinoma invasion by stabilizing microtubules and promoting the Rab11 trafficking of the alpha6beta4 integrin. Cancer Research, 2005. 65(7): p. 2761-9.

215. Seebohm, G., et al., Regulation of endocytic recycling of KCNQ1/KCNE1 potassium channels. Circulation Research, 2007. 100(5): p. 686-92.

216. Whitman, E.M., et al., Endothelin-1 mediates hypoxia-induced inhibition of voltage-gated $K+$ channel expression in pulmonary arterial myocytes. American Journal of Physiology - Lung Cellular \& Molecular Physiology, 2008. 294(2): p. L309-18.

217. Kumar, P. and P. Kumar, Sensing hypoxia in the carotid body: from stimulus to response. Essays in Biochemistry, 2007. 43: p. 43-60.

218. Peng, W., et al., Effect of chronic hypoxia on $K+$ channels: regulation in human pulmonary vascular smooth muscle cells. American Journal of Physiology, 1997. 272(4 Pt 1): p. C1271-8.

219. Moudgil, R., et al., The role of $k+$ channels in determining pulmonary vascular tone, oxygen sensing, cell proliferation, and apoptosis: implications in hypoxic pulmonary vasoconstriction and pulmonary arterial hypertension. Microcirculation, 2006. 13(8): p. 615-32. 
220. Peers, C. and E. Carpenter, Inhibition of Ca2+-dependent $K+$ channels in rat carotid body type I cells by protein kinase C. Journal of Physiology, 1998. 512(Pt 3): p. 743-50.

221. Choi, W.S., et al., Kv1.5 surface expression is modulated by retrograde trafficking of newly endocytosed channels by the dynein motor. Circulation Research, 2005. 97(4): p. 363-71.

222. Fang, J.S., et al., Adaptation to hypoxia and acidosis in carcinogenesis and tumor progression. Seminars in Cancer Biology, 2008. 18(5): p. 330-7.

223. Hance, A.J., et al., Regulation of glycolytic enzyme activity during chronic hypoxia by changes in rate-limiting enzyme content. Use of monoclonal antibodies to quantitate changes in pyruvate kinase content. Journal of Clinical Investigation, 1980. 66(6): p. 1258-64.

224. Xu, R.H., et al., Inhibition of glycolysis in cancer cells: a novel strategy to overcome drug resistance associated with mitochondrial respiratory defect and hypoxia. Cancer Research, 2005. 65(2): p. 613-21.

225. Hochachka, P.W. and P.L. Lutz, Mechanism, origin, and evolution of anoxia tolerance in animals. Comparative Biochemistry \& Physiology Part B, Biochemistry \& Molecular Biology, 2001. 130(4): p. 435-59.

226. Wang, Q., et al., Cardiac phosphatase-deficient 6-phosphofructo-2kinase/fructose-2,6-bisphosphatase increases glycolysis, hypertrophy, and myocyte resistance to hypoxia. American Journal of Physiology - Heart \& Circulatory Physiology, 2008. 294(6): p. H2889-97.

227. Bartrons, R., et al., Hypoxia, glucose metabolism and the Warburg's effect. Journal of Bioenergetics \& Biomembranes, 2007. 39(3): p. 223-9.

228. Brazil, D.P., et al., Advances in protein kinase B signalling: AKTion on multiple fronts. Trends in Biochemical Sciences, 2004. 29(5): p. 233-42.

229. Fayard, E., et al., Protein kinase B/Akt at a glance. Journal of Cell Science, 2005. 118(Pt 24): p. 5675-8.

230. Song, G., et al., The activation of Akt/PKB signaling pathway and cell survival. Journal of Cellular \& Molecular Medicine, 2005. 9(1): p. 59-71.

231. Wick, A., et al., Neuroprotection by hypoxic preconditioning requires sequential activation of vascular endothelial growth factor receptor and Akt. Journal of Neuroscience, 2002. 22(15): p. 6401-7.

232. Shiraishi, I., et al., Nuclear targeting of Akt enhances kinase activity and survival of cardiomyocytes.[see comment]. Circulation Research, 2004. 94(7): p. 884-91.

233. Mehrhof, F.B., et al., In cardiomyocyte hypoxia, insulin-like growth factor-Iinduced antiapoptotic signaling requires phosphatidylinositol-3-OH-kinasedependent and mitogen-activated protein kinase-dependent activation of the transcription factor cAMP response element-binding protein. Circulation, 2001. 104(17): p. 2088-94.

234. Perkins, J., et al., Modulation of trophoblast cell death by oxygen and EGF. Molecular Medicine, 2002. 8(12): p. 847-56.

235. Taylor, J.M., et al., Impact of oxidative stress on neuronal survival. Clinical \& Experimental Pharmacology \& Physiology, 2004. 31(7): p. 397-406. 
236. Noshita, N., et al., Evidence of phosphorylation of Akt and neuronal survival after transient focal cerebral ischemia in mice. Journal of Cerebral Blood Flow \& Metabolism, 2001. 21(12): p. 1442-50.

237. Andreucci, M., et al., Renal ischemia/reperfusion and ATP depletion/repletion in $L L C-P K(1)$ cells result in phosphorylation of FKHR and FKHRLI. Kidney International, 2003. 64(4): p. 1189-98.

238. Uchiyama, T., et al., Role of Akt signaling in mitochondrial survival pathway triggered by hypoxic preconditioning. Circulation, 2004. 109(24): p. 3042-9.

239. Roviezzo, F., et al., Protective role of PI3-kinase-Akt-eNOS signalling pathway in intestinal injury associated with splanchnic artery occlusion shock. British Journal of Pharmacology, 2007. 151(3): p. 377-83.

240. Ozaki, M., et al., Inhibition of hypoxia/reoxygenation-induced oxidative stress in $H G F$-stimulated antiapoptotic signaling: role of PI3-K and Akt kinase upon racl. Cell Death \& Differentiation, 2003. 10(5): p. 508-15.

241. Brunet, A., et al., Akt promotes cell survival by phosphorylating and inhibiting a Forkhead transcription factor. Cell, 1999. 96(6): p. 857-68.

242. Haendeler, J., et al., Regulation of telomerase activity and anti-apoptotic function by protein-protein interaction and phosphorylation. FEBS Letters, 2003. 536(13): p. 180-6.

243. Mazure, N.M., et al., Induction of vascular endothelial growth factor by hypoxia is modulated by a phosphatidylinositol 3-kinase/Akt signaling pathway in Ha-rastransformed cells through a hypoxia inducible factor-1 transcriptional element. Blood, 1997. 90(9): p. 3322-31.

244. Zhong, H., et al., Modulation of hypoxia-inducible factor lalpha expression by the epidermal growth factor/phosphatidylinositol 3-kinase/PTEN/AKT/FRAP pathway in human prostate cancer cells: implications for tumor angiogenesis and therapeutics. Cancer Research, 2000. 60(6): p. 1541-5.

245. Beitner-Johnson, D., et al., Hypoxia activates Akt and induces phosphorylation of GSK-3 in PC12 cells. Cellular Signalling, 2001. 13(1): p. 23-7.

246. Barnett, S.F., et al., Identification and characterization of pleckstrin-homologydomain-dependent and isoenzyme-specific Akt inhibitors. Biochemical Journal, 2005. 385(Pt 2): p. 399-408.

247. Zhao, Z., et al., Discovery of 2,3,5-trisubstituted pyridine derivatives as potent Akt 1 and Akt2 dual inhibitors. Bioorganic \& Medicinal Chemistry Letters, 2005. 15(4): p. 905-9.

248. Xingshun Xu, C.C.C., Jinping Gaoa, Kao-Wei Chuaa, Hong Wanga, Ronald C. Hamdya, and a.B.H.L. Chua, Neuroprotective effect of humanin on cerebral ischemia/reperfusion injury is mediated by a PI3K/Akt pathway. Brain Res, 2008. 1227: p. 12-18.

249. Datta, S.R., A. Brunet, and M.E. Greenberg, Cellular survival: a play in three Akts. Genes \& Development, 1999. 13(22): p. 2905-27.

250. Dudek, H., et al., Regulation of neuronal survival by the serine-threonine protein kinase Akt.[see comment]. Science, 1997. 275(5300): p. 661-5.

251. Liu, L., et al., Hypoxia-induced energy stress regulates $m R N A$ translation and cell growth. Molecular Cell, 2006. 21(4): p. 521-31. 
252. Hochachka, P.W., et al., Unifying theory of hypoxia tolerance:

molecular/metabolic defense and rescue mechanisms for surviving oxygen lack. Proceedings of the National Academy of Sciences of the United States of America, 1996. 93(18): p. 9493-8.

253. Kinouchi, H., et al., Attenuation of focal cerebral ischemic injury in transgenic mice overexpressing CuZn superoxide dismutase. Proceedings of the National Academy of Sciences of the United States of America, 1991. 88(24): p. 11158-62.

254. Kondo, T., et al., Reduction of CuZn-superoxide dismutase activity exacerbates neuronal cell injury and edema formation after transient focal cerebral ischemia. Journal of Neuroscience, 1997. 17(11): p. 4180-9.

255. Ishibashi, N., et al., Glutathione peroxidase inhibits cell death and glial activation following experimental stroke. Brain Research Molecular Brain Research, 2002. 109(1-2): p. 34-44.

256. Srirangam, A., et al., Effects of HIV protease inhibitor ritonavir on Akt-regulated cell proliferation in breast cancer. Clinical Cancer Research, 2006. 12(6): $\mathrm{p}$. 1883-96.

257. Smith JR, C.P., Billy E de and Workman P, Silencing the cochaperone CDC37 destabilizes kinase clients and sensitizes cancer cells to HSP9O inhibitors Oncogene, 2008: p. 1-13.

258. Kurokawa, M., et al., Inhibition of apoptosome formation by suppression of Hsp90beta phosphorylation in tyrosine kinase-induced leukemias. Molecular \& Cellular Biology, 2008. 28(17): p. 5494-506.

259. Osten, P., et al., Mutagenesis reveals a role for ABP/GRIP binding to GluR2 in synaptic surface accumulation of the AMPA receptor. Neuron, 2000. 27(2): $p$. 313-25.

260. Liu, S.J., et al., Subunit interaction with PICK and GRIP controls Ca2+ permeability of AMPARs at cerebellar synapses. Nature Neuroscience, 2005. 8(6): p. 768-75.

261. Steiner, P., et al., Interactions between NEEP21, GRIPI and GluR2 regulate sorting and recycling of the glutamate receptor subunit GluR2. EMBO Journal, 2005. 24(16): p. 2873-84.

262. Lai, C., et al., Amyotrophic lateral sclerosis 2-deficiency leads to neuronal degeneration in amyotrophic lateral sclerosis through altered AMPA receptor trafficking. Journal of Neuroscience, 2006. 26(45): p. 11798-806.

263. Kulangara, K., et al., Phosphorylation of glutamate receptor interacting protein I regulates surface expression of glutamate receptors. Journal of Biological Chemistry, 2007. 282(4): p. 2395-404.

264. Jayakar, S.S., et al., AMPA receptor regulation mechanisms: future target for safer neuroprotective drugs. International Journal of Neuroscience, 2004. 114(6): p. 695-734.

265. Yoshioka, A., B. Bacskai, and D. Pleasure, Pathophysiology of oligodendroglial excitotoxicity. Journal of Neuroscience Research, 1996. 46(4): p. 427-37.

266. Iizuka, M., et al., The lethal expression of the GluR2flip/GluR4flip AMPA receptor in HEK293 cells. European Journal of Neuroscience, 2000. 12(11): p. $3900-8$. 
267. Hoogenraad, C.C., et al., GRIPI controls dendrite morphogenesis by regulating EphB receptor trafficking. Nature Neuroscience, 2005. 8(7): p. 906-15.

268. Hock, B., et al., PDZ-domain-mediated interaction of the Eph-related receptor tyrosine kinase EphB3 and the ras-binding protein AF6 depends on the kinase activity of the receptor. Proceedings of the National Academy of Sciences of the United States of America, 1998. 95(17): p. 9779-84.

269. Smith, M.J., et al., Mapping the GRIF-1 binding domain of the kinesin, KIF5C, substantiates a role for GRIF-I as an adaptor protein in the anterograde trafficking of cargoes. Journal of Biological Chemistry, 2006. 281(37): p. 2721628.

270. Setou, M., et al., Glutamate-receptor-interacting protein GRIPI directly steers kinesin to dendrites. Nature, 2002. 417(6884): p. 83-7.

271. Kuramoto, N., et al., Phospho-dependent functional modulation of $G A B A(B)$ receptors by the metabolic sensor AMP-dependent protein kinase.[see comment]. Neuron, 2007. 53(2): p. 233-47.

272. Bellocq, A., et al., Somatostatin increases glucocorticoid binding and signaling in macrophages by blocking the calpain-specific cleavage of Hsp 90. Journal of Biological Chemistry, 1999. 274(52): p. 36891-6.

273. Jeon, Y.K., et al., The heat-shock protein 90 inhibitor, geldanamycin, induces apoptotic cell death in Epstein-Barr virus-positive NK/T-cell lymphoma by Akt down-regulation. Journal of Pathology, 2007. 213(2): p. 170-9. 
APPENDIX

\section{Abbreviations}

AF-6 = Afadin; binds to EphB6R

AGC family kinases $=$ a family of kinases that includes cyclic nucleotide regulated protein kinases (PKA and PKG), diacylglycerol-activated/phospholipid-dependent PKC, and kinases related to PKA and PKC (RAC and Akt)

$\mathrm{AK}=$ Autophosphorylation-dependent protein kinase

Akt $=$ Protein kinase $\mathrm{B}$

Akti1/2 = Akt Inhibitor VIII

Aktide-2T = peptide substrate for Akt;

Ala-Arg-Lys-Arg-Glu-Arg-Thr-Tyr-Ser-Phe-Gly-His-His-Ala

ANOVA $=$ Analysis of variance

$\mathrm{BAF}=$ Bafilomycin $\mathrm{A}_{\mathrm{I}}$

$\mathrm{BCEC}=$ bovine coronary endothelial cells

$\mathrm{CA}=$ constitutively active

$\mathrm{CHO}=$ chinese hamster ovary

$\mathrm{CKII}=$ casein kinase II

$\mathrm{CMA}=$ chaperone mediated autophagy

DAPI = 4', 6-diamidino-2-phenylindole dihydrochloride

$\mathrm{DCF}=2^{\prime}, 7^{\prime}$-dichlorofluorescin

DMSO = dimethyl sulfoxide 
1-D RP LC-MS-MS = 1-dimensional reverse phase liquid chromatography mass spectrometry-mass spectrometry

DTT $=$ Dithiothreitol

Dynein $=$ cytosolic dynein heavy chain

EDTA $=$ ethylenediaminetetraacetic acid

$\mathrm{EGF}=$ epidermal growth factor

EGFR $=$ epidermal growth factor receptor

EphB6R = Ephrin type-B receptor 6

ErbB2 = v-erb-b2 erythroblastic leukemia viral oncogene homolog 2

Fru-2,6-P2 = fructose-2,6-bisphosphate

$\mathrm{G}, \mathrm{GA}=$ Geldanamycin

GABA receptor $=$ gamma-aminobutyric acid receptor

GluR2 = ionotrophic AMPA glutamate receptor subunit 2

GPX = glutathione peroxidase

GRASP1 = GRIP1-associated protein 1

GRIF1 = kinesin-binding GABA receptor interacting fragment 1

GRIP1 = glutamate receptor interacting protein

GSK $3-\alpha=$ Glycogen synthase kinase $3 \alpha=$ Factor $\mathrm{A}$ is phosphorylated by Akt

HEK293 = human embryonic kidney cells

Hif- $1 \alpha=$ hypoxia-inducible factor $1 \alpha$

H/R = hypoxia/reoxygenation

$\mathrm{HRP}=$ horseradish peroxidase

$\mathrm{HSP}=$ heat shock protein 
Hsp90 $=$ heat shock protein 90

$\mathrm{IPG}=\mathrm{immobilized} \mathrm{pH}$ gradient

$\mathrm{IEF}=$ isoelectric focusing

IKK $=$ I $\kappa B$ kinase

KREBS $^{+}=$Krebs-Ringer phosphate buffer, $\mathrm{pH} 7.2$

$\mathrm{M}, \mathrm{MEN}=$ menadione

MALDI-ToF = Matrix assisted laser desorption/ionization time-of-flight mass spectrometry

MCF-7 = human breast adenocarcinoma cell line from a 69 year old Caucasian woman MG-132 = Z-Leu-Leu-Leu-aldehyde (Z-LLL-CHO)

MTT = 3-(4, 5-dimethyldiazol-2yl)-2, 5, -diphenyltetrazolium bromide

$\mathrm{NAC}=\mathrm{N}$-acetyl cysteine

$\mathrm{NADPH}=$ Reduced form of nicotinamide adenine dinucleotide phosphate

$\mathrm{NF}-\kappa \mathrm{B}=$ nuclear factor kappa B subunit

$\mathrm{NGF}=$ nerve growth factor

NIH3T3 = mouse embryonic fibroblast cell line from an NIH Swiss mouse embryo.

NIK = NF- $\kappa B$-inducing kinase; Mitogen-activated protein kinase kinase kinase 14

NOS 1 = neuronal nitric oxide synthase 1

NOS3 = endothelial nitric oxide synthase 3

NP-40 = nonyl phenoxylpolyethoxylethanol (Tergitol-type NP-40)

PAEC $=$ pulmonary artery endothelial cells

PAGE $=$ polyacrylamide gel electrophoresis

PBS = phosphate-buffered saline 
PFK1 = phosphofructokinase 1

PFK2 = phosphofructokinase 2

PI3K = phosphatidylinositol 3-kinase

PKA = cAMP-dependent protein kinase

$\mathrm{PKC}=$ protein kinase $\mathrm{C}$

PMSF $=$ phenylmethylsulphonyl fluoride

$\mathrm{PP} 2 \mathrm{~A}=$ protein phosphatase $2 \mathrm{~A}$

PTEN $=$ phosphatase and tensin homolog deleted on chromosome 10

PTPase $=$ protein tyrosine phosphatase

Rab2 = Ras-related protein

Rab3-IM1 = Rab3 interacting molecule 1

Rab3-IM2 = Rab3-interacting molecule 2

RPMI1640 = serum-free medium with L-glutamine used for the culture of PC-12 cells and developed by Moore et. al. at Roswell Park Memorial Institute

SDS = sodium dodecyl sulfate

$\mathrm{SH}=0.1 \% \mathrm{O}_{2}$ sustained hypoxia, $5 \% \mathrm{CO}_{2}$, and balanced $\mathrm{N}_{2}$

siRNA = small interfering RNA

SGK = serum- and glucocorticoid-regulated kinase

SKBr3 = human breast adenocarcinoma cell line from a 43 year old Caucasian woman

SNAP25 $=25 \mathrm{kDa}$ synaptosomal-associated protein

SNIP $=$ SNAP25-interacting protein

SOD-1 = superoxide dismutase 1

TBST $=$ tris-buffered saline with Tween-20 
$\mathrm{TEABC}=$ triethyl ammonium bicarbonate

TERT $=$ telomerase reverse transcriptase

$\mathrm{WT}=$ wild type

Tris $=$ tris (hydrox ymethyl $)$ aminomethane $\left(\left(\mathrm{HOCH}_{2}\right)_{3} \mathrm{CNH}_{2}\right)$

VEGF = vascular endothelial growth factor

V-dep L-type $\mathrm{Ca}^{+2}$ channel = voltage-dependent L-type calcium channel 


\section{CURRICULUM VITAE}

\section{Christina Blume Clark}

\section{LABORATORY ADDRESS}

Dr. Evelyne Gozal Laboratory

Kosair Children's Hospital Research Institute

Baxter I Research Building, Room 324

570 South Preston Street

Louisville, Kentucky 40202

cbwieg01@louisville.edu

\section{HOME ADDRESS}

313 Rosewood Drive

Louisville, Kentucky 40223

EDUCATION

2002 - 2010 Medical school years $3 \& 4$

Ph.D. in Pharmacology \& Toxicology

Medical school years $1 \& 2$

University of Louisville MD/PhD Program, Louisville, Kentucky

1998 - 2002 B.A. Double Major in Biochemistry \& Molecular Biology and

Germanic Literature \& Languages

Magna cum laude (honors thesis) in Biochemistry \& Molecular Biology

Washington University, St. Louis, Missouri

\section{PROFESSIONAL POSITIONS}

2005-2008 NIH/NINDS National Research Service Award MD/PhD fellow

2000

Biology tutor, Dept. of Biology, Washington University

1999-2002 Undergraduate research assistant in Dr. Thomas Baranski's Lab, Dept. of Molecular Biology \& Pharmacology,

Washington University School of Medicine

1998-1999 Undergraduate research assistant in Dr. Paul Goodfellow's Lab, Dept. of Genetics, Washington University School of Medicine 


\section{AWARDS}

University of Louisville School of Medicine MD/PhD Program full-tuition scholarship and stipend for medical school years

American Academy of Neurology U of L SIGN vice-president

Washington University School of Medicine PEW Conference speaker

Washington University HHMI Summer Fellowship

Washington University Pre-Medical Society officer

Washington University dean's list

Washington University School of Engineering Myers Summer Research scholar

Washington University HHMI Pre-Freshman Biology Summer scholar

\section{PUBLICATIONS}

\section{In Progress}

Role of oxidative stress in GA induced cytotoxicity and disruption of Hsp 90 signaling complex. Clark CB, Rane MJ, Miller CJ, Sachleben LR Jr, Gozal E.

Phosphorylation of Akt regulates survival to hypoxia by regulating $H$ sp 90 binding.

Clark CB, Rane MJ, Merchant M,

Sachleben LR, Gozal E.

\section{Published}

Wheeler TJ, Wiegand CB, Chien S. Fructose-1, 6-Bisphosphate Enhances Hypothermic Preservation of Cardiac Myocytes. Journal of Heart and Lung Transplantation. 2005 Sept; 24(9): 1378-84.

Klco JM, Wiegand CB, Narzinski K, Baranski TJ. Essential role for the second extracellular loop in C5a receptor activation. Nature Structural \& Molecular Biology. 2005 April; 12(4): 320 - 326.

Maggi LB Jr, Sadeghi H, Wiegand C, Scarim AL, Heitmeier MR, Corbett JA. Antiinflammatory actions of 15-deoxy-delta 12,14-prostaglandin J2 and troglitazone: evidence for heat shock-dependent and-independent inhibition of cytokine-induced inducible nitric oxide synthase expression. Diabetes. 2000 March; 49(3): 346 - 55.

\section{ABSTRACTS AND PRESENTATIONS \\ International and National Conferences}

\section{Selected for slide presentations}

Disruption of the Hsp 90 protein complex by Geldanamycin in PC-12 cells:

Role of oxidative stress. Neuroscience Conference 2007. Wiegand CB, Miller CJ, Sachleben Jr LR, Rane MJ, Gozal E. Departments of Pediatrics KCHRI, Pharmacology \& Toxicology, Physiology \& Biophysics, Medicine/Nephrology, University of Louisville. 
Hsp90 inhibition induces PC-12 cell death and Akt downregulation without altering hypoxia induced Akt phosphorylation. Neuroscience Conference 2004. Gozal E, Sachleben Jr LR, Wiegand CB, Wu R, Rane MJ. Departments of Pediatrics, Pharmacology \& Toxicology, and Medicine, University of Louisville.

\section{Posters}

Geldanamycin induces cytotoxic oxidative stress and disrupts Hsp90 binding, targeting proteins to non-proteasomal degradation in $\mathrm{PC}-\mathrm{I} 2$ cells. Society for Neuroscience

Conference 2008. Wiegand CB, Miller CJ, Sachleben Jr LR, Rane MJ, Evelyne Gozal. Departments of Pharmacology \& Toxicology, Physiology \& Biophysics, Pediatrics, and Medicine, University of Louisville.

Disruption of Hsp90 Protein Complex by Geldanamycin in PC-12 Cells: Role of Oxidative Stress. University of Colorado Medical Scientist Training Program Annual MD/PhD Student Conference 2007. Wiegand CB, Miller CJ, Sachleben Jr LR, Rane MJ, Gozal E. University of Louisville.

Role of Geldanamycin in Akt/ERK-mediated PC12 cells survival. Society for Neuroscience Conference 2006. Wiegand CB, Rane MJ, Gozal E, Departments of Pharmacology \& Toxicology, Pediatrics, and Medicine, University of Louisville.

Hsp90 Inhibition by Geldanamycin Upregulates Expression of Heat Shock Proteins in PC-12 Cells. Cell Signaling World Conference 2006. Wiegand CB, Rane MJ, Sachleben Jr LR, Wu R, Gozal E, Departments of Pharmacology \& Toxicology, Pediatrics, Medicine, University of Louisville, Louisville, KY.

Effect of Hsp90 Inhibition by Geldanamycin on PC-12 Cell Survival and Hypoxic Stress Response. Society for Neuroscience Conference 2005. Wiegand CB, Rane, MJ, Sachleben Jr LR, Wu R, Gozal E, Departments of Pharmacology \& Toxicology, Pediatrics, Medicine, University of Louisville, Louisville, KY.

\section{Research Louisville Posters}

Disruption of Hsp90 Protein Complex by Geldanamycin In PC-12 Cells: Role of Oxidative Stress. Research Louisville 2007. Wiegand CB, Miller CJ, Sachleben Jr LR, Rane MJ, Gozal E. Departments of Pediatrics KCHRI, Pharmacology \& Toxicology, Physiology \& Biophysics, Medicine/Nephrology, University of Louisville.

Role of Geldanamycin in Akt/ERK-mediated PC12 cell survival. Research Louisville 2006. Wiegand CB, Rane MJ, Gozal E. Departments of Pediatrics KCHRI, Pharmacology \& Toxicology, Physiology \& Biophysics, Medicine/Nephrology, University of Louisville. 
Effect of Hsp90 Inhibition by Geldanamycin on PC-12 Cell Survival and Hypoxic Stress Response. Research Louisville 2005. Wiegand C, Rane MJ, Sachleben Jr LR, Wu R, Gozal E. Kosair Children's Hospital Research Institute, Departments of Pediatrics, Pharmacology \& Toxicology, and Medicine, and Kidney Disease Program.

Neuronal Survival to Hypoxia: Heat Shock Protein 90 Interactions with Akt and Heat Shock Protein 70 in PC-12 Cells. Research Louisville 2004. Wiegand C, Rane MJ, Lominadze G, Sachleben Jr LR, Gozal D, Gozal E. Kosair Children's Hospital Research Institute, Departments of Pediatrics, Pharmacology \& Toxicology, and Medicine, and Kidney Disease Program.

Akt regulates hypoxia-induced transcriptional activation in PC-12 neuronal cells. Research Louisville 2003. Wiegand C, Rane MJ, Lominadze G, Sachleben LR Jr., Gozal D, Gozal E. KCHRI, Departments of Pediatrics, Pharmacology \& Toxicology, Medicine, University of Louisville.

Metabolic approaches to enhancing isolated cardiac myocyte survival during cold preservation. Research Louisville 2002. Wiegand C, Wheeler T, Chien S, Departments of Biochemistry \& Molecular Biology, Surgery, University of Louisville.

\section{RESEARCH SUPPORT}

NIH/NINDS 1 F30 NS051998-01 Wiegand (PI), 4/1/05 - 3/31/08

Role of Hsp90 Interactions in PC-12 Survival to Hypoxia

The role of the ATP-dependent chaperone heat shock protein 90 (Hsp90) in the survival of the pheochromocytoma PC-12 cell line was investigated. Hypoxic PC-12 cells are an established model for investigating cellular responses to hypoxia. The focus of the project was on the role of $\mathrm{Hsp} 90$ complex protein interactions in survival to $0.1 \% \mathrm{O}_{2}$ sustained hypoxia. This study shows that $\mathrm{Hsp} 90$ binding positively regulates survival by maintaining expression of Hsp90-binding proteins. Hsp90 plays a role in general cellular survival, rather than in the survival responses to hypoxia. Geldanamycin (GA), a classical benzoquinone Hsp90 ATPase inhibitor, was used to disrupt Hsp90 binding in the presence and absence of an antioxidant. GA induced cell death by disrupting Hsp90 binding, by degrading Hsp90-binding proteins, and by oxidative stress. Basal phosphorylation of Akt, a hypoxia-responsive survival kinase that binds to and phosphorylates Hsp90, plays a general role in cellular survival, and hypoxia-induced phosphorylation of Akt is not critical to cellular survival to hypoxia. Phosphorylation of Hsp90 by Akt may regulate survival by modulating the protein interactions of normoxic and hypoxic Hsp90 complexes.

\section{TECHNICAL SKILLS}

Grant writing, proteomics, plasmid and siRNA design and synthesis, and cell culture 